\title{
Niederösterreich im 19. Jahrhundert. Dokumentation eines Buchprojekts
}

Ab 2017 wurde durch das Niederösterreichische Institut für Landeskunde am Niederösterreichischen Landesarchiv ein groß angelegtes Buchprojekt umgesetzt, das sich mit dem 19. Jahrhundert im Kronland Niederösterreich befasste und 2021 mit der Veröffentlichung abgeschlossen wurde:

Oliver KüHSCHELM, Elisabeth LOINIG, Stefan EMINGER u. Willibald ROSNER, Niederösterreich im 19. Jahrhundert, Bd. 1: Herrschaft und Wirtschaft. Eine Regionalgeschichte sozialer Macht; Bd. 2: Gesellschaft und Gemeinschaft. Eine Regionalgeschichte der Moderne (St.

Pölten 2021)

http://doi.org/10.52035/noil.2021.19jh01

http://doi.org/10.52035/noil.2021.19jh02

Das Vorwort der Herausgeberin und der Herausgeber erläutert in Band eins die Vorgeschichte des Projekts. Die vorliegende Zusammenstellung bündelt weitere Materialien zu dem Buchvorhaben. Einige davon sind aktuell auf der Website des NÖ Instituts für Landeskunde zugänglich (www.noe.gv.at/landeskunde), so das Programm des Symposions, das im Juli 2019 stattfand. Bei anderen handelt es sich um die interne Dokumentation des Diskussionsprozesses mit den Autor*innen.

Die Materialien, die in diesem Konvolut auf Dauer zugänglich sein werden, sollen transparent machen, wie an dem Buchvorhaben gearbeitet wurde. Im Abgleich mit den publizierten Bänden lassen sie erkennen, wie sich das Konzept entwickelt hat. Die hier zusammengestellten Materialien sind gegenüber den projektintern kursierenden oder im Internet veröffentlichten Dokumenten inhaltlich unverändert, wurden aber von Heidemarie Bachhofer redigiert.

St. Pölten im Juli 2021

Oliver Kühschelm, Elisabeth Loinig, Stefan Eminger, Willibald Rosner 


\section{Verzeichnis der Materialien}

I. Bilanz der Peer-Review: Erläuterung von Vorgangsweise und Ergebnissen der externen Peer-Review (double blind)

II. Wissenschaftliches Konzept (Fassung vom 29.3.2018)

III. Workshop der Autor*innen am 13.4.2018

Programm des Workshops

Folien der Konzeptpräsentation

IV. Diskussionsrunden zu Literatur und Quellen

1. Diskussion am 19.2.2018 zur Theorie sozialer Macht von Michael Mann

2. Diskussion am 12.3.2018 zu Mikro- und Makroperspektiven

3. Diskussion am 3.4.2018 - ein langes 19. Jahrhundert?

4. Diskussion am 10.7.2018 - Geschichte sozialer Macht in Quellen I

5. Diskussion am 11.9.2018 - Geschichte sozialer Macht in Quellen II

V. Themenüberblick (Fassung vom September 2018)

VI. Symposion des NÖ Instituts für Landeskunde: Beharrung und Wandel, 1.-3.7.2019

Programm des Symposions

Tagungsbericht; zuerst veröffentlicht via H-Soz-Kult:

<www.hsozkult.de/conferencereport/id/tagungsberichte-8528>

VII. Erläuterung des Farbkonzeptes der Bände 


\section{Bilanz der Peer-Review}




\section{Bilanz der Peer Review}

Die Forschungsaufsätze wurden zusätzlich zur herausgeberischen Betreuung einer externen Begutachtung („doppelblind“) unterzogen. 47 Texte wurden für die Veröffentlichung empfohlen.

\section{Gutachten}

- Alle Gutachter*innen sind durch viele Publikationen ausgewiesen, oft im engeren Forschungsfeld des Aufsatzes. Die meisten sind universitär verankert, einige an Wissenschaftsakademien und anderen außeruniversitären Forschungseinrichtungen.

- Wir haben für die Einschätzung der Texte zumeist nicht eine Expertise in der Geschichte der engeren Region gesucht, sondern wollten wissen, ob auch Wissenschaftler*innen, die in ihrer Forschung keinen Schwerpunkt auf Niederösterreich legen, die Aufsätze für relevant halten.

- Herkunft der Gutachten: aus Österreich 10, hingegen 40 aus dem Ausland: 27 aus Deutschland, 6 aus der Schweiz, 3 aus Italien, 2 aus Tschechien, je eines aus den Niederlanden und Slowenien.

\section{Gender-Bilanz}

- (für die Veröffentlichung akzeptierte) Autor*innen: 37 Männer, 18 Frauen (67 Prozent : 33 Prozent), gesamt 55 (inkl. geteilte Autorenschaft an einem Aufsatz)

- Gutachten: 38 Männer, 12 Frauen (76 Prozent : 24 Prozent)

\section{Konsequenzen aus den Gutachten}

- Die Gutachten wurden vollinhaltlich weitergegeben.

- Die Autor*innen wurden aufgefordert, sich mit Kritik und Vorschlägen des Gutachtens auseinanderzusetzen und eine entsprechende Bearbeitung des Aufsatzes vorzunehmen.

- Insbesondere bei ausführlichen und kritischen Gutachten wurden die Autor*innen ersucht, in einer Stellungnahme darauf einzugehen, auf welche Vorschläge sie mit einer Überarbeitung reagiert haben und welche sie (warum?) nicht umgesetzt haben.

\section{Nutzen für das Buchvorhaben}

- Die Perspektive der externen Peer Review erforderte es, in der herausgeberischen Betreuung hohe Maßstäbe an die Texte anzulegen.

- Viele Gutachten haben konstruktive Hinweise auf relevante Literatur, Lücken in der Argumentation und Möglichkeiten struktureller Verbesserung gegeben. Die Überarbeitung nach der externen Begutachtung hat daher bei einer Reihe von Texten nochmals eine deutliche Qualitätssteigerung bewirkt.

- Peer Review ist das aktuell im Wissenschaftsbetrieb akzeptierte Gütesiegel für sorgfältiges Publizieren auf internationalem Niveau. Diese Anforderung erfüllt das Buchprojekt.

- Insbesondere für jüngere Autor*innen macht das die Publikation für ihre wissenschaftliche Laufbahn besser verwertbar.

- 51 Gutachter*innen, überwiegend aus dem Ausland, darunter sehr renommierte Forscher*innen, haben auf dem Weg der Peer Review von dem Buchprojekt erfahren. 


\section{Manuskript:}

Gutachter*in:

Sehr geehrte Gutachterin, sehr geehrter Gutachter!

Vielen Dank, dass Sie sich bereit erklärt haben, unsere Publikation durch Ihre Expertise zu unterstützen! Ihr Gutachten erfolgt in einem double-blind-Verfahren. Wir bitten Sie, nachfolgend Ihre Einschätzung durch Ankreuzen der jeweils zutreffenden Kategorie bekannt zu geben. Das ausformulierte Kurzgutachten im dritten Abschnitt dient als Grundlage der Überarbeitung. Aus diesem Grund ersuchen wir um möglichst präzise Kommentare und Überarbeitungsvorschläge. Für Rückfragen stehen wir Ihnen gerne zur Verfügung.

Oliver Kühschelm

Elisabeth Loinig

\section{Bitte beurteilen Sie das Manuskript:}

\begin{tabular}{lccc} 
& sehr gut & akzeptabel & unzureichend \\
\hline Strukturiert, klar im Aufbau & ( ) & ( ) & ( )
\end{tabular}

Entspricht dem Forschungsstand

zum Thema

Wissenschaftliche Qualität insgesamt

Sprache und Stil
( )

( )

( )
( )

( )

( )

Ja akzeptabel Nein

Ja akzeptabel Nein

Resümee: Es handelt sich um einen wertvollen Beitrag für das gegenständliche Publikationsprojekt. ( ) ( )

\section{Das Manuskript sollte:}

()

( )

()

( )

( ) in dieser Fassung für die Veröffentlichung angenommen werden nach geringfügiger Überarbeitung veröffentlicht werden nach gründlicher Überarbeitung veröffentlicht werden nach gründlicher Überarbeitung erneut begutachtet werden abgelehnt werden 
III. Ausformuliertes Kurzgutachten: 
II. Wissenschaftliches Konzept (Fassung vom 29.3.2018) 


\title{
Niederösterreich im 19. Jahrhundert
}

\section{Ein Publikationsprojekt des NÖ Landesarchivs - NÖ Instituts für Landeskunde in Kooperation mit \# Netzwerk Geschichte NÖ \#}

\author{
Herausgeber*innen: Elisabeth Loinig, Oliver Kühschelm, Willibald Rosner, Stefan Eminger \\ Projektleitung: Elisabeth Loinig, Projektmanagement: Oliver Kühschelm
}

\section{Ziele}

Die Publikation soll regionale Geschichte für ein interessiertes Publikum aufschließen. Zugleich soll sie als Katalysator für geschichtswissenschaftliche Forschung dienen, die auf Quellen aus Niederösterreich zugreift und in der Auseinandersetzung mit regionaler Geschichte Fragen aufwirft, die über Niederösterreich hinaus wissenschaftliche Relevanz besitzen.

\section{Umfang}

- Ca. 50 Beiträge

- Zwei Bände

\section{Zeitplan}

April 2018 Workshop der Autor*innen in St. Pölten

Juli 2019 Symposion des NÖ Instituts für Landeskunde

Herbst 2019 Beide Bände werden veröffentlicht

\section{Aufbau, Fokussierungen und Leitfragen}

Betrachtungszeitraum ist ein langes 19. Jahrhundert, das im späten 18. Jahrhundert einsetzt und bis zum Ende des Ersten Weltkriegs reicht. Die Beiträge sollen möglichst große Teile des Betrachtungszeitraums umfassen. ${ }^{1}$ Das Projekt ist auf zwei Bände ausgelegt, die jeweils ein schlüssiges Konstruktionsprinzip aufweisen sollen. ${ }^{2}$ Daraus lassen sich Leitfragen generieren,

\footnotetext{
${ }^{1}$ Das kann nicht für alle Themen im gleichen Maß gelten und die Autor*innen müssen im Betrachtungszeitraum die der Sache gemäßen Schwerpunkte setzen können.

${ }^{2}$ Als Referenz für das Projekt können jüngere Sammelwerke zur Habsburgermonarchie und zu Niederösterreich dienen, insbesondere: als Begleitbuch zu einer Ausstellung: Peter URBANITSCH u. Helmut RumPLER (Hrsg.), Politische Öffentlichkeit und Zivilgesellschaft. 1. Teilband: Vereine, Parteien und Interessenverbände als Träger der politischen Partizipation (= Die Habsburgermonarchie 1848-1918, Bd. VIII/1) (Wien 2006); Helmut RUMPLER u. Peter URBANITSCH (Hrsg.), Soziale Strukturen (= Die Habsburgermonarchie 1848-1918, Bd. IX) (Wien 2010); Stefan Eminger, Ernst Langthaler, Oliver Kühschelm u. Peter Melichar (Hrsg.), Niederösterreich im 20. Jahrhundert, 3 Bde. (Wien, Köln, Weimar 2008); Stefan EMINGER, Elisabeth LoINIG u. Willibald Rosner (Hrsg.), Ein Land im Zeitraffer. Niederösterreich seit 1848 (St. Pölten 2013).
} 
auf die sich die empirischen Beiträge aus unterschiedlichen Perspektiven beziehen können. Ziel ist es, ohne den Autor*innen einen bestimmten Zugriff aufzuzwingen, über die einzelnen Beiträge hinweg eine geteilte Diskussionsgrundlage zu schaffen, die über die Gemeinsamkeit von Untersuchungsregion und -periode hinausgeht.

Während der erste Band sich mit der politischen Ökonomie Niederösterreichs befasst, somit eine Geschichte von Staatlichkeit im regionalen Rahmen betreibt, wird der zweite Band sozialgeschichtliche und historisch-anthropologische Perspektiven ins Zentrum stellen. Der erste Band widmet sich der administrativen, politischen, wirtschaftlichen und ideologischen Konstruktion Niederösterreichs als Herrschaftszusammenhang, der zweite sozialen Großformationen und Lebenswelten in Niederösterreich und seinen Regionen. ${ }^{3}$ Der erste Band betreibt tendenziell eine Geschichte Niederösterreichs, der zweite eine Geschichte von sozialen Gruppen, Alltagspraktiken und -räumen in Niederösterreich.

Beide Fokusbildungen verweisen aufeinander, doch Herrschaft reicht nicht in alle Fasern des Alltags hinein bzw. füllt sie diesen nicht vollständig aus. Umgekehrt verzahnen sich Alltagspraktiken zwar mit Herrschaft, arbeiten ihnen zu und widerstreben ihnen, doch lässt sich nicht aus einer imaginären Summe des Alltags - des Sich-Ernährens, Wohnens, FesteFeierns, Betens, familiärer Rituale und lebensgeschichtlicher Ereignisse - die Herrschaftskonstellation ableiten. Ein überkommener Blick auf dieses Verhältnis trennt zwischen Staat und Gesellschaft als einer binären Opposition oder einer sich zum Ganzen fügenden Dualität. Der zweite Band zu sozialen Formationen und Alltagsräumen geht hingegen davon aus, dass sich soziale Beziehungen nicht zu einer vom Staat respektive Land aus gedachten Gesellschaft fügen müssen. Sie reichen über dessen Grenzen hinaus, sie gestalten sich auch quer und unabhängig von staatlichen Parametern. Allerdings wuchs der Anspruch auf Intervention, fordernder und fördernder, im Laufe des 19. Jahrhunderts, insbesondere in dessen letzten Jahrzehnten und am Beginn des 20. Jahrhunderts. Der Erforschung regionaler Geschichte dürfen die Landesgrenzen in ihrer Alltagsdimension nicht zur Zwangsjacke werden, die einengt und zur Behauptung des spezifisch Niederösterreichischen nötigt (das es eher auf einer kleinteiligeren Ebene von Landesvierteln und wirtschaftlichen Regionen geben mag).

Niederösterreich war flächenmäßig ein Kronland mittlerer Größe, in punkto Bevölkerung eines der größten und jenes mit der höchsten Wirtschaftskraft pro Kopf ${ }^{4}$ - allerdings stets unter Berücksichtigung Wiens. Ein Buchprojekt über Niederösterreich im 19. Jahrhundert muss sich daher der Frage stellen, wie die Beiträge mit Wien als der Hauptstadt von Reich und Kronland umgehen sollen. Zu überprüfen und differenzieren gilt jene Gewissheit, die aus den Worten eines Vortrags des Innenministers von 1849 sprach: dass nämlich „das gesammte politische

\footnotetext{
${ }^{3}$ Als Vorbild kann hier insbesondere der Band Soziale Strukturen (=Die Habsburgermonarchie 1848-1918, Bd. IX) dienen.

${ }^{4}$ Max Stephan Schulze, Regional Income Dispersion and Market Potential in the Late Nineteenth Century Hapsburg Empire. In: LSE Working Papers 106 (2007) hier 26.
} 
und sociale Leben Niederösterreichs in allen Richtungen in Wien den letzten alles, absorbierenden Knotenpunkt besitzt". ${ }^{5}$ Das Projekt kann Wien daher nicht aussparen, muss das Verhältnis jedoch stets vom ,flachen Land' aus und von Wechselbeziehungen zwischen Metropole, kleinstädtischen und dörflichen Strukturen denken.

Seit Langem wird die analytische Verschränkung von Makro- und Mikroebenen gefordert, zuletzt war vor allem die Verflechtung von global- und mikrogeschichtlichen Perspektiven ein Diskussionsgegenstand. ${ }^{6}$ Für eine niederösterreichische Regionalgeschichte ist es daher wünschenswert, Vernetzungen nicht nur über die Landesgrenzen innerhalb des Verbunds der Kronländer oder zu benachbarten Reichen zu berücksichtigen, sondern Verkettungen von Gütern, Kapital- und Ideentransfers sowie Migrationsbewegungen im gesamten Spektrum von kleinräumig bis Kontinente übergreifend.

Nachdem eine Begeisterung über Marktgesellschaften, die in Zentraleuropa 1989 anhob, den Staat als Thema zwischenzeitlich verblassen ließ, interessiert sich die historische Forschung seit der Jahrtausendwende wieder vermehrt dafür, wie Staatlichkeit ihre unterschiedlichen Gestalten annahm. ${ }^{7}$ Neben dem Nationalstaat, der lange ein Endpunkt der Geschichte, auch der österreichischen, schien, sind Alternativen aus Gegenwart und Vergangenheit - Imperien, multinationale Staaten und die Europäische Union - in den Blickpunkt der Aufmerksamkeit getreten. ${ }^{8}$ Diskussionen über das Scheitern der Habsburgermonarchie und seine Unvermeidlichkeit tragen nun unverkennbar das Signum einer Sorge, dass auf Schritte europäischer und globaler Integration eine Renationalisierung folgen könnte. ${ }^{9}$

Eine Geschichte Niederösterreichs im 19. Jahrhundert als Auseinandersetzung mit Staatlichkeit anzulegen, ist daher zeitgemäß und der Untersuchungszeit gemäß, denn das lange 19. Jahrhundert war jenes, in dem sich die Fühlung zwischen dem Territorialstaat und seinen Subjekten exponentiell vermehrte. Diese „Verwandlung der Welt" und insbesondere

\footnotetext{
${ }^{5}$ Beiträge zur Geschichte der Niederösterreichischen Statthalterei (Wien 1897) 113.

${ }^{6}$ Francesca TRIVELLATO, Is There a Future for Italian Microhistory in the Age of Global History? In: California Italian Studies 2/1 (2011), http://scholarship.org/uc/item/Oz94n9hq (20.1.2017); Angelika EPPLE, Lokalität und die Dimensionen des Globalen. In: Historische Anthropologie 21/1 (2013) 4-25; Relationale Geschichtsschreibung: Gegenstand, Erkenntnisinteresse und Methode globaler und weltregionaler Geschichtsschreibung. In: H-Soz-Kult (2.11.2017), https://www.hsozkult.de/debate/id/diskussionen-4291 (15.12.2017); Hans MEDICK, Turning Global? Microhistory in Extension. In: Historische Anthropologie 24/2 (2016) 241-252; Sigurður Gylfi MAGNússon, FarReaching Microhistory: the Use of Microhistorical Perspective in a Globalized World. In: Rethinking History 21/3 (2017) 312-341; viele Autor*innen orientieren sich in dem Versuch, Mikro- und Makroperspektiven zusammenzudenken, an: Bruno LATOUR, Eine neue Soziologie für eine neue Gesellschaft. Einführung in die Akteur-Netzwerk-Theorie (Frankfurt am Main 2010); z. B.: Margareth LANZINGER, Das Lokale neu positionieren im actor-network-Raum - globalgeschichtliche Herausforderungen und illyrische Steuerpolitiken. In: Ewald HIEBL u. Ernst LANGTHALER (Hrsg.), Im Kleinen das Große suchen. Mikrogeschichte in Theorie und Praxis. Hanns Haas zum 70. Geburtstag (Innsbruck 2012) 48-56.

${ }^{7}$ Bob JESSOP, The State: Past, Present, Future (Cambridge 2016) 4; Patrick JOYCE U. Chandra MUKERJ, The State of Things: State History and Theory Reconfigured. In: Theory and Society 46/1 (2017) 1-19.

8 Jürgen OSTERHAMMEL, The European model and imperial contexts. In: Journal of Modern European History 2/2 (2004) 157-181.

${ }^{9}$ Steven BeLLER, What has the empire ever done for us? The surprising legacies of the Habsburg monarchy, and the lessons for today's European Union. In: Eurozine (3.11.2017), www.eurozine.com/what-has-the-empire-everdone-for-us/ (5.2.2018); John DEék, Forging a Multinational State: State Making in Imperial Austria from the Enlightenment to the First World War (Stanford, Cal. 2015).
} 
der "Leviathan 2.0", die beschleunigte Expansion des Staats im letzten Drittel des 19. Jahrhunderts, waren Themen globalgeschichtlicher ebenso wie nationalgeschichtlicher Synthesen. ${ }^{10}$ Zentralisierungsbestrebungen und die Zentralverwaltungen als ihre Akteurinnen erhalten seit jeher viel Aufmerksamkeit. Weniger gilt das für die regionale Formierung des Staats, wie sie im Rahmen der Habsburgermonarchie die Kronländer - samt den darunter liegenden Verwaltungseinheiten, den Kreisen, Bezirken und Gemeinden - darstellen.

Während außerdem die Interaktion zwischen dem Zentrum Wien und peripheren Kronländern immer wieder Gegenstand von Forschung war, etwa über Dalmatien und vor allem Galizien, geriet Niederösterreich als Untersuchungsgegenstand primär über die Metropole Wien als Sitz der Zentralverwaltung in den Blick.

Die räumliche Nähe von Landes- und Zentralverwaltung ist eine Besonderheit, deren Relevanz es zu untersuchen gilt: sowohl im Hinblick auf die Apparaturen des Zentralstaats als auch hinsichtlich ihrer Auswirkungen auf regionale Staatlichkeit. Zu denken ist etwa an die für Niederösterreich von Statthalter Erich von Kielmansegg durchgeführte Kanzleireform in ihrem Verhältnis zur Ambition einer umfassenden Verwaltungsreform. Zumal das Landesarchiv als Initiator des Buchprojekts die für eine solche Fokussierung wesentlichen Quellen bewahrt, drängt es sich daher auf, in eine Geschichte Niederösterreichs Untersuchungen einer neuen Verwaltungsgeschichte einzubeziehen. ${ }^{11}$ Sie widmet sich neben dem institutionellen Gefüge den Praktiken und der Subjektivierung von Beamten; sie spürt außerdem dem Zusammenspiel von Behörden und Bürgern nach, leuchtet die Potentiale von Rechtsstaat und obrigkeitlicher Disziplinierung aus.

Ein Rahmen, der den ersten Band konzeptuell integriert, muss aber über Bürokratiegeschichte hinausreichen und insbesondere die Wirtschaft als zentralen Gegenstand von Regierung erfassen. So wie man außerdem nach einer Gesellschaft der Habsburgermonarchie als sinnhafter Untersuchungseinheit fragen kann, ${ }^{12}$ muss derselbe Zweifel jede Forschung über

\footnotetext{
${ }^{10}$ Jürgen OsterhammeL, Die Verwandlung der Welt. Eine Geschichte des 19. Jahrhunderts (München 2011); Charles S. MAIER, Leviathan 2.0: Inventing Modern Statehood. In: Emily Schlacht RoSEnBERG (Hrsg.), A World Connecting, 1870-1945 (Cambridge, Mass. 2012) 27-282; wie Maier eine Periodisierung konzeptualisierend: Ulrich HERBERT, Europe in High Modernity: Reflections on a Theory of the 20th Century. In: Journal of Modern European History 5/1 (2007) 5-20; Jakob TANNER, Geschichte der Schweiz im 20. Jahrhundert = Europäische Geschichte im 20. Jahrhundert (München 2015); als Übertragung Wehler'scher Gesellschaftsgeschichte bereits in den 1990er Jahren: Ernst HANISCH, Der lange Schatten des Staates: Österreichische Gesellschaftsgeschichte im 20. Jahrhundert (Wien 1994); an den von Wehler im Anschluss an Weber unterschiedenen drei Potenzen aus Herrschaft/Politik, Ökonomie und Kultur orientierte sich auch der Aufbau des dreibändigen Sammelwerks: EMinger, LANGTHALER, KüHSCHelm u. Melichar, Niederösterreich im 20. Jahrhundert; mit einer auf Wallersteins Weltsystemtheorie aufgebauten Modellierung der Beziehungen von Zentrum und Peripherie hat Andrea Komlosy immer wieder die Wirtschafts- und Sozialgeschichte Niederösterreichs und insbesondere des Waldviertels analysiert, u. a.: Vom Kleinraum zur Peripherie. Entwicklungsphasen der wirtschaftlichen Abhängigkeit im 19. Jahrhundert. In: Herbert KNITTLER (Hrsg.), Wirtschaftsgeschichte des Waldviertels (Waidhofen an der Thaya 2006) 217-340.

${ }^{11}$ Peter BECKER, Bürokratie, Version: 1.0. In: Docupedia-Zeitgeschichte (30.8.2016), http://dx.doi.org/10.14765/zzf.dok.2.695.v1.

12 Ernst BRUCKMÜLLER, Was There a "Habsburg Society" in Austria-Hungary? In: Austrian History Yearbook 37 (2009) 1-16.
} 
Niederösterreich begleiten. ${ }^{13}$ Eine Regionalgeschichte mit diesen Zielen kann sich an Michael Manns monumentaler Geschichte der Macht orientieren, die als historische Soziologie auf den Spuren Max Webers ihre abstrakten Kategorien in der Auseinandersetzung mit Geschichte gewinnt. ${ }^{14}$ Mann geht von vier eigenständigen Quellen sozialer Macht - Ideologie, Ökonomie, Militär, Politik - aus, um ihre historisch-spezifischen Konstellationen und Gewichtungen ohne Fortschrittsgewissheit zu untersuchen. ${ }^{15}$ Den Staat sieht er als polymorphe Figur, die in der Kombination von Machtressourcen auskristallisiert. Mit diesem Instrumentarium gelangte er zu einer Analyse der Habsburgermonarchie, deren Schlussfolgerungen sich mit jenen der jüngeren historischen Forschung, zuletzt bei Pieter Judson, ${ }^{16}$ decken. So hält Mann die Monarchie nicht für ein Herrschaftsgefüge, das seine Abweichung vom Modell des Nationalstaats zum Untergang verdammte. Den Übergang zu einem Kapitalismus auf industrieller Basis habe die Monarchie erfolgreich bewältigt und sei erst an ihrem Militarismus respektive dem Ersten Weltkrieg gescheitert. ${ }^{17}$ Generell nimmt er für das 19. Jahrhundert eine Dominanz ökonomischer und politischer Machtressourcen an. ${ }^{18}$

Zu welchen Schlüssen aber gelangt man, wenn man den Blick vom Staat auf die ihm untergeordneten oder ihn aufbauenden Gebietskörperschaften, im konkreten Fall ein Kronland und seine Regionen, richtet und eine Regionalgeschichte der Macht betreibt?

- Welche Machtressourcen und welche funktionalen Kristallisierungen ${ }^{19}$ traten in welchen Kombinationen in den Vordergrund, parallel oder unterschieden von lokalen und gesamtstaatlichen Kristallisierungen?

- Wie trugen Land und Gemeinden zur Expansion infrastruktureller Macht ${ }^{20}$ bei, dem wesentlichen Merkmal moderner Staatlichkeit?

\footnotetext{
${ }^{13}$ Die Frage nach der Konstruktion von Niederösterreich zieht sich daher auch durch viele Beiträge der drei Bände Niederösterreich im 20. Jahrhundert.

${ }^{14}$ Relevant sind hier insbesondere die ersten beiden von vier Bänden: Michael MANN, The Sources of Social Power 1: A History of Power from the Beginning to A.D.1760 (Cambridge 1986); The Sources of Social Power 2: The Rise of Classes and Nation-States, 1760-1914 (Cambridge 1993). Auf Deutsch erschienen als: Geschichte der Macht, 3 Bde. (Frankfurt am Main 1990-2001).

${ }^{15}$ Wie die Wehler'sche Gesellschaftsgeschichte (oder der Parsons'sche Funktionalismus) ist Manns Konzept von Max Weber inspiriert, verfolgt aber nicht den Anspruch, das Soziale in ein totalisierendes Ganzes namens Gesellschaft modernisierungstheoretisch einzuschließen, sondern geht von offenen und kontingenten Netzwerken aus. Manns Geschichte der Macht ist zudem in seiner Umsetzung keine Nationalgeschichte wie Wehlers Deutsche Gesellschaftsgeschichte, sondern tatsächlich komparativ angelegt, wenn auch auf Europa und die USA fokussiert.

${ }^{16}$ Pieter M. JUDSON, The Habsburg Empire: A New History (Cambridge, Massachusetts 2016); Habsburg. Geschichte eines Imperiums, 1740-1918 (München 2017); ohne dass allerdings Judson auf Mann oder andere Konzepte aus der historischen Soziologie Bezug nehmen würde. Hingegen: DEÁK, Forging, 162.

17 MANN, Sources 2, 330-353.

18 Ebd., $1 \mathrm{f}$.

${ }^{19}$ Es handelt sich um die Formen, in denen Staaten als Knotenpunkt von Machtnetzwerken Gestalt annehmen. Mann geht für das 19. Jahrhundert von wiederum vier Haupttypen aus: kapitalistische, militaristische, repräsentative und nationale.

${ }^{20}$ Michael MANN, Infrastructural Power Revisited. In: Studies in Comparative International Development 43/3-4 (2008) 355-365.
} 
- Wie verhielten sich rechtliche, verwaltungstechnische, budgetäre und parteipolitische Mechanismen zueinander im Geflecht von regionalen, staatlichen, parastaatlichen und zivilgesellschaftlichen Institutionalisierungen, die sich unter anderem zum Land fügen?

Viele weitere Fragen lassen sich aus der Theorie Manns heraus formulieren, die sowohl in einer Einleitung synthetisierend behandelt werden können als auch in jenen Beiträgen, die sich im weitesten Sinn dem Land als einer für Akteur*innen und Handlungen relevanten Bezugsgröße widmen.

Manns Konzept ist allerdings weder handlungs- noch akteurszentriert. ${ }^{21}$ Für eine Mikrophysik der Macht (ebenso wie für eine Sozial- und Alltagsgeschichte, die im zweiten Band im Vordergrund steht) bedarf es zusätzlicher analytischer Orientierungsmarken, wie sie z. B. Michel Foucaults Begriff der Gouvernementalität bereitstellt. ${ }^{22}$ Die Aufgabe des Regierens umfasst dann sowohl soziale Aggregate wie das Selbst, die Subjektivierung. Weit über das Administrieren hinaus betrifft sie außerdem auch ein Agieren auf Märkten und diversen Institutionen der Zivilgesellschaft. Es handelt sich um Normen, Diskurse und Praktiken, die Menschen einüben, vom Verwaltungsbeamten zum Kommunalpolitiker, vom Gewerbetreibenden zum Mitglied des Gesangsvereins, und sie in soziale Netzwerke - und damit u. a. ins Land - integrieren.

Der zweite Band wird zum einen sozialgeschichtlich soziale Großformationen untersuchen, zum anderen den Blick auf Praktiken und Räume als Hebel einsetzen, um die Konstituierung des Sozialen in Alltagsszenen, in der Konkretisierung und Lokalisierung der Netze des Handelns zu beobachten. Die beiden Perspektiven überschneiden und ergänzen einander, erlauben dem Band insgesamt Mikro-, Meso- und Makroebenen zu behandeln - im Idealfall nicht nebeneinander gereiht, sondern in ihren Wechselverhältnissen.

\section{Nō̄CA Nōil NÖ Institut für Landeskunde 3109 St. Pölten, Landhausplatz 1 | Kulturbezirk 4 www.noe.gv.at/landeskunde}

\footnotetext{
${ }^{21}$ Hans JOAS, Sozialtheorie: zwanzig einführende Vorlesungen (4., aktualisierte Aufl., Frankfurt am Main 2013) 400.

22 Michel Foucault, Geschichte der Gouvernementalität, 2 Bde. Vorlesung am Collège de France, 1977-1978 und 1978-1979 (Frankfurt am Main 2004); Ulrich BRöcKLING, Gute Hirten führen sanft (Berlin 2017).
} 
III. Workshop der Autor*innen am 13.4.2018 


\section{Autor*innenworkshop}

Freitag 13. April, Niederösterreichische Landesbibliothek, St. Pölten

\section{9:30-09:45 Begrüßung}

Roman Zehetmayer (Leiter NÖ Landesarchiv u. NÖ Landesbibliothek)

Hermann Dikowitsch (Leiter Gruppe Kultur, Wissenschaft u. Unterricht, Land Niederösterreich)

Elisabeth Loinig (Leiterin NÖ Institut für Landeskunde)

\section{9:45-11:00 Zum Buchvorhaben - Organisatorisches}

- Zeitplan

- Autor*innenvereinbarung (Umfang der Beiträge, Honorar, Abstracts, Bildvorschläge)

- Textgestaltung und Zitierweise

- Peer Review

- Veröffentlichungs- und Disseminationsstrategien

- Ressourcen der Recherche in Landesarchiv und -bibliothek

11:00-11:30 Kaffeepause

\section{1:30-12:30 Zum Buchvorhaben - Inhaltliches}

- Präsentation und Diskussion des Konzepts

12:30-13:30 Mittagessen

\section{3:30-15:00 Arbeitsgruppen I: Diskussion der Beitragskonzepte}

Moderation: Stefan Eminger, Elisabeth Loinig, Oliver Kühschelm, Willibald Rosner

\section{5:00-15:30 Kaffeepause}

\section{5:30-16:30 Arbeitsgruppen II}

(A) Macht (Moderation: Rita Garstenauer)

(B) Mikro/Makroperspektiven (Moderation: Margareth Lanzinger)

(C) Periodisierungen - ein langes 19. Jahrhundert? (Moderation: Ernst Bruckmüller)

(D) Modernisierung/Fortschritt? (Moderation: Ernst Langthaler) 


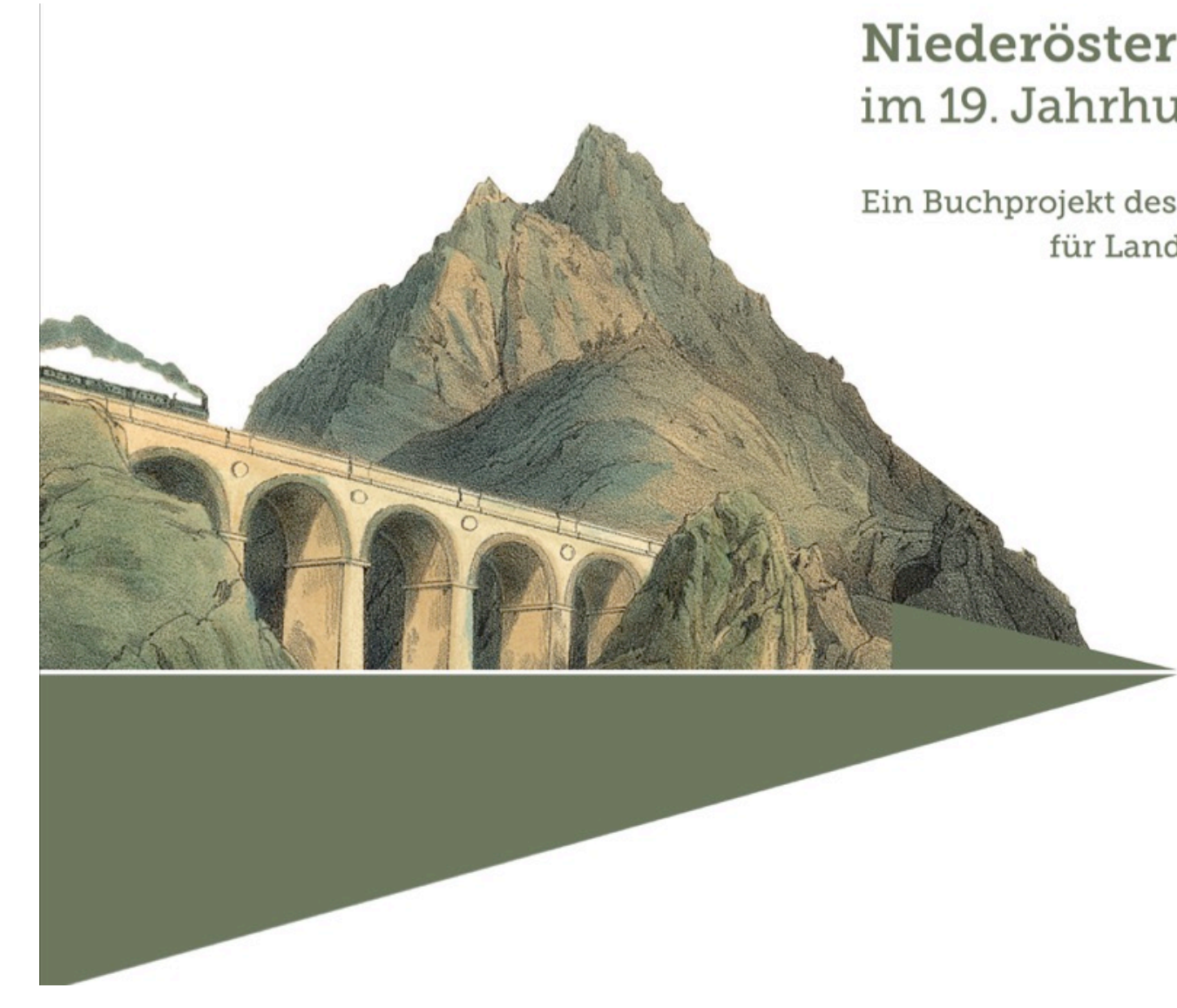

\section{Buchkonzept und Leitfragen}

Workshop der Autoren und Autorinnen,

13. April 2018 


\section{Zwei Bände, 46 Beiträge, 50 Autor*innen}

Band 1:

Politische Ökonomie, Herrschaft und Wirtschaft Regionalgeschichte der Macht,

Geschichte von regionaler Staatlichkeit

Band 2:

Soziale Formationen und Alltag, Lebenswelten, Praktiken und Räume

sozialgeschichtliche und historischanthropologische Perspektiven 


\section{Balanceakte}

Gute Lesbarkeit

Regionales Wissen als Ziel

Regionaler Zugriff

Überblicke

Eine Umschau zum Thema
Wissenschaftliche Präzision

Scientific Community

Thematischer Zugriff

Tiefenbohrung, Fallbeispiel

Selektion entlang von Forschungsfrage 


\section{I. „Wann war das 19. Jahrhundert?“}

Ein langes 19. Jahrhundert - Grenzen und Merkmale?

- von Krieg zu Krieg?

- Von Untertanen zu Staatsbürger*innen?

- Von Agrar-zu Industriegesellschaft?

- Von Revolution des Fleißes zur Konsumgesellschaft?

Und wann war das 19. Jahrhundert in NÖ? 


\section{Untergliederungen des 19. Jahrhunderts?}

Sattelzeit, 1770 bis 1830 (Kriege, Staatsbürgerschaft)

Das «eigentliche» 19. Jahrhundert, 1830-1880 - eine Zeit des Übergangs (Industrialisierung)

Zeitalter der Imperien, 1880er bis ca. 1920 (energetische Moderne, neue Techniken, Massenkonsum)

(nach Jürgen Osterhammel in Anschluss an Eric Hobsbawm)

Jürgen Osterhammel, Die Verwandlung der Welt. Eine Geschichte des 19. Jahrhunderts (München 2011) 102- 116. 


\section{Moderne}

Das 19. Jhdt. als die Moderne der Sozialgeschichte?

- Die Revolutionierung der ewigen Agrargesellschaft zur ewigen Industriegesellschaft?

- Das Zeitalter der Gesellschaft?

Paul NOLTE, Abschied vom 19. Jahrhundert oder Auf der Suche nach einer anderen Moderne. In: Geschichte und Gesellschaft. Sonderheft 22 (2006) 103-132. 


\section{Modernisierung}

Modernisierung als ...

Perspektiven der ,klassischen` Sozialgeschichte

- Ständisch-industrieller Übergang

- Nationalisierung und Verbürgerlichung

- Industrialisierung und Klassenbildung

Mit Blick auf das 20. Jhdt.

- Massendemokratie/kultur/konsum Kolonialisierung von Lebenswelt

- Radikalisierung und Systematisierung von Gewalt 


\section{Niederösterreich im 19. Jhdt.?}

- NÖ und das lange 19. Jhdt. als Horizont der Beiträge

- Forschen mit Material aus NÖ und Forschen über NÖ

- Wodurch zeigt sich NÖ als administrative und politische Einheit?

- Inwiefern wird eine imaginierte Gemeinschaft NÖ konstruiert?

- Wien und das ,flache Land"

- Inwiefern ist NÖ wirtschaftsgeschichtlich eine sinnvolle Untersuchungseinheit? 


\section{Vermittlung von Mikro- und Makroperspektiven?}

- Relationierung von Untersuchungsräumen

- Mittlere (institutionelle) Ebenen

- Akteursnetzwerke als Vermittlung von Strukturen und Lebenswelten

- Überregionale, transnationale Verflechtungen

- Räume in Bewegung 


\section{Regionalgeschichte der Macht Geschichte regionaler Macht}

Die Eroberung sozialer Beziehungen durch/für Staat/ Gesellschaft

Oder neutraler formuliert:

Die Formierung des Sozialen in Staat und Gesellschaft; von kulturellen, politischen, wirtschaftlichen Zusammenhängen, die sich auf Staat/Land beziehen 


\section{Gesellschaft als organisierte Machtnetzwerke (Michael Mann)}



(National)Staat: Gesellschaft als Produkt des „Einsperrens" von Akteursgruppen in einander überlagernde Machtnetzwerke Ideologie - Wirtschaft - Militär - Politik

Vgl. Michael MANN, Geschichte der Macht, 3 Bde. (Frankfurt am Main 1990-2001). 


\section{Staatsbildung regional}

- Distributive

- Autoritative (Militär/Bürokratie)

- Despotische kollektive

Macht

diffuse

(z. B. Märkte, Vereine) infrastrukturelle

- Ausweitung des Staats, „Durchstaatlichung“?

- Wachstum von Wissen, Aufgaben und Zugriffen, Einnahmen und Ausgaben $\rightarrow$ Infrastrukturmacht

- Zentral - regional - lokal (z. B. Gemeinden)

- Verwaltung, Parlamente, Unternehmen, Vereine 
IV. Diskussionsrunden zu Literatur und Quellen 


\section{Einladung zur Lektürerunde am 19.2.2018 über Manns Theorie sozialer Macht}

(Auszug aus dem Mail an die Autor*innen)

Liebe Kolleginnen und Kollegen,

Bei Sammelbänden stellt sich stets die Frage, ob sie mehr zusammenhält als nur die Buchdeckel. Eine Verdichtung von Kommunikation entlang gemeinsamer Fragen erhoffen wir uns vom Autor*innenworkshop (13.4., 10:00-17:00). Um auch schon davor ins Gespräch zu kommen, haben wir uns entschlossen, am Niederösterreichischen Landesarchiv eine Lektürerunde zu organisieren, in deren Rahmen wir bei voraussichtlich drei Terminen konzeptuell relevante Literatur diskutieren werden.

Einem Vorhaben, das ca. 50 Autor*innen rund um einen Arbeitstitel „NÖ im 19. Jhdt.“ versammelt, geht es unleugbar ums Ganze: um Gesellschaft also, selbst wenn man diesen Begriff - wie Michael Mann - vermeidet. Manns „Geschichte der Macht“ ist ein Orientierungsangebot, das in unserem Buchkonzept zentral platziert ist. Wir werden Manns Analysekategorien daher bei einem ersten Termin am Mo 19.2., 14:00-15:30 (Ort: Foyer des NÖLA in St.Pölten) unter die Lupe nehmen und ihre Anwendbarkeit für eine Regionalgeschichte der Macht diskutieren.

Alle Autor*innen sind natürlich herzlich zur Teilnahme eingeladen. Für die einen oder anderen, die Recherchen am NÖLA planen, bietet sich so vielleicht die Gelegenheit, einen Archivbesuch in St. Pölten mit inhaltlicher Diskussion zu verbinden (für eine Ankündigung der Teilnahme an der Lektürerunde wären wir dankbar, per Mail an: oliver.kuehschelm@univie.ac.at).

\section{Konkret werden wir folgenden Text lesen:}

Michael MANN, Geschichte der Macht Bd. 3. Die Entstehung von Klassen und Nationalstaaten. Teilbd. 1 (Frankfurt am Main/New York 1998): Einleitung (S. 13-37) sowie aus Kapitel 3 „Eine Theorie des modernen Staates", S. 73-83.

Die drei auf Deutsch bei Campus erschienenen Bände von Manns "Geschichte der Macht" sind inzwischen vergriffen bzw. nur antiquarisch erhältlich. Daher finden Sie anbei die für unsere Diskussion relevanten Kapitel, außerdem ein Word-File mit Literaturhinweisen und Vorschlägen zu Fragen, die wir am 19.2. und bei weiteren Terminen verfolgen könnten.

Für das Projektteam

Oliver Kühschelm, Projektmanagement

Elisabeth Loinig, Projektleitung

Stefan Eminger

Willibald Rosner

Niederösterreich im 19. Jahrhundert

Ein Publikationsprojekt des NÖ Landesarchivs - NÖ Instituts für Landeskunde 
- Eine Kontrastierung mit Wehlers Gesellschaftsgeschichte. Sie stand unausgesprochen Pate für die Dreiteilung in Politik, Wirtschaft und Kultur, die für die Bände zu Niederösterreich im 20. Jahrhundert gewählt wurde, dem Vorläufer unseres aktuellen Projekts. Sowohl Hans-Ulrich Wehler als auch Michael Mann entwickelten ihre Konzepte in den 1970er Jahren. In beiden Fällen stand Max Webers historische Soziologie Pate. Worin gleichen und worin unterscheiden sich die beiden Entwürfe, was sind die Vor- und Nachteile dieser Versuche, das Soziale im Großen - und Ganzen? - historisch zu rekonstruieren?

- In Band zwei der englischen Originalausgabe vergleicht Mann die Entwicklung Preußens und der Habsburgermonarchie im 19. Jahrhundert. Die gekürzte deutsche Ausgabe verzichtete $u$. a. auf diese Kapitel, weil sie - so die editorische Notiz - „am wenigsten die analytischen Neuerungen von Michael Mann zur Geltung bringen“ (Mann 1998: 10 f.). Es würde trotzdem lohnen, Manns historisch-soziologische Deutung mit jüngeren synthetisierenden Publikationen zur Habsburgermonarchie aus den Geschichtswissenschaften, v. a. jener von Pieter Judson, zu vergleichen. Auf diese Weise könnte man dem Nutzen und Nachteil einer in ihren Kategorien expliziten Modellierung des Sozialen nachgehen - im Allgemeinen und mit Blick auf Anliegen einer regionalgeschichtlichen Forschung im Besonderen.

- Lässt sich also mit Bausteinen aus Manns Analyseapparat eine Regionalgeschichte der Macht schreiben? Welchen Erklärungswert birgt eine Orientierung an seinen Konzepten, wie müsste man die Untersuchungen anlegen?

- An Manns Konzeption wird oft ein handlungstheoretisches Defizit beklagt. Ähnlich wie bei der Gesellschaftsgeschichte Bielefelder Herkunft rücken die Akteur*innen und ihre Perspektiven an den Rand der Aufmerksamkeit.

- Inwiefern können mikrogeschichtliche/historisch-anthropologische Zugriffe dieses Defizit beheben? Wie können sie mit einer Geschichte der Macht nach Mann'scher Fasson zusammenspielen? Oder ist mehr als ein Nebeneinanderstellen nicht denkbar?

- Mann analysiert Machtnetzwerke, die sich in der Überschneidung verschiedener Machtressourcen ausbilden. Somit lässt sich die Suche nach einer Verbindung aus mikro- und makrosoziologischen bzw. -historischen Perspektiven auch konkret als Frage ausbuchstabieren, inwiefern Manns Instrumentarium mit dem der Akteur-Netzwerk-Theorie vereinbar ist.

- Mann geht in Anwendung seines IEMP-Modells (Ideologie - Ökonomie - Militär Politik) auf das 19. Jahrhundert davon aus, dass ökonomische und politische Machtressourcen dominierten.

- Welche Quellen der Macht fehlen in seiner Analyse? Die Literatur, die sich mit seinem Werk befasst, hebt hervor, dass er die Rolle militärischer Quellen der Macht für die Durchbildung des Sozialen - auch im Inneren des Staats - in ein schärferes Licht rückt. Hingegen habe er kulturelle Quellen der Macht und somit auch die Wissenschaft in seiner Auseinandersetzung vernachlässigt.

- Inwiefern lässt sich Zahl und Art der Quellen - über die von Mann unterschiedenen vier hinaus - vermehren oder ist es analytisch gerechtfertigt, sich an dieses Quartett zu halten?

- Wie wird man bei Analysen regionaler Gesellschaft gewichten? Anders als Mann, der größere Aggregate (Nationalstaaten und Imperien) im Blick hat? 
- Die Mischungsverhältnisse werden sich zudem für jedes soziale Feld anders darstellen. Wie könnte man zu übergreifenden Einschätzungen gelangen? Oder soll man derlei bleiben lassen? Überhaupt oder insbesondere, wenn man von einer quellengesättigten Regionalgeschichtsforschung ausgeht?

- Last but not least: Theoretisch anspruchsvolle Konzepte werfen immer die Frage nach ihrer Übersetzbarkeit in Texten auf, die über ein wissenschaftliches Publikum hinaus auch für historisch interessierte Laien zugänglich sein sollen. Was bleibt von den Konzepten, wenn die Begriffsmaschine zurückfährt, um breitere Lesbarkeit zu erreichen?

\section{Michael Manns Geschichte der Macht:}

The Sources of Social Power 1: A History of Power from the Beginning to A.D. 1760 (Cambridge 1986).

The Sources of Social Power 2: The Rise of Classes and Nation-States, 1760-1914 (Cambridge 1993).

The Sources of Social Power 3: Global Empires and Revolution, 1890-1945 (Cambridge 2012). The Sources of Social Power 4: Globalizations, 1945-2011 (Cambridge 2013).

In deutscher Übersetzung erschienen (entspricht dem ersten und dem gekürzten zweiten Band der englischen Fassung):

Geschichte der Macht Bd. 1. Von den Anfängen bis zur griechischen Antike (Frankfurt am Main/New York 1990.

Geschichte der Macht Bd. 2. Vom Römischen Reich bis zum Vorabend der Industrialisierung (Frankfurt am Main/New York 1991).

Geschichte der Macht 3 (2 Teilbände). Die Entstehung von Klassen und Nationalstaaten

(Frankfurt am Main/New York 1998, 2001).

\section{Online verfügbare Texte von Mann:}

Infrastructural Power Revisited. In: Studies in Comparative International Development 3/43 (2008) 355-365: https://doi.org/10.1007/s12116-008-9027-7.

Mehrere Aufsätze, die Einleitungs- und Schlusskapitel seiner Werke (darunter das Einleitungskapitel zum ersten Band der "Sources": „Societies as organized power networks") sind zum Download auf der Faculty-Website der UCLA unter "selected publications“ verfügbar: http://www.soc.ucla.edu/faculty/michael-mann.

\section{Literatur zu Manns Konzeption:}

Miguel BANDEIRA JeRÓNIMO, Empires, Globalizations, and Historical Sociology: An Interview with Michael Mann. In: Análise Social 209/48 (2013) 947-952.

Heinrich HAFERKAMP u. Wolfgang KNÖBL, Die Logistik der Macht. Michael Manns Historische Soziologie als Gesellschaftstheorie. In: Michael MANN, Geschichte der Macht Bd. 3. Die Entstehung von Klassen und Nationalstaaten. Teilbd. 2 (Frankfurt am Main/New York 2001) 303-340.

John A. Hall u. Ralph Schroeder (Hrsg.), An Anatomy of Power: The Social Theory of Michael Mann (Cambridge 2005).

George LAWSON, A Conversation with Michael Mann. In: Millennium: Journal of International Studies 2/34 (2006) 477-485.

Ralph SCHROEDER (Hrsg.), Global Powers: Michael Mann's Anatomy of the Twentieth Century and Beyond (Cambridge 2016). 


\section{Notizen zur Diskussion über Michael Manns Geschichte der Macht}

\section{EINLEITUNG}

2. MANNS GESCHICHTE DER MACHT UND WEHLERS GESELLSCHAFTSGESCHICHTE

3. ZUM IEMP-MODELL UND SEINER KRITIK

4. THESEN MICHAEL MANNS ZUM 19. JAHRHUNDERT

5. FORMEN DER MACHT

6. WAS LÄSST SICH DAMIT FÜR UNSER BUCHPROJEKT ANFANGEN?

\section{DISKUSSION}

\section{Einleitung}

Warum der Vorschlag einer Auseinandersetzung mit Michael Mann?

Ein Zusammenhang jenseits eines Titels „NÖ im 19. Jhdt.“ lässt sich nur durch Bemühen um gemeinsame Fragen erzeugen, für die wiederum die Beschäftigung mit theoretischen Zugriffen dienen kann. Die Erwartung ist nicht, dass Michael Manns mehrbändige Untersuchung zu den sozialen Quellen der Macht alle für unser Projekt nötigen Antworten liefert, aber sie kann den Anstoß geben, einige Fragen zu formulieren, um als ein kohärenzstiftendes Moment eine Regionalgeschichte der Macht bzw. eine Geschichte regionaler Macht in den Blick zu nehmen.

Der Begriff der „Macht“ bezeichnet ein tragendes Moment sozialer Beziehungen aller Art buchstäblich aller Art. Soziale Beziehungen sind damit nicht erschöpfend beschrieben, aber Macht spielt stets eine Rolle. Für eine Konzeptualisierung von Macht lassen sich viele Autor*innen heranziehen, in den Geschichtswissenschaften wird seit geraumer Zeit Michel Foucault am intensivsten rezipiert, ${ }^{1}$ in den letzten Jahren, darin den Sozialwissenschaften folgend, zunehmend die Literatur zu Gouvernementalität. ${ }^{2}$ Manns Konzept folgt nicht kulturwissenschaftlichen (und in der empirischen Umsetzung zumeist: diskurshistorischen) Mustern, sondern ist einer historisch-soziologischen bzw. sozialhistorischen Perspektive verbunden. Diese hatte in den 1970er und 1980er Jahren ihren Höhepunkt.

Bezeichnenderweise sind nur die ersten beiden, 1986 und 1993 auf Englisch erschienenen Bände ins Deutsche übersetzt worden. Das ist aber mehr Grund als Hindernis, sich mit solchen historisch-soziologischen Analysen (wieder) auseinanderzusetzen, zumal Manns Arbeit sowohl inhaltlich als auch in seiner Forschungstätigkeit bis in die Gegenwart reicht.

An Manns „Geschichte der Macht“ ist vieles interessant, hervorgehoben seien:

- Das IEMP-Modell als Versuch einer Modellierung des Sozialen

- Seine Unterscheidungen von Formen der Macht als Analysewerkzeug

- Sein „organisatorischer Materialismus“, die Aufmerksamkeit für ein in Institutionen

\footnotetext{
${ }^{1}$ Mann selbst hat sich in keiner Publikation mit Foucaults Machtanalyse auseinandergesetzt. Risto HeISKALA, The Evolution of the Sources of Social Power, and some Extensions. In: Global Powers: Michael Mann's Anatomy of the Twentieth Century and Beyond. (Hrsg.) Ralph SCHROEDER (Cambridge 2016) 11-37, hier $30 \mathrm{f}$.

${ }^{2}$ Im deutschsprachigen Raum etwa der Soziologe Ulrich BRÖCKLING, zuletzt die Aufsatzsammlung: Gute Hirten führen sanft (Suhrkamp: Berlin 2017), siehe dazu online https://soziopolis.de/lesen/buecher/artikel/das-pastoraleselbst/. Die Figur des Hirten ist wohl auch für das lange 19. Jahrhundert in einem katholisch dominierten Land suggestiv.
} 
eingebettetes Handeln

- Als Anregung, die Durchstaatlichung des Sozialen in der Spannung aus Zwang, auch militärischem, und Kooperation zu untersuchen. Intensivierung und Formwandel von Staatlichkeit entfalteten gerade im langen 19. Jahrhundert eine enorme Dynamik.

\section{Manns Geschichte der Macht und Wehlers Gesellschaftsgeschichte}

Zu einer groben Platzierung von Michael Mann in der Gesellschaftstheorie siehe Abbildung $1 .^{3}$ Interessant ist ein Vergleich mit Hans-Ulrich Wehlers Projekt einer Gesellschaftsgeschichte, die sich ebenfalls am Schnittpunkt von Soziologie und Geschichte ansiedelt. Beide Autoren entwickelten ihr Konzept einer makrosoziologisch argumentierenden historischen Gesellschaftsanalyse seit den 1970er Jahren, beide orientieren sich wesentlich an Max Weber, in beiden Fällen mündete die Konzeption in ein mehrbändiges Werk, dessen erste Bände 1986 (Mann) und 1987 (Wehler) erschienen und das jeweils erst nach zwei Jahrzehnten zum Abschluss kam. ${ }^{4}$ Sowohl Wehler als auch (der nicht ganz ein Jahrzehnt jüngere) Mann standen der Sozialdemokratie nahe und identifizierten sich mit den Perspektiven, die eine liberale Demokratie eröffnete. Bei Mann unterlaufen allerdings seine Grundannahmen die optimistische Erwartung einer sozialdemokratisch moderierten Zukunft. ${ }^{5}$ Dem nationalen Fokus Wehlers kontrastiert außerdem der globale (um nicht zu sagen: imperiale) von Mann.

Während zudem Wehler funktionalistisch gesellschaftliche „Fundamentaldimensionen“ als eigene Sphären behandelt, wendet sich Mann gegen die Vorstellung von Gesellschaften als einer Totalität, bestehend aus Subsystemen, die sich ihrerseits autonom entsprechend ihrer Eigenlogik entfalten. ${ }^{6}$ Statt in sich geschlossener Sphären propagiert er eine Analyse, die von einander überlagernden Netzwerken sozialer Macht ausgeht. ${ }^{7}$ Es sei ein Ansatz, um „Wirrwarr"8 zu durchdringen. Der Wehler'sche Zugang, den er in seinen Bänden konsequent durchzieht, erinnert an musterhafte Verwaltung. Er setzt ordentliche Aktenablagesysteme - im Buch dann: Kapitel - für die behandelten Phänomene ein, um systematische Forschung zu ermöglichen und nachzuweisen. Manns Ansatz ist demgegenüber offener. Das muss er auch sein, da er sich nicht darauf beschränkt, die deutsche Gesellschaft in einem Zeitraum von zweihundert Jahren erfassen zu wollen. Vielmehr arbeitet sich Mann an einer Geschichte der Menschheit ab, indem er die jeweils führenden Spitzen („leading edges“) der Anhäufung und

\footnotetext{
${ }^{3}$ Zur Positionierung in der zeitgenössischen angelsächsischen historischen Soziologie vgl. Dennis SMITH, The return of big historical sociology. In: Global Powers: Michael Mann's Anatomy of the Twentieth Century and Beyond. (Hrsg.) Ralph Schroeder (Cambridge 2016) 38-61.

${ }^{4}$ Paul Nolte, Hans-Ulrich Wehler. Historiker und Zeitgenosse (München 2015); Heinrich HAFERKAMP u. Wolfgang KNÖBL, Die Logistik der Macht. Michael Manns Historische Soziologie als Gesellschaftstheorie. In: Michael MANN, Geschichte der Macht, Bd. 3: Die Entstehung von Klassen und Nationalstaaten, Teilbd. 2 (Frankfurt am Main/New York 2001) 303-340; John A. HALl, Political Questions. In: John A. HaLl u. Ralph Schroeder (Hrsg.), An Anatomy of Power: The Social Theory of Michael Mann (Cambridge 2005) 33-55.

${ }^{5}$ HALL, Political questions, 41.

${ }^{6}$ Michael ManN, The Sources of Social Power 2: The Rise of Classes and Nation-States, 1760-1914 (Cambridge 1993) 9. Bei Grundlegung seines Programms in der Einleitung zum ersten Band hält Mann fest: „Gesellschaften sind nicht einheitlich. Sie sind keine sozialen Systeme (ob geschlossen oder offen); und sie sind keine Gesamtheiten. Eine in einem geographischen oder sozialen Raum völlig für sich stehende, nach außen hin abgeschlossene Gesellschaft wird sich nicht finden lassen. Und weil es kein System, keine Gesamtheit gibt, kann es auch keine „Subsysteme“, ,Dimensionen“ oder ,Ebenen“ einer solchen Gesamtheit geben.“ Michael MANN, Geschichte der Macht, Bd. 1: Vom Römischen Reich bis zum Vorabend der Industrialisierung (Frankfurt am Main/New York 1991) 14; vgl. auch ebda., 30-34.

${ }^{7}$ Ebd.

${ }^{8}$ In der deutschen Fassung: „Durchdringung des gesellschaftlichen Wirrwarrs“. Michael MANN, Geschichte der Macht, Bd. 3: Die Entstehung von Klassen und Nationalstaaten, Teilbd. 1 (Frankfurt am Main/New York 1998) 22. Das Attribut „gesellschaftlich“ ist, da sich Mann gegen eine Vorstellung von Gesellschaft richtet, die diese als Totalität analytisch voraussetzt, sinnwidrig. Im englischen Original heißt es an dieser Stelle über das IEMP Modell auch schlicht: „,it forms an analytical point of entry for dealing with mess.“ MANN, Sources 2, 10.
} 
Produktion von Macht rekonstruiert.

Abbildung 1

Karl Marx

Ontologie des Sozialen

Produktionsverhältnisse

(Wirtschaft)

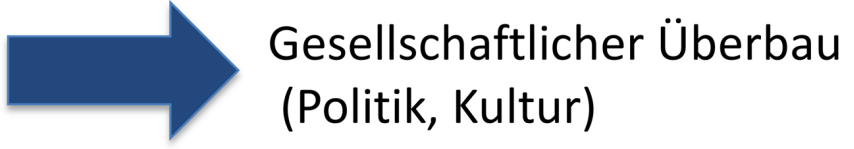

Max Weber

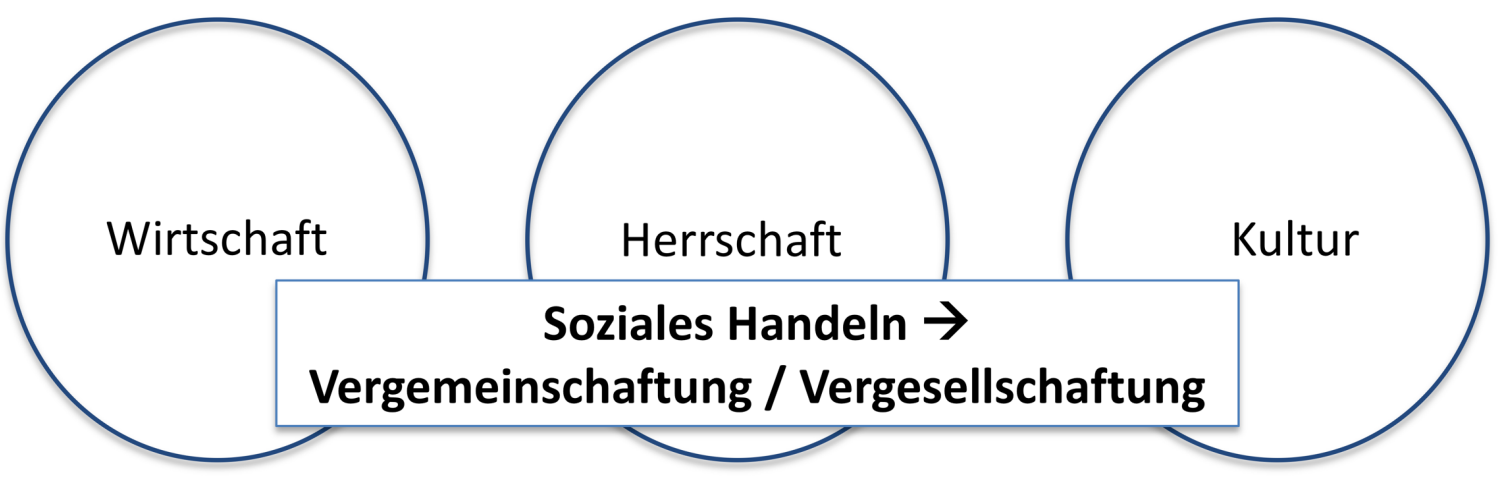

Hans-Ulrich Wehler: Deutsche Gesellschaftsgeschichte

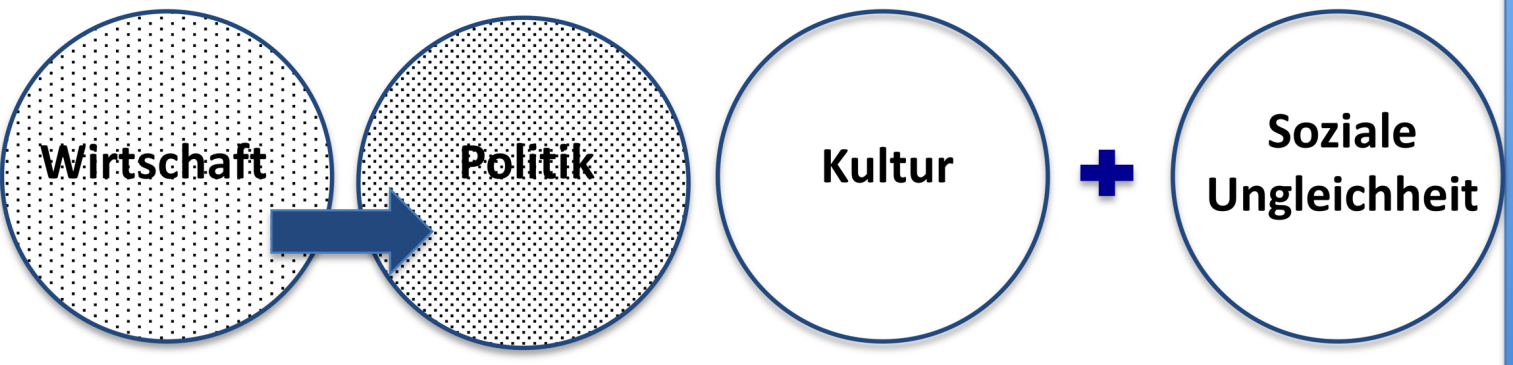

Wechselwirkung gleichrangiger Fundamentaldimensionen/Achsen oder doch „überlegene Wirkungskraft" des „sozioökonomischen Kernbereichs"?

Michael Mann: IEMP-Modell

Analytisches Werkzeug?



Die Frage, ob und wie sich Mikro- und Makroebenen verknüpfen lassen, gehört zu den ewigen Problemen der geschichts- und sozialwissenschaftlichen Theorie (und wohl noch mehr der Forschungspraxis). Das Soziale in Netzen zu denken, macht Manns Theorie aber anschlussfähig für jüngere soziologische Ansätze wie die Akteur-Netzwerk-Theorie. Das kann m. E. den Weg weisen, um eine Brücke zwischen dem Blick auf die ,große' Geschichte und der Beschäftigung 
mit ,kleineren' (Lebens-)Welten zu schlagen.

\section{Zum IEMP-Modell und seiner Kritik}

Mann geht davon aus, dass Menschen soziale, aber nicht gesellschaftliche Wesen seien. Die Existenz von Gesellschaft darf also nicht einfach als gegeben vorausgesetzt werden. Sie kann allenfalls durch Prozesse ohne evolutionäre Zwangsläufigkeit als historisches Produkt (vorübergehend) hergestellt werden.

Die Netzwerke sozialer Macht waren historisch überwiegend nicht auf den Staat bezogen und sind es in vieler Hinsicht immer noch nicht. So überschreiten wirtschaftliche Beziehungen politisch-administrative Grenzen häufig genug. Der fiscal-military state baute aber in der frühen Neuzeit einen territorialstaatlichen Kern auf, der zunächst die Eliten ,einfing' und so seit dem 17. Jahrhundert eine auf diese Eliten begrenzte „Ein-Klassen-Nation“ hervorbrachte. Mit der steigenden Verdichtung von Netzwerken ging eine Durchstaatlichung des Sozialen einher. Den Vorgang, immer mehr Netzwerke rund um den Staat zu organisieren und Grenzen einzuziehen, bezeichnet Mann mit der an Max Weber angelehnten Metapher des "Caging“, als das Einsperren von Akteursgruppen in einen staatlichen Rahmen (Abbildung 2).

Zunehmend kamen dadurch über die Eliten hinausgehend Akteur*innen, namentlich die Arbeiterklasse und die bürgerlichen Mittelschichten, in die Lage, dass sie sich als Teil einer Gesellschaft erfahren und beschreiben konnten. Die politischen Horizonte der Arbeiterklasse und des mittleren Bürgertums beschränkten sich damit zugleich auf den gesellschaftsinternen

Abbildung 2

\section{Michael Mann: Machtnetzwerke statt Gesellschaft}

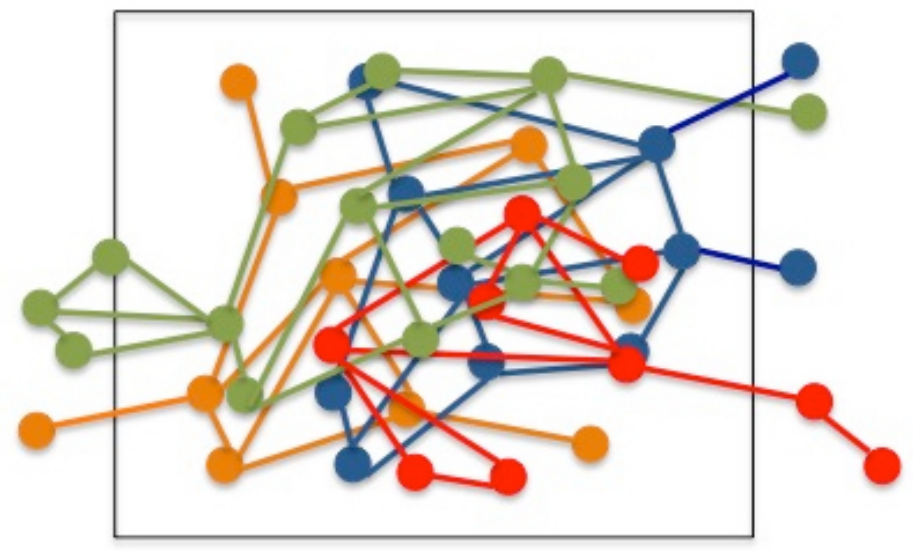

„Societies as organized power networks" (Mann, Sources, vol. 1, Chapter 1)

Entgegen Wehler, Luhmann, Parsons: „Societies do not contain autonomous levels or subsystems, each developing separately according to its own logic." (Mann, Sources vol. 2, 9)

(National)Staat: Gesellschaft als Produkt des „Einsperrens“ von Akteursgruppen in einander überlagernde Machtnetzwerke Ideologie - Wirtschaft - Militär - Politik

Rahmen, während sie die Außenpolitik den alten Eliten überließen. ${ }^{9}$

Michael Mann unterscheidet vier Quellen sozialer Macht: Ideologie, Wirtschaft, Militär, Politik. Die Literatur hebt hervor, dass er die Rolle militärischer Quellen der Macht für die

\footnotetext{
${ }^{9}$ Dieser Abriss nach HAFERKAMP u. KNÖBL, Logistik der Macht, 318-325.
} 
Durchbildung des Sozialen - auch im Inneren des Staats - in ein schärferes Licht rückt.

Kritikpunkte:

- Zu politik- und staatszentrierte Perspektive

- Kulturelle Quellen der Macht und somit auch die Wissenschaft sind vernachlässigt.

- Keine geschlechtergeschichtlichen Fragen

- Dinge, technische Infrastrukturen fehlen als Quelle von Macht.

- Natürliche Ressourcen als Quelle von Macht? Umweltgeschichtliche Perspektiven?

Die Kritikpunkte treffen die Etappen seines Werks in unterschiedlichem Maß. Die kulturwissenschaftliche Wende, größere Aufmerksamkeit für Geschlecht/Gender als Analysekategorie und Kritik am Eurozentrismus ziehen an Manns Arbeit nicht spurlos vorüber.

Abbildung 3

NACEMP-Modell - Vorschlag einer Erweiterung von Risto Heiskala Dingliche (artfefactual)

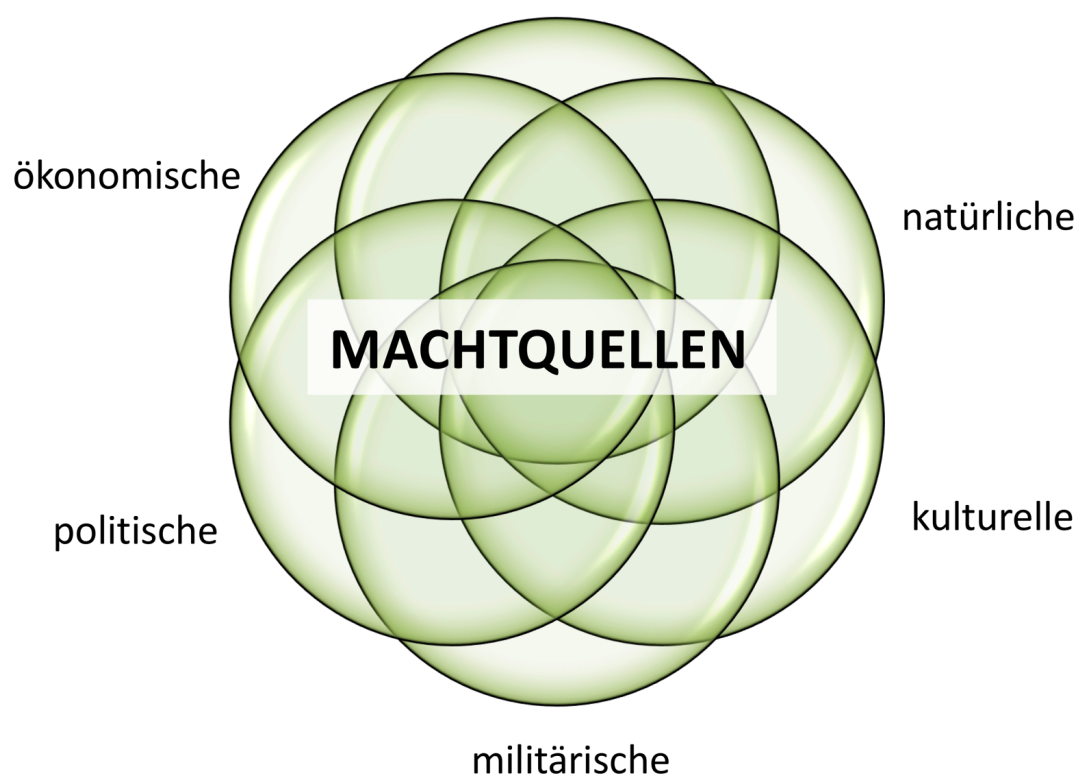

Risto HEISKALA, The Evolution of the Sources of Social Power, and some Extensions. In: Ralph SCHROEDER (Hrsg.), Global Powers: Michael Mann's Anatomy of the Twentieth Century and Beyond (Cambridge 2016) 11-37.

Überlegungen, das Konzept um weitere Machtquellen zu erweitern, drängen sich auf. Ein Beispiel ist das NACEMP-Modell von Risto Heiskala. ${ }^{10} \mathrm{Er}$ schlägt vor, Dinge/Artefakte (A) und die Natur ( $\mathrm{N}$ ) als eigenständige Quellen von Macht zu berücksichtigen (Abbildung 3). ${ }^{11}$ Gegen die Einbeziehung von Natur als Machtquelle wendet Mann ein, dass er eine Geschichte sozialer Macht geschrieben habe. Natürliche Bedingungen seien als begünstigende oder limitierende Bedingungen in die Darstellung eingegangen. Das ist eine eingängige, aber auch

\footnotetext{
${ }^{10}$ Risto HeIskala, The Evolution of the Sources of Social Power, and some Extensions. In: Ralph SCHROEDER (Hrsg.), Global Powers: Michael Mann's Anatomy of the Twentieth Century and Beyond (Cambridge 2016) 1137.

${ }^{11}$ Mit Bezug auf die Argumente der Akteur-Network-Theorie. Mann merkt an, Heiskalas Modell habe gegenüber dem seinen den Vorteil, dass sich das Akronym aussprechen lasse, weist aber ansonsten die Erweiterung zurück. Michael MAnN, Response to the critics. In: Ralph Schroeder (Hrsg.), Global Powers: Michael Mann's Anatomy of the Twentieth Century and Beyond (Cambridge 2016) 281-322, hier $288 \mathrm{f}$.
} 
verdächtig einfache Antwort. Auch ist es sicherlich nötig, Handlungspotentiale von Wissen(schaft), von gebauten Infrastrukturen, von den Alltagsdingen stärker zu berücksichtigen, insbesondere um analytisch näher an Erfahrungen und Lebenswelten, an das Einzelne und die Einzelnen, heranzurücken. Michael Mann bevorzugt die Vogelperspektive und sieht daher keine Dringlichkeit, Bezirksamt, Vereinslokal, Kirchengebäude und Altar, Theatersitz und Kartenschalter, Bahnsteig und Straßenlampe genauer anzusehen und nicht bloß als Abstraktion, als infrastrukturelle Macht und fiskalische Herausforderung zu behandeln.

\section{Thesen Michael Manns zum 19. Jahrhundert}

Wenn keine der vier unterschiedenen Machtquellen als diejenige angenommen wird, welche die Geschichte vorantreibt, und wenn der Menschheitsgeschichte insgesamt keine evolutionäre Logik eingebaut ist, so ergibt das die Aufgabe, die Beziehung der Machtquellen zueinander, die Schwerpunkte und deren Verschiebung in empirischen Beobachtungen erst zu bestimmen. Das gilt für lokale und regionale Konstellationen ebenso wie für gesamt- und zwischenstaatliche, für die sich Mann vorwiegend interessiert. Sozialer Wandel drückt sich in einem veränderten Zusammenspiel von Machtressourcen aus bzw. bringen diese den sozialen Wandel hervor.

Den Übergang von der frühen Neuzeit zum 19. Jahrhundert fasst Mann in drei Behauptungen, deren pauschalierender Charakter regionalgeschichtliche Korrekturen, Ergänzungen und Präzisierungen geradezu provoziert:

„1. Es waren zwei Quellen von sozialer Macht, die ökonomische und die militärische, die im achtzehnten Jahrhundert westliche Gesellschaftsstrukturen vorrangig prägten. Die ,militärische Revolution', Nährboden einer überwiegend ,autoritativen' Macht, und die Entstehung des Kapitalismus, der einer vornehmlich ,diffusen' Macht den Boden bereitete, bewirkten, daß der Okzident im Jahr 1800 anders aussah als hundert Jahre zuvor. Da beide Machtquellen engstens ineinander verschlungen waren, kommt keiner von ihnen ein höchster Vorrang, ein oberster Primat zu.

2. Anders die Situation im neunzehnten Jahrhundert, in dem die Einbettung der militärischen Macht in den ,modernen Staat' und die fortwährende Revolutionierung der Wirtschaft durch den Kapitalismus der ökonomischen und der politischen Machtquelle ein Übergewicht verliehen. Der Kapitalismus und seine Klassen sowie Staaten und Nationen entwickelten sich zu den entscheidenden Machtakteuren der Moderne - erstere nach wie vor eher Diffusität und Ambiguität begünstigend, letztere für die autoritative Auflösung dieser Ambiguität sorgend. Wiederum fest ineinander verschlungen, kann auch hier keine der beiden Machtquellen einen obersten Primat für sich beanspruchen.

3. Die ideologischen Machtbeziehungen verloren in dieser Periode zunehmend an Gewicht. Während das mittelalterliche Europa maßgeblich vom Christentum bestimmt war und die Kirchen noch im Jahre 1760 (höchstens) die Mittel der diskursiven Kommunikation für erneuerungs- und veränderungsbedürftig erachteten, läßt sich danach keine ideologische Bewegung von vergleichbarer Potenz mehr ausmachen [...]. “12

\section{Formen der Macht}

Mann versteht Macht zum einen als einen Vorrat, den Akteur*innen und Institutionen anhäufen können. Zum anderen untersucht er Macht relational, als etwas, das Akteur*innen gemeinsam - obschon nicht unbedingt in gleicher Weise - erzeugen. Macht ist produktiv, sie

\footnotetext{
${ }^{12}$ MANN, Geschichte 3, 14.
} 
verdichtet soziale Beziehungen. Das Ausmaß an verfügbarer sozialer Macht hat sich im Laufe der Geschichte gesteigert. ${ }^{13}$

Entlang von vier Gegenüberstellungen differenziert Mann zwischen verschiedenen Formen von Macht, die sich miteinander überkreuzen und als Analysewerkzeug auf alle möglichen Beziehungsgefüge, z. T. auch informelle, vor allem aber institutionalisierte, anwenden lassen:

kollektive vs. distributive Macht

„Distributive Macht ist die Macht von Akteur A über Akteur B. Damit B mehr distributive Macht erringen kann, muß A einen Teil der seinen verlieren. Kollektive Macht hingegen ist die gemeinsame Macht von A und $B$, die kooperieren, um gemeinsam die Natur oder einen dritten Akteur, Akteur C, ausbeuten zu können. "14

extensive vs. intensive Macht

„Extensive Macht impliziert das Vermögen, eine große Zahl von Menschen über weite Räume hinweg zu organisieren. Intensive Macht erlaubt es, den an der Organisation Beteiligten ein hohes Maß an Engagement abzuverlangen. "

autoritative vs. diffuse Macht

„Autoritative Macht setzt die gebieterischen Anweisungen eines Akteurs (in der Regel einer Kollektivität) und den bewußten Gehorsam der ihm (bzw. ihr) Unterworfenen voraus. Ihre typischste Ausprägung erfährt die autoritative Macht in militärischen und politischen Machtorganisationen. Anders die diffuse Macht, sie wird nicht direkt ausgeübt, sondern breitet sich in einer eher spontanen, unwillkürlichen und dezentralen Weise aus. Die Menschen sehen sich genötigt, in einer bestimmten Manier zu handeln, aber nicht auf Anweisung einer speziellen Person oder Organisation. Diffuse Macht findet ihre typischste Ausprägung in ideologischen und ökonomischen Machtorganisationen. Ein gutes Beispiel liefert der Markttausch im Kapitalismus, von dem ein erheblicher, jedoch unpersönlicher und häufig scheinbar ,natürlicher' Zwang ausgeht. “16

Abbildung 4

Societies as organized power networks

$\begin{array}{lll} & \text { Authoritative } & \text { Diffused } \\ \text { Intensive } & \text { Army command structure } & \text { A general strike } \\ \text { Extensive } & \text { Militaristic empire } & \text { Market exchange }\end{array}$

Figure 1.1. Forms of organizational reach

Michael MANN, The Sources of Social Power 1: A History of Power from the Beginning to A.D. 1760 (Cambridge 1986) 9.

\footnotetext{
${ }^{13}$ HeISKALA, Evolution, 31.

${ }^{14}$ MANN, Geschichte 3/1, 15.

${ }^{15}$ Ebd., 17.

${ }^{16}$ Ebd., $17 \mathrm{f}$.
} 
Mit der letzteren Unterscheidung eng verknüpft ist die folgende Gegenüberstellung:

despotische vs. infrastrukturelle Macht

„Despotische Macht ist die distributive Macht staatlicher Eliten über die Zivilgesellschaft. Sie erwächst aus der Summe der Handlungen, die Staatseliten tätigen können, ohne vorher in routinemäßige Verhandlungen mit verschiedenen gesellschaftlichen Gruppierungen eintreten zu müssen. “17

„Infrastrukturelle Macht ${ }^{18}$ ist das institutionelle Vermögen eines Zentralstaates, ob despotisch oder nicht, sein Hoheitsgebiet zu durchdringen und politische Entscheidungen logistisch zu implementieren. Das ist kollektive Macht, gesellschaftlich , vermittelte Macht', die das soziale Leben vermittels staatlicher Infrastrukturen koordiniert. Sie begreift den Staat als ein Gefüge von zentralen und radialen Institutionen, die sein gesamtes Territorium durchdringen. " ${ }^{19}$

Auf der Basis dieser letzteren Unterscheidung differenziert Mann vier Idealtypen von Staatlichkeit. Siehe dazu Abbildung 5.

\section{Was lässt sich damit für unser Buchprojekt anfangen?}

Abbildung 5

\begin{tabular}{|c|c|c|}
\hline \multicolumn{3}{|c|}{ Tabelle 3.1 Zwei Dimensionen von staatlicher Macht } \\
\hline \multicolumn{3}{|c|}{ infrastrukturelle Macht } \\
\hline despotische Macht & gering & groß \\
\hline gering & feudaler Staat & $\begin{array}{l}\text { bürokratisch- } \\
\text { demokratischer Staa }\end{array}$ \\
\hline groß & $\begin{array}{l}\text { imperialer/ } \\
\text { absolutistischer Staat }\end{array}$ & autoritärer Staat \\
\hline
\end{tabular}

Michael MANN, Geschichte der Macht Bd. 3, Teilbd. 1: Die Entschehung von Klassen und Nationalstaaten (Frankfurt am Main/New York 1998) 79.

- Erstens lässt sich hier anknüpfend diskutieren, womit wir es im Fall der Habsburgermonarchie zu tun haben. „What do we call it? The political unit we are now discussing, had a long and powerful history but no secure name," beginnt das entsprechende Kapitel. ${ }^{20}$

- Zweitens gilt es zu untersuchen, wie sich lokal und regional Formen von Macht zu jener „Durchstaatlichung" fügen (oder auch sich ihr entziehen und ihr widerstreben), die das 19. Jahrhundert wesentlich kennzeichnet.

- Drittens bietet es sich an, die Unterscheidungen, die Mann hinsichtlich der Formen von Macht trifft, als ein Handwerkszeug (oder vorsichtiger: als einen Ausgangspunkt) einzusetzen, um diverse Institutionen als Vehikel von despotischer/infrastruktureller Macht zu untersuchen.

\footnotetext{
17 Ebd., 77.

${ }^{18}$ Dazu auch: Michael MANN, Infrastructural Power Revisited. In: Studies in Comparative International Development 3/4/43 (2008) 355-365.

${ }^{19}$ MANN, Geschichte 3/1, 78.

${ }^{20}$ In der deutschen Übersetzung des Bands ist es nicht enthalten. MANN, Sources 2, 330.
} 
- Viertens gilt das für die von Mann verwendeten Begriffspaare insgesamt. Sie bieten sich als Mittel an, um einige einfache, aber wichtige Fragen zu stellen - und das präzise zu tun. Man kann damit beschreiben, dass manche Akteur*innen (bestimmte Formen von) Macht haben und sie manchen aus demselben Grund fehlt. Ebenso kommt in den Blick, dass bei anderen Formen von Macht Akteur*innen zusammenwirken. Solche Fragerichtungen zu überschneiden, legt einen Zugriff auf soziale Beziehungen an, der weder blind für Hierarchien und ungleiche Verteilung ist noch den Untersuchungsgegenstand in einem tiefen Schwarz von Kulturpessimismus oder radikaler Modernekritik verhüllt.

- Fünftens ermöglicht das Begriffswerkzeug eine ergebnisoffene Auseinandersetzung. Es gibt keinen Grund, seine Anwendbarkeit exklusiv in der Beschäftigung mit ,großen“ Zusammenhängen zu sehen. Die Untersuchungsskala (wie groß also die Region, Gruppe, Institution sind) sollte dafür keine Rolle spielen, auch wenn Mann selbst auf eine ,Weltgeschichte' der Macht zielt.

- Sechstens ist es prinzipiell möglich, den von Mann unterschiedenen Formen der Macht in allen Themen, die das Buchprojekt anspricht, nachzuspüren. Die Unterscheidungen und Fragen sind nicht nur für politik- und verwaltungsgeschichtliche Themen tauglich, sondern ebenso für die Rekonstruktion von konkreten Lebenswelten und Erfahrungen (zu denen im Übrigen auch die Beteiligung an Verwaltung und dem Verwaltet-werden gehört).

Um das an einigen Beispielen anzudeuten: Nicht nur die Zentralbürokratie übt autoritative Macht aus, sondern die katholische Kirche, Gemeindeverwaltungen, Lehrer*innen gegenüber Schüler*innen, der Hausherr gegenüber dem Dienstmädchen. Infrastrukturelle Macht ist ebenso wenig alleine oder auch nur vordringlich eine Sache des Zentralstaats, sondern baut sich im späten 19. Jahrhundert vor allem in den Gemeinden auf (und führt zu ihrer Verschuldung). Sie formiert sich über Verbände und Vereine, von politischen Vereinen bis Gebetsvereinen, Sparkassen, Genossenschaften etc. Wenn man nach Institutionen fragt, die das ganze Territorium durchdringen, nach extensiver Macht also, muss man wiederum lange Zeit eher an die katholische Kirche denn an einen säkularen Arm des Staats denken, die Dienstbarkeit und Autonomie der Kirche gegenüber anderen Akteuren von Staatlichkeit untersuchen.

Diffuse Macht, die punktuell, bei momentanen politischen Zuspitzungen, z. B. Wahlkämpfen, intensiv werden kann, formiert sich in lokaler Öffentlichkeit. Diese Prozesse werden von politischen und religiösen Vereinen angetrieben, die Kristallisationspunkte der Erzeugung einer lokalen und regionalen intensiven Macht sind. Zudem rezipieren viele Menschen Publikumsmedien: vor allem die Regionalzeitungen, im frühen 20. Jahrhundert aber auch bereits Filme. Diese Publikumsmedien sind Instrumente extensiver Macht, die helfen, Menschen auf große Distanz zu organisieren. Säkulare und religiöse Ideologien sind Vehikel diffuser Macht. Sie zwingen nicht, sie überreden, auch wenn sie mit hierarchischen Institutionen wie der katholischen Kirche verbunden sein können.

Unternehmen sind Orte despotischer Macht, die über ihre Beteiligung an Märkten die Infrastrukturmacht steigern, die z. B. im Kriegsfall Bürokratie und Militär in Anspruch nehmen. Märkte lassen sich als Instrument kollektiver Macht, als kooperative Steigerung, beschreiben und als Instrument, um Verteilungen herzustellen. Sie verleihen bestimmten Akteuren distributive Macht, die anderen fehlt - etwa je nachdem, ob es sich um einen Käufer- oder Verkäufermarkt handelt, auf Konsumenten- oder Produzentenseite.

Vereine sind Instrumente, um durch Kooperation intensive Macht zu erzeugen, doch Vereinsvorstände verfügen über (distributive) Macht, die den übrigen Mitgliedern abgeht. 
Fabriken oder Schulen, wenn sie nach dem Muster autoritärer Pädagogik operieren, können durch Sanktionsdrohungen intensive Macht erzeugen, zugleich ist noch die übelste frühindustrielle Produktionsstätte ein Ort der kollektiven Machtsteigerung - Macht über Natur, Macht gegen Konkurrenz, im Rahmen der Standortgemeinde etc.

\section{Diskussion}

An der Diskussionsrunde am Montag, 12.2., nahmen dreizehn Personen teil, Autor*innen des NÖ-Bands und Mitarbeiter*innen von NÖ Forschungsinstituten (NÖLA, Landesbibliothek, IGLR, ZfM). Nachfolgend eine kurze Zusammenfassung einiger Diskussionsbeiträge.

\section{Thomas Stockinger:}

betont das Potential, das in Untersuchungen der Entwicklung von Staatlichkeit im 19. Jahrhundert steckt. Die Genese des Staats wird vor allem für die frühe Neuzeit viel beforscht. Sie wird meist in zwei einander entgegengesetzte Narrative gefasst: War makes state and state makes war vs. state building from below. Im Hinblick auf das 19. Jahrhundert wird das weniger diskutiert, weil man den Staat bereits als gegeben voraussetzt statt zu fragen, wer den Staat im 19. Jahrhundert macht und welche Vorstellungen kursieren, warum es ihn überhaupt geben soll.

Positive Ansätze bei Mann:

-) Mann zeigt, wie sich Forschung zu kollektiven Akteuren operationalisieren lässt, ohne diese zu reifizieren. Er weist darauf hin, dass Gruppen keine einheitlichen Entitäten sind, nach innen heterogen und ohne starre Außengrenzen

-) Der Staat wird von Mann nicht als Ding mit einem einheitlichen Willen behandelt.

-) Die Grenzen zwischen Staat und civil society sind keine fest gezogenen. Vielmehr ist die Herstellung dieser Grenzen selbst ein Mittel, mit dem sich Akteure in Machtkämpfe einbringen.

-) Mann untersucht die Territorialisierung von Staatlichkeit, seine Konzepte sind raumbezogen.

Für eine Anwendung in einem Buch über Niederösterreich ergeben sich aber mehrere Fragen:

-) die Frage der Untersuchungsebenen: Niederösterreich und seine Subregionen ist ein anderer Schauplatz als die von Mann in den Blick genommene Makroebene.

-) Wie konstruieren sich Räume, wie kommt man vom Globalen zum Regionalen?

-) Mann fokussiert auf die organisatorische Dimension des Sozialen. Er verfügt über keine explizite Handlungstheorie. Auch deshalb spielt Geschlecht keine Rolle im Untersuchungsdesign. Offen bleibt, wie eine von Mann inspirierte Forschung auf die Akteursebene zugreifen kann.

-) Sprache: Mann hat die Tendenz, geläufige Wörter in einer nicht geläufigen Weise zu verwenden, und im Hinblick auf ein Buch, dessen Inhalte auch einem nicht-akademischen Publikum zugänglich sein sollen, ist das ein Problem.

\section{Zsuzsanna Török:}

findet die Auseinandersetzung mit unterschiedlichen Staatskonzepten, auch den für die Analyse der frühen Neuzeit entwickelten wie jenem des composite state für wichtig und meint, dass das auch dem Buchprojekt guttun könnte. Es geht nicht darum, sich auf ein Konzept von Staatlichkeit zu verpflichten, sondern einen gemeinsamen Interpretationsrahmen aufzuspannen.

Achim Doppler:

betont die Inkonsistenzen im Theoriegebäude von Michael Mann. Er spricht dem Sozialen die 
Einheitlichkeit ab, Gesellschaft ist kein System, die Entwicklung von sozialer Macht vollzieht sich in kontingenten Prozessen. Wie lässt sich auf diese Weise über die Erzählung hinaus zu einer Analyse gelangen? Welche sind die Einheiten, die zueinander in Wechselbeziehung treten? Wie lässt sich sozialer Wandel erklären, wenn keine Bewegungslogik, keine Determinanten benannt werden?

Mann spricht häufig von „Strategien“, ohne dass klar wäre, wer hier Absichten verfolgt und welchen Handlungsbegriff er voraussetzt.

\section{Rita Garstenauer:}

Mann weist mit seiner Beschreibung seiner u. a. gegen Webers Überschätzung von Bürokratie gerichteten Vorstellung vom Staat als Wirrwar darauf hin, was für ein grobes Werkzeug Verwaltung im 19. Jahrhundert noch ist, wie viel nicht funktioniert. Das Fehlen einer Bewegungslogik entspricht also dem empirischen Zustand. Dem Verwaltungsstaat seine Selbstverständlichkeit zu nehmen, ist eine Einsicht, die eine von Mann angeregte Auseinandersetzung erbringen kann, um damit unsere an den Erfahrungen des 20. und 21. Jahrhunderts ausgeprägten Vorstellungen in Perspektive zu setzen. Umgekehrt ist es nötig, nicht einen Bias aus dem 21. Jahrhundert in die Analyse von Staatlichkeit im 19. hineinzutragen.

\section{Jessica Richter:}

Die Lektüre von Mann muss nicht eine Vorstellung von Staatlichkeit einbringen, die zufriedenstellt; wenn sie dazu anregt, über den Staat nachzudenken, ist bereits durch diese Problematisierung etwas gewonnen.

\section{Willibald Rosner:}

Der Staat ist zu Anfang des 19. Jahrhunderts schon angelegt und wächst im weiteren Verlauf zwar, aber auch die Revolution 1848 ist ein weniger großer Bruch als oft angenommen. Die ständischen Strukturen halten sich in Überresten erstaunlich zäh. Der tatsächliche Bruch erfolgt 1918, nicht nur durch den Zerfall des Habsburgerreichs, sondern auch weil die Länder, die davor bloße Provinzen des Reichs und der Zentralgewalt nachgeordnet waren, nun erhebliche Macht an sich ziehen.

Die Vorstellung des Staats als Netzwerk aus vielen Gruppen ist gerade auch mit Blick auf die tragende Rolle der Gemeinden plausibel.

\section{Klemens Kaps:}

Kritisiert Mann aus globalgeschichtlicher Perspektive. Österreich-Ungarn als Teil des ,Westens' zu behandeln, ist z. B. fragwürdig.

Staat/Gesellschaft als Netzwerke - der Netzwerkbegriff hat enorme Konjunktur und wird inflationär verwendet. Was ist tatsächlich der Vorteil, das Soziale in Netzwerken zu denken?

Ralph Andraschek:

greift Manns These auf, dass ideologische Machtbeziehungen, d. h. auch kirchliche, im 19. Jahrhundert auf dem Rückzug seien. Das scheint wenig überzeugend, wenn man an die Rolle der katholischen Kirche in der Habsburgermonarchie denkt.

Gertrude Eigelsreiter-Jashari:

Eine Geschichte von Niederösterreich im 19. Jahrhundert sollte Geschlecht als wesentliche Kategorie behandeln, außerdem nicht nur die Aufmerksamkeit auf die Region richten, 
sondern überregionale und globale Verflechtungen adäquat berücksichtigen.

Literaturhinweise:

- Hinsichtlich der Einbettung in einen globalhistorischen Kontext: Conrad, Sebastian/Randeria, Shalini (Hg.) 2002: Jenseits des Eurozentrismus. Postkoloniale Perspektiven in den Geschichts- und Kulturwissenschaften, Capus V, Frankfurt/New York - insbesondere die Einleitung (S. 9-49), in der sie auch auf Michael Mann (S. 15) Bezug nehmen.

- Kreckel, Reinhard 1997: Politische Soziologie der sozialen Ungleichheit, Campus V., F/NY - bietet zwar keine eigene Macht-Theorie an, behandelt aber in seinen theoretischen Perspektiven vertikale Ungleichheiten (Klasse, Stand, Hierarchie, Wissen u. a.) und berücksichtigt insbesondere auch das Geschlechterverhältnis (Kap. IV, S. 212-284).

Ernst Bruckmüller (via Email):

Michael Mann ist als großer Welterklärer bekannt. Ob uns das für unsere kleine Welt weiterhilft? Nun ist Macht sicher eine zentrale Kategorie in den menschlichen Beziehungen. Nur wer über Macht verfügt, kann Herrschaft ausüben. In der Regel genügt für das normale gesellschaftliche Leben die Androhung von Machtausübung. Man wird die verschiedenen Ebenen von Herrschaft analytisch auseinanderhalten müssen - Haus- und Grundherrschaft, die Herrschaft des Unternehmers (primär auch Hausherrschaft), schließlich die Herrschaft des abstrakten modernen Staates mit den Machtmitteln Armee, Gendarmerie und Polizei.

Für die ländliche Gesellschaft stellen sich für mich folgende Fragen:

-) Inwiefern bleiben auch nach Joseph II. und 1848 grund- oder gutsherrschaftliche Herrschaftsansprüche erhalten? Auf welcher Basis an Machtmitteln? Rein ökonomisch (monopolistische Stellung als Arbeitgeber) oder auf Grund gesetzlicher Zuschreibung (Jagdrecht, Forstgesetz, Servitutenregulierung)?

-) Wie sieht das Machtgefälle innerhalb der ländlichen Gemeinden aus?

-) Haben die Landgemeinde überhaupt genug Machtmittel, um ihre Aufgaben insbesondere im polizeilichen Bereich wahrzunehmen?

-) Gerade in Niederösterreich kann man sich der Machtzumutung in den Landgemeinden durch Abwanderung nach Wien entziehen. Das geht wiederum solange gut, als die Abwanderer nicht verarmen.

Oliver Kühschelm, 27.2.2018 
Einladung zur zweiten Lektürerunde am 12.3.2018 zu Mikro- und Makroperspektiven

(Auszug aus dem Mail an die Autor*innen)

Liebe Kolleginnen und Kollegen,

Die erste Lektürerunde letzte Woche war erfreulich gut besucht. Für Mo 12.

März (wiederum 14:00-15:30 im Foyer des Landesarchivs) laden wir zu einer zweiten Lektürerunde ein. Wir wollen diesmal von mikrohistorisch orientierten Texten ausgehen. Wir werden somit dem mit Michael Mann verbundenen makrosoziologischen Zugriff eine Diskussion folgen lassen, die am anderen Ende der Skala ansetzt, um nach den Brücken, nach Kompatibilität und Unvereinbarkeit, nach Schwierigkeiten und Potentialen einer Verbindung von Mikro- und Makroperspektiven zu fragen.

Zur gemeinsamen Lektüre schlage ich vor:

1. einen theoretisch angelegten Aufsatz von Angelika Epple zur Konstituierung von lokalem/globalem Raum;

2. einen kurzen Text von Margareth Lanzinger zu illyrischen Steuerpolitiken, um auch die Diskussion von Staatlichkeit fortzuführen;

3. einen Aufsatz von Claudia Ulbrich zu Eheschließung und Netzwerkbildung (eine Empfehlung von Margareth Lanzinger).

Hinweisen möchte ich außerdem auf einen Aufsatz von Patrick Joyce und Chandra Mukerji $\mathrm{zu}$ „The state of things“. Hier geht es, wie der Titel signalisiert, um den Staat und einen Fokus auf Materialität, u. a. orientiert an Bruno Latours Akteur-Netzwerk-Theorie. Diese wiederum scheint mir die aussichtsreichste Antwort auf die Frage, wie denn Makro- und Mikroebenen zusammengedacht werden können.

Was die Verbindung aus lokaler/regionaler Beobachtung mit großem Detail und globalgeschichtlicher Perspektive angeht, so gibt es in jüngerer Zeit viele Versuche in diese Richtung. Als eine sehr gelungene wird Michael Kwass, „Contraband. Louis Mandrin and the Making of a Global Underground“, über einen Schmuggler im Frankreich des 18.

Jahrhunderts gehandelt. Das Buch habe ich nicht auf die Dropbox gestellt, wohl aber einen interessanten Review-Artikel.

Für das Projektteam

Oliver Kühschelm, Projektmanagement

Elisabeth Loinig, Projektleitung

Stefan Eminger

Willibald Rosner

Niederösterreich im 19. Jahrhundert

Ein Publikationsprojekt des NÖ Landesarchivs - NÖ Instituts für Landeskunde 


\section{Zum Verhältnis von Mikro- und Makroperspektiven}

\section{EINLEITUNG 1}

NOTIZEN ZU DEN TEXTEN

Die Relationierung von Untersuchungsgegenständen und -räumen 2

Was ist eine Region? 3

Methoden und Strategien $\quad 5$

Räume in/und Bewegung 8

NOTIZEN AUS DER DISKUSSION

Epples Kritik an der Actor-Network-Theory

Absolute und relative Räume $\quad 10$

Eine mittlere Beobachtungsebene?

\section{Einleitung}

Die Diskussion bei unserem ersten Treffen, die von Michael Manns Geschichte der Macht ausging, warf $u$. a. die Frage auf, ob sich eine solche makrosoziologische Vogelperspektive für regionalgeschichtliche Forschung nützen lässt, ob sie nicht zu,groß' und zu grob für solche Zwecke ist. Näher scheinen Zugriffe, die dezidiert von kleinen, überschaubaren Untersuchungseinheiten ausgehen. Daher haben wir bei unserem zweiten Treffen einige Texte diskutiert, die sich mit den Möglichkeiten von mikrogeschichtlichen und historischanthropologischen Zugängen theoretisch befassen bzw. auch Einblick in die Forschungswerkstatt geben.

In den meisten der ausgewählten Texte setzen sich Vertreter*innen mikrogeschichtlicher Forschungsstrategien damit auseinander, ob es Brücken zu der Forderung geben kann, ,große' Zusammenhänge aufzuschließen, die seit den 1990er Jahren vor allem mit der Globalgeschichte verbunden ist. Der Aufsatz von Hans Medick vertritt das z. B. mit erheblichem Enthusiasmus.

Als Grundlage für die Diskussion bei dem Treffen im NÖLA waren vor allem die in der untenstehenden Liste blau markierten Texte vorgesehen. Epple setzt sich mit theoretischen Fragen auseinander, die Aufsätze von Lanzinger und Ulbrich spielen konzeptuelle Überlegungen an empirischen Beispielen durch: der Verwaltungsgeschichte der Illyrischen Provinzen in den wenigen Jahren nach 1809 und der Netzwerkbildung wohlhabender jüdischer Familien im deutsch-französischen Grenzgebiet des 18. Jahrhunderts.

Dropbox-Link: https://www.dropbox.com/sh/uheew4a38s8bmht/AABOPjUN 3WPtoRMKBHzujfa?dl=0

Angelika EPPLE, Lokalität und die Dimensionen des Globalen. In: Historische Anthropologie 1/21 (2013) $4-25$.

Margareth LANZINGER, Das Lokale neu positionieren im actor-network-Raum - globalgeschichtliche Herausforderungen und illyrische Steuerpolitiken. In: Ewald HIEBL u. Ernst LANGTHALER (Hrsg.), Im Kleinen das Große suchen. Mikrogeschichte in Theorie und Praxis. Hanns Haas zum 70. Geburtstag. (Innsbruck 2012) 48-56. 
Sigurður Gylfi MAGNÚSSON, Far-reaching microhistory: the use of microhistorical perspective in a globalized world. In: Rethinking History 3/21 (2017) 312-341.

Hans MEDICK, Turning Global? Microhistory in Extension. In: Historische Anthropologie 2/24 (2016) 241-252.

Paul-André ROSENTAL, Between Macro and Micro: Theorizing Agency in Nineteenth-Century French Migrations. In: French Historical Studies 3/29 (2006) 457-481.

Francesca TrivelLATo, Is There a Future for Italian Microhistory in the Age of Global History? In: California Italian Studies 2/1 (2011).

Claudia ULBRICH, Eheschließung und Netzwerkbildung. Am Beispiel der jüdischen Gesellschaft im deutsch-französischen Grenzgebiet. In: Andrea GRIESEBNER et al. (Hrsg.), Verflochtene Geschichten. Ausgewählte Aufsätze zu Geschlecht, Macht und Religion in der Frühen Neuzeit. (Wien/Köln/Weimar 2014) 99-119.

\section{Außerdem:}

Patrick JOYCE u. Chandra MUKERJ, The state of things: state history and theory reconfigured. In: Theory and Society 1/46 (2017) 1-19.

David BeLL, Shameless, Lucifer and Pug-Nose. In: London Review of Books 1/37 (2014), https://www.Irb.co.uk/v37/n01/david-a-bell/shameless-lucifer-and-pug-nose (20.2.2018);

Rezension von: Michael KWASS, Contraband. Louis Mandrin and the Making of a Global Underground (Cambridge 2014).

\section{Notizen zu den Texten}

\section{Die Relationierung von Untersuchungsgegenständen und -räumen}

Epple macht eine relationale Analyse von Untersuchungsgegenständen als wesentliches Merkmal jüngerer Forschung aus, die damit u. a. auf die Herausforderung reagiert, die eine breite gesellschaftliche Wahrnehmung von Globalisierung und ihre wissenschaftliche Spiegelung in der Globalgeschichte darstellen. ${ }^{1}$

Hingegen habe sich, so Epple, „in der traditionellen Lokal- und Regionalgeschichtsschreibung [...] teilweise bis heute ein nicht-relationales Verständnis von historischer Wahrheit erhalten. Hier gilt die Annahme, aus den Quellen könnten Fakten direkt abgeleitet werden. Aufgrund des naiven Wahrheitsbegriffs in Kombination mit der begrenzten Relevanz für übergeordnete Zusammenhänge haben Lokal- und Regionalgeschichte (im Gegensatz zur Mikrogeschichte) in der Zunft daher keinen guten Ruf. “2

Zwei Probleme erkennt Epple allerdings am Bemühen, der „Analyse der Relationen den Vorrang vor der Analyse gesetzter, in sich geschlossener Einheiten“3 einzuräumen - dass das Bemühen in mancher Hinsicht zu weit gehe (1) und in anderer nicht weit genug (2):

\footnotetext{
${ }^{1}$ Vgl. auch Angelika EPPLE, Relationale Geschichtsschreibung: Gegenstand, Erkenntnisinteresse und Methode globaler und weltregionaler Geschichtsschreibung. In: H-Soz-Kult (02.11.2017), online: hsozkult.de/debate/id/diskussionen-4291 (20.3.2018).

2 EPPLE, Lokalität, 9.

${ }^{3}$ Ebd., 6.
} 
(1) Der Fokus auf Beziehungen lässt die Elemente, zwischen denen Beziehungen hergestellt werden, in ihrem Eigengewicht in den Hintergrund treten. ${ }^{4}$ Sind die einzelnen Akteur*innen nicht mehr als das Produkt der Beziehungsnetze, in denen sie stehen?

(1a) Kausalität: Wenn die Forschung Beziehungen genau beschreibt, eine Beziehung nach der anderen abschreitet, bis sie ein Netzwerk dargestellt hat, ist sie dadurch bei einer Erklärung angelangt?

Auch Francesca Trivellato meint, die mikrogeschichtliche Forschung sei mehr an den Verbindungen zwischen den Phänomenen interessiert als daran, kausale Ursachen für Wandel im Zeitverlauf zu benennen. ${ }^{5}$

Latour empfiehlt in seiner Anleitung zu einer "flachen Soziologie“, die Forscher*innen mögen sich „als gute Ameisen zu verhalten“, „so beschränkt, buchstäblich, positivistisch, relativistisch wie möglich“. ${ }^{6}$ Die Empfehlung hat insbesondere gegenüber der theoriefreundlichen französischen Soziologie ihren Stachel. Allerdings formuliert sie nicht, was eine an ANT inspirierte Regionalgeschichte von den Heimatforscher*innen und volkskundlichen Sammler*innen unterscheidet. Diese haben seit dem 19. Jahrhundert oft buchstäblich und positivistisch Landes- und Ortskunde betrieben. Die Beschreibung eines Netzes bietet jedenfalls nicht zwangsläufig Erkenntnis. Sie kann sich schlicht darauf beschränken, dass sie zu einer Gedächtnisleistung einlädt. Die von Genealogen nachgezeichneten Verwandtschaftsnetze sind oft genug ein Wissen dieses Typs. Hingegen macht erst Argumentation, die notwendigerweise abstrahiert, die positivistische Ameise zur Analytikerin, die (wie bei Ulbrich oder auch Rosental) Verwandtschaftsnetzen mehr als die visuelle Darstellung eines Stammbaums abgewinnt.

(2) Relationierung setzt meist nur bei den oberen Raumkategorien an. Das beobachtet Epple auch in den Werken von zwei Großmeistern der Globalgeschichte. So gehe Christopher Bayly davon aus, dass jegliche lokale, nationale oder regionale Geschichte auch globale Geschichte sei. „Bezüglich der Vorstellungen des Staates und der Nation gelingt es inm auch, die jeweiligen Untersuchungseinheiten selbst relational zu denken. Anders sieht dies allerdings aus, wenn es um kleinere Einheiten geht", z. B. Stadtentwicklungen. ${ }^{7}$

Jürgen Osterhammel definiert Regionen als „Interaktionsräume, die sich durch die Dichte von Verkehr und Migration, Kommunikation und Handel konstituieren“. Seine Vorstellung von Orten sei hingegen nicht relational, verzichte auf "das Wechselspiel von Interaktion/Relation und Begrenzung". ${ }^{8}$

\section{Was ist eine Region?}

Epple zitiert Jürgen Osterhammels Definition der Region. Es lohnt den Abschnitt bei

\footnotetext{
4 "Das zweite Risiko einer zunehmenden Relationierung besteht darin, dass der Blick auf die Relationen so stark betont wird, dass die Einheiten, zwischen denen diese Relationen bestehen, vollkommen aus dem Blick geraten. Paradigmatisch zeigte sich diese Gefahr in der Netzwerktheorie von Bruno Latour." Ebd., 21.

5 Jakob Tanner sieht in Makro- und Mikroperspektiven unterschiedliche und unvereinbare Begriffe von Kausalität am Werk. Er diskutiert das knapp und erhellend: Historische Anthropologie zur Einführung (Hamburg 2004) 110122.

${ }^{6}$ Bruno LATOUR, Eine neue Soziologie für eine neue Gesellschaft. Einführung in die Akteur-Netzwerk-Theorie (Frankfurt am Main 2010) 295.

${ }^{7}$ EPPLE, Lokalität, 17

8 Ebd., $19 \mathrm{f}$.
} 
Osterhammel insgesamt zu lesen, auch weil er mit einem Beispiel aus dem Habsburgerreich einen wichtigen Punkt zu illustrieren sucht: ${ }^{9}$

„Raum als Region - Geschichten begrenzter Identitäten: Bei jedem Raum stellt sich die zentrale Frage nach den Faktoren, die seine Einheit begründen und die es erlauben, von einem integrierten Raumzusammenhang zu reden. Globalhistorisch gesehen, sind Regionen Interaktionsräume, die sich durch die Dichte von Verkehr und Migration, Kommunikation und Handel konstituieren. Aber auch ein Verständnis von Region als einer kleinräumigen, sub-nationalen Einheit ist in einer solchen Sicht der Geschichte unterzubringen. Denn in der historischen Wirklichkeit spielen sich Interaktionen auch über große Entfernungen hinweg viel eher zwischen kleineren Gebieten als zwischen ganzen Nationalstaaten ab. Netze werden zwischen Regionen geknüpft. Die eine Region entsendet Migranten, eine andere empfängt sie; eine Region produziert Rohstoffe, eine andere auf einem fernen Kontinent ist Standort ihres Konsums oder ihrer Weiterverarbeitung. Das ökonomische Zentrum des British Empire war nicht ,Großbritannien', sondern ganz präzise London mit Südengland. Auch Vergleiche sind oft nur zwischen Regionen sinnvoll oder gar statthaft. So gelangt man zu unterschiedlichen Ergebnissen, wenn man ganz Großbritannien mit ganz China vergleicht oder Mittel- und Südengland mit der wirtschaftlich schon seit Jahrhunderten dynamischen Gegend um Shanghai und Nanjing. Nicht immer ist es freilich einfach, festzustellen, was Regionen ausmacht und zusammenhält. Das ostmitteleuropäische Galizien etwa war im 19. Jahrhundert ein kleiner Raum, allgemein als eigenständige Region anerkannt, mit einer Vielfalt von Nationen, Sprachen und Konfessionen, ein Raum, der sich eher durch Kontraste als durch Einheit bestimmen lässt, der Brückenfunktionen erfüllte und dessen Bevölkerung zugleich durch tiefe Gräben gespalten war. Es gibt viele ähnliche Beispiele für Zwischenzonen von hoher Uneindeutigkeit und Instabilität.“ (Osterhammel 2011: 156 f.)

Für eine Regionalgeschichte Niederösterreichs kann man mit Osterhammel folgende Schlüsse ziehen (siehe auch die Notizen zur Diskussion weiter unten):

- Selbst wenn man von Niederösterreich ausgeht, weil es in der Gegenwart ein Bundesland gibt, das ein Landesarchiv betreibt, das ein Buchprojekt initiiert, so ist historisch die Relevanz eines regionalen Zusammenhangs „Niederösterreich“ stets erst zu erweisen - im Sinn einer Untersuchungsebene, die als Interaktionsraum anzunehmen einen Mehrwert gegenüber anderen größeren oder kleineren Untersuchungsräumen aufweist.

- Manche Teile Niederösterreichs, zuvorderst Wien, lassen sich als Zentrum des Habsburgerreichs ansprechen. Auf andere trifft das gerade nicht $z u,{ }^{10}$ obwohl sie räumlich näher an den Machtzentren liegen als die schon dem kartographischen Augenschein nach peripheren Kronländer. Die Einheit ist in dieser Hinsicht einer besonderen Spannung aus Metropole und Peripherie ausgesetzt.

- Niederösterreich hat als fürstliches Herrschaftsgebiet eine lange Geschichte, aber man könnte die Vermutung aussprechen, dass das Land erst im Laufe des 19. Jahrhunderts für breitere Bevölkerungsteile erfahrbar wurde und sich emotional aufladen ließ. Vielleicht galt

\footnotetext{
${ }^{9}$ Jürgen OsterhAMmel, Die Verwandlung der Welt. Eine Geschichte des 19. Jahrhunderts (München 2011).

${ }^{10} \mathrm{Vgl}$. Andrea KomLosY, Vom Kleinraum zur Peripherie. Entwicklungsphasen der wirtschaftlichen Abhängigkeit im 19. Jahrhundert. In: Herbert KNITTLER (Hrsg.), Wirtschaftsgeschichte des Waldviertels (Waidhofen an der Thaya 2006) 217-340.
} 
das aber nach wie vor nur für soziale Eliten in einem weiten Sinn, ob das nun die Stände waren, die 1791 eine Topographie Niederösterreichs in Auftrag gaben, oder Geistliche und Lehrer, die aus Eigenem begannen, sich mit Heimatforschung und Landeskunde zu beschäftigen. Sind also die Nation und das Land parallel entstehende Identifikationsmuster, die zuerst in einer Spitzenformation und sodann in bildungs(klein)bürgerlichen Gruppen kursieren?

- Wodurch wird Niederösterreich zu einer administrativen Realität? Inwiefern zu einer politischen im Sinn moderner Massenpolitik? Die kommunale Ebene ist seit 1850 klar konturiert. Inwiefern ist der 1861 konstituierte Landtag mehr als nur eine Durchgangsstation zum Reichstag? Ist Niederösterreich eine wirtschaftsgeschichtlich sinnvolle Untersuchungseinheit? Man kann die territorial organisierten Interessenverbände ins Treffen führen - und sonst?

- Wenn man Niederösterreich nicht einfach als feste Größe annehmen will, so sind außerdem die „Zwischenzonen von hoher Uneindeutigkeit und Instabilität" besonders interessant. Das gilt für ein fürstliches Herrschaftsgebiet, dessen Konturen sich bis ins Mittelalter zurückführen lassen, nicht weniger als für ein junges administratives Konstrukt wie Galizien, das Osterhammel ins Auge sticht. Um nicht ein allzu bukolisches Bild von imaginierter und administrierter Gemeinschaft zu zeichnen, muss Forschung auf die sozialen und politischen Konflikte achten und darf die Gewaltförmigkeit der Auseinandersetzungen um soziale Macht nicht als bloße Ausnahme auf dem Weg zum liberalen Staat behandeln.

\section{Methoden und Strategien}

Mikrogeschichte ist, wie Trivellato betont, nicht zwangsläufig erzählend, auch wenn sie vor allem in ihrer englischsprachigen Variante meist mit dieser Darstellungsform assoziiert wird. Sie unterscheidet zwei Strategien der italienischen Mikrogeschichte:

- von einem bestimmen Text ausgehend dessen Verknüpfungen in einer „Galaxie von Texten“ zu verfolgen (Carlo Ginzburg), eine eher kulturgeschichtlich angelegte Herangehensweise;

- ein Entfalten von Beziehungsnetzen, das auch mit quantifizierenden Verfahren operiert, um die Handlungen und Vorstellungen eines Individuums in einem sozialen Raum zu platzieren (Giovanni Levi).

Die erste Strategie treibt Sigurđur Magnússon auf die Spitze, der auch als Autor einer Einführung in die Mikrogeschichte hervorgetreten ist. ${ }^{11}$ Seinen Zugang nennt er „singularization of history“. Darunter versteht er offenbar die minutiöse Auseinandersetzung mit einem lokalen Sozialgefüge rund um einzelne Akteur*innen. Es gelte aller Versuchung zur Abstraktion und damit zu generalisierenden Schlüssen zu widerstehen. ${ }^{12}$ Das Material, mit dem er arbeitet, ist faszinierend: die Texte isländischer Bauern, die ein erstaunlicher Wille zum Wissen auszeichnet. Die Konzeptualisierung überzeugt (mich jedenfalls) nicht. In

\footnotetext{
${ }^{11}$ Sigurður Gylfi MAgnússon, What is Microhistory? Theory and Practice (London 2013).

12 "I am arguing for the need to separate the desire to contextualize from temptation to expand that contextualization into realms of the abstract - where contextualization morphs into generalization. "Sigurður Gylfi Magnússon, Far-reaching microhistory: the use of microhistorical perspective in a globalized world. In: Rethinking History 3/21 (2017) 312-341, hier 323.
} 
beschwörenden Worten richtet er sich gegen eine Mikrogeschichte, die unter dem Druck einer globalgeschichtlichen Konjunktur der „Versuchung“ zum großen Narrativ verfällt. Sie wird damit ihrer Mission untreu, die er zugleich als eine der historischen Analyse überhaupt präsentiert: a) Konzentration auf die handelnden Personen, b) auf ihre Erfahrungen und ihre Subjektivität, c) akribische, philologisch präzise Quellenarbeit. ${ }^{13}$ Der probate Weg für mikrohistorische Forschung scheint ihm ein ganz enges Arbeiten an einem Quellentext und den Texten, die ihn begleiten. Anregungen entnimmt er der Literaturtheorie. ${ }^{14}$

Ein häufiges Verfahren, mikro- und globalgeschichtliche Perspektiven zu verbinden, setzt bei besonders beweglichen sozialen Gruppen und weitgereisten Individuen an. ${ }^{15}$ Magnússon propagiert stattdessen eine Strategie, die er "weitreichende Mikrogeschichte“ nennt. Sein Beispiel sind Bauern, die gerade nicht weit gereist waren und trotzdem in ihren Horizont und ihren Alltag Wissen und Dinge von weither integrierten - geistige Beweglichkeit statt Migration. „What takes place when nothing happens", lautet die Frage. ${ }^{16}$ Eine Antwort findet Magnússon in einem vielbändigen illustrierten Manuskript enzyklopädischen Charakters, an dem Mitte des 19. Jahrhunderts der Bauer Jón in einem entlegenen Tal der entlegenen Insel schrieb, um das Wissen der Welt in seiner Umgebung zu verbreiten.

Die singularisierende Strategie, die Magnússon entwirft, besteht in der radikalen Abkehr von der großen Erzählung. Auch die Texte von Rosental, Ulbrich, Lanzinger unternehmen es zwar, Großerklärungen und -narrative zu unterlaufen. Das entspricht dem Anliegen, das Mikro- und Alltagsgeschichte seit ihren Anfängen kennzeichnet. Allerdings schlagen sie vor, eine Ebene zu finden, die zwischen großflächigen Modellierungen und kleinteiligen Einzelbeobachtungen liegt. Lanzinger und Rosental sprechen explizit von einer mittleren Ebene.

Ziel ist es jeweils, eine gängige Vorstellung und eine generalisierende These in Frage zu stellen, die weit über die Forschung hinaus das Bild von dem untersuchten Sachverhalt prägen. Dem gängigen und eingängigen Bild setzen sie dabei kein neues, ebenso eingängiges Bild entgegen. Es winkt ein Differenzierungsgewinn, aber die Argumentation bleibt möglicherweise von der Gegenthese abhängig, die sie kritisieren und nicht ersetzen oder nicht ersetzen wollen.

Das lässt sich auch positiver formulieren: Makrosoziologische Behauptungen und quellennähere historische Forschung können und müssen einander ergänzen. Für das 19. Jahrhundert ist z. B. ein produktiver Umgang mit modernisierungstheoretischen Annahmen wesentlich, ob sie nun den Fortschritt feiern oder Gewalt, Zerstörung und Entfremdung kritisieren. Wenn Rosental Eugen Webers Peasants into Frenchmen ${ }^{17}$ als modernisierungstheoretisch unterfütterten Reibebaum verwendet, ist das in diesem Sinn.

Margareth Lanzinger präsentiert zunächst das von Stefan Zweig entworfene Bild von Illyrien als Operettenstaat. Die ungewollte Parodie auf Staatlichkeit erweist sich daran, dass die Finanzverwaltung „nichts als ungefüllte Kassen“ vorzeigen kann. Die implizite These ist hier

\footnotetext{
${ }^{13}$ Ebd., 331.

${ }^{14}$ Sigurður Gylfi Magnússon, Tales of the Unexpected. In: Cultural and Social History 1/12 (2015) 77-94, bes. 8688.

${ }^{15}$ Francesca Trivellato, The Familiarity of Strangers: the Sephardic Diaspora, Livorno, and Cross-cultural Trade in the Early Modern Period (New Haven, CT 2012); Natalie Zemon DAVIS, Leo Africanus. Ein Reisender zwischen Orient und Okzident (Berlin 2008).

${ }^{16}$ MAgnússon, Far-reaching Microhistory, 322.

${ }^{17}$ Eugen Weber, Peasants into Frenchmen: The Modernization of Rural France, 1870-1914 (Stanford, Calif. 1976).
} 
eine an mehreren Faktoren notwendig scheiternde Staatlichkeit. Indem sie „die mittlere, die Distriktebene" als den wesentlichen Beziehungsknoten ausmacht und Staatsbildung in diesem „konkreten Raum“ untersucht, kommt sie zu einem Befund, der die Annahme eines „betrunkenen Herrscherwillen“, wie sie Zweig platziert, nicht unbedingt widerlegt, aber eine andere Erklärung für die leeren Kassen hinzufügt.

Claudia Ulbrich richtet sich gegen die Vorstellung eines typisch jüdischen Heiratsverhaltens, das schichtübergreifend und überzeitlich Gültigkeit besaß, jüdische Verwandtschaftsnetze von christlichen unterscheidet und auf einem "Gemisch von Vorurteilen und normativen Texten"18 beruht. Ulbrich wirft außerdem anhand dieses Untersuchungsgegenstands nicht nur die grundsätzliche Frage auf: „Lassen sich durch die Verbindung von Mikro-Perspektive und Makro-Modellen validere Aussagen treffen über die Kategorien, die Menschen wichtig waren, über deren Bedeutungen und Stellenwert?" Noch weitergehend fragt sie auch, ob die auf diese Weise gewonnenen Erkenntnisse dazu dienen können, „Makro-Fragen zu beantworten oder neue Fragestellungen zu generieren" ${ }^{19}$ Die Antwort auf letztere Frage gibt sie inhaltlich nur als eine Feststellung, die sich fast alles offen lässt, nämlich dass es „eine Vielzahl von Heiratsmustern" gegeben habe, die "in bestimmten Situationen bedeutend wurden“ ${ }^{20}$ Stattdessen skizziert sie eine Strategie, die auf Grundlage der Beobachtungen zu einzelnen biographisch gut rekonstruierbaren Fällen eine quantitative Untersuchung von Verwandtschaftsnetzen, konkret mittels Heiratsverträgen, empfiehlt. Sie entwirft also eine Vorgangsweise, in der eine mikrohistorische Skala und ein qualitativer Zugang mit MakroModellierung und quantifizierendem Zugriff zusammenspielen sollen. Was Sie „MakroModelle“ nennt, bezeichnet Rosental als „mesoskopische Perspektive“.

\section{Netzwerke und Staatlichkeit}

Die Vorstellung des Netzwerkes tritt in den Texten von Lanzinger und Epple prominent als Metapher und Forschungsstrategie auf, oft mit Bezug auf die Akteur-Netzwerk-Theorie (ANT) und insbesondere Bruno Latour.

Das gilt auch für Joyce und Mukerji, die den Staat als eine veränderliche Kombination aus Dingen und Menschen beschreiben. ${ }^{21}$ Sie sprechen von logistischer Macht, weitgehend ein Pendant zu Michael Manns Begriff der Infrastrukturmacht. Sie erzeugt einen starken, da für viele Zwecke adaptierbaren Staat, in dem sich soziale Macht nicht nur in einem Zentrum bündelt, sondern von vielen Menschen beansprucht wird. Über die Infrastrukturen wie das Postwesen wird der Staat für alle zu einem unverzichtbaren Teil des Alltags. ${ }^{22}$ Die Menschen können ihn daher auch nicht loswerden: „People can object to policies or want to shrink government, but they want roads and functioning sewer and garbage collection systems. ${ }^{23}$

\footnotetext{
${ }^{18}$ ULBRICH, Eheschließung, 106.

19 Ebd., 101.

${ }^{20}$ Ebd., 117.

21 "A shape-shifting assemblage of people and things“. JOYCE U. MUKERJ, State of Things, 15.

${ }^{22}$ Patrick JOYCE, The State of Freedom: A Social History of the British State Since 1800 (Cambridge 2013).

23 JOYCE/MUKERJI, State of Things, 15. Fraglich ist allerdings, ob er hier nicht eine Vernunft unterstellt, die selbst historisch ist und die Perspektive am Ausgang des Wohlfahrtsnationalstaats der Nachkriegsjahrzehnte nach 1945 naturalisiert. In stark fragmentierten Gesellschaften wollen viele eben nicht für Infrastrukturen zahlen, die sie selbst nicht benötigen oder die ihrer Ansicht nach zu vielen anderen zugute kommt.
} 
Während sich aber Mann mit der Vogelperspektive begnügt, betonen Joyce und Mukerji die Bedeutung der Analyse von kleinen Werkzeugen, Techniken, organisatorischen Arrangements, die sich zu einem umfassenden Netz, der Gesellschaft, fügen. Diese mikrogeschichtliche Sensibilität ist ein wesentlicher Unterschied in einer ansonsten ähnlichen Herangehensweise an den Staat, ${ }^{24}$ die von ähnlichen Überlegungen ausgeht: Der Staat ist kein Ding im Singular, sondern ein Beziehungsnetz, sein Zusammenhalt immer ein Problem. Die Durchdringung des Alltags durch Infrastrukturen macht inn aber auch zu einer Selbstverständlichkeit des sozialen Lebens, deren Geschichtlichkeit - und deren Alternativen - sich dem Blick der Menschen zu entziehen tendiert. ${ }^{25}$

\section{Räume in/und Bewegung}

Die Auseinandersetzung mit Migration eignet sich, einer Festschreibung von Räumen, z. B. einer allzu einfachen Entgegensetzung von Wien und „flachem Land“, entgegenzuwirken. Das rechtfertigt es, Migration im Rahmen des Buchvorhabens zu Niederösterreich im 19. Jahrhundert einige Aufmerksamkeit zu widmen. Das wiederum macht den Text von André Rosental interessant, der sich gegen die Diagnose einer ökonomisch motivierten „Landflucht" richtet:

„Rural exodus, and migration more generally, is often associated with a veritable black legend. From the moralizing denunciations of the Old Regime to the Marxist vision of the forced exodus of a proletarianized peasantry, the migrant has been perceived as a miserable wretch who either succumbs to urban delusions or is tragically uprooted." 26

Dem einfachen Bild hält er Beobachtungen entgegen, die komplexere Bewegungsmuster zeichnen. So bestanden Einkommensgefälle nicht nur zwischen Großstadt und Land, sondern ebenso zwischen ländlichen Regionen. Das würde selbst eine Argumentation verkomplizieren, die allein um diesen ökonomischen Indikator aufgebaut ist. Außerdem weist Rosental auf Migrationsbewegungen hin, die sich als ein Nachrücken von Gruppen entlang von „vacancy networks" vollziehen: Wenn Menschen aus dem Umland von Paris in die Hauptstadt migrierten, gaben sie damit den Platz für andere frei, die aus benachbarten Regionen zuwanderten. Die Dichotomie von Stadt und Land unterläuft auch der Hinweis auf ähnliche saisonale Rhythmen im Arbeitskräftebedarf: So wie viel landwirtschaftliche Arbeit im Winter ruhte, galt das für die städtischen Bauvorhaben. Auch die frühen Industrien unterlagen saisonalen Schwankungen, die eine starke Fluktuation von Arbeitskräften mit sich brachte. All diese Beobachtungen lassen sich unschwer zu Fragen an Niederösterreich im 19. Jahrhundert formulieren, in dessen Mitte sich Wien befindet, eine Metropole, die ihr Umland nicht weniger dominierte als Paris das seine. Diese Situation legt den - auch von Zeitgenoss*innen oft ausgesprochenen - Eindruck nahe, alle Bewegung von Gütern, Menschen und Ideen führe von und nach Wien.

Rosental münzt seine Überlegungen in ein dreigliedriges Modell um, das die Migration im Frankreich des 19. Jahrhunderts beschreiben soll: (1) Migration auf weite Distanzen als Option von bessergestellten Gruppen, (2) Migration auf kurze Distanzen, für die sich Menschen aus

\footnotetext{
${ }^{24}$ Die Ähnlichkeiten nimmt auch Joyce selbst wahr: Patrick JoYCE, What is the Social in Social History. In: Past \& Present Nr. 205 (2009) 175-210, hier 200.

${ }^{25}$ Michael MANN, Geschichte der Macht Bd. 3: Die Entstehung von Klassen und Nationalstaaten, Teilbd. 1

(Frankfurt am Main/New York 1998) 81.

${ }^{26}$ ROSENTAL, Micro and Macro, 473.
} 
ärmeren Verhältnissen entscheiden und (3) Sesshaftigkeit als eine Mittlerposition zwischen den beiden Verhaltensweisen. ${ }^{27}$

Wie dieses Modell funktioniert, wird m. E. in dem Beitrag nicht völlig klar. Als Forschungsstrategie empfiehlt Rosental jedenfalls die Wahl einer mesoskopischen

Perspektive. ${ }^{28}$ Darunter versteht er die Analyse von Strukturen, verwandtschaftliche, dörfliche und berufliche Netze. Sie vermitteln ökonomischen Anreiz und Druck erst in jenen Horizont, in dessen Rahmen Menschen sich für oder gegen Migration entscheiden. Die Beobachtung soll sich zwischen einem mikroskopischen Blick auf einzelne Individuen und einem makroskopischen Level ansiedeln, das er etwas vage "global environment" benennt. ${ }^{29}$ Epple formuliert am Schluss ihres Aufsatzes zwei Überlegungen, um das Lokale und Globale durch ihr Verhältnis zueinander zu bestimmen.

- Lokal: „Lokale Dynamiken oder lokale Verfestigung sind keine schlichte Reaktion auf Globalisierungsprozesse. Nicht das Globale bestimmt das Lokale, sondern translokale und andere soziale Beziehungen bestimmten Lokalität."

- Global: „Nicht der Gegensatz zu einem stabilen, im besten Falle auf globale Veränderungen reagierenden Ort charakterisieren ,das Globale'. Vielmehr wird es aufgelöst in die nicht zählbare, stets in Bewegung befindliche Menge seiner translokalen Beziehungen. “30

\section{Notizen aus der Diskussion}

\section{Epples Kritik an der Actor-Network-Theory}

Rita Garstenauer wendet sich gegen Epples Kritik an Latour und hält es für eine Unterstellung, dass es der Akteur-Netzwerk-Theorie um bloße Beschreibung gehe, mit der eine Frage nach Ursachen aus dem Blick rücke. Epple habe schlicht die Pointe nicht verstanden, dass Latour eben nicht das Soziale über abstrakte Großkategorien bestimmen, also Gesellschaft über Gesellschaft erklären will. Er will induktiv vorgehen, bei der präzisen Beobachtung lokaler Konstellationen beginnen.

Erklärungen aus dem Feld zu nehmen heißt aber nicht, dass man sich der Verallgemeinerungen enthält. Zugleich hilft das eine Redeweise zu vermeiden, die soziale Großaggregate als Akteure einsetzt und systematisch übersieht, dass etwa „Verwaltung“ nicht bloß ein anonymer Apparat ist, sondern selbst in der Zentralverwaltung, die ihrem Anspruch nach ein ganzes Territorium samt Bevölkerung umspannt, echte Menschen echte Dinge tun. Auch hier kommen wiederum konkrete Verknüpfungen zwischen konkreten Elementen, Dingen und Akteuren (oder mit Latour gesprochen: Aktanten) zum Tragen. Das gilt für jegliches Skalenniveau und insofern ist es irreführend zwischen lokal und global so zu trennen, dass lokal mit klein/konkret und global mit groß/abstrakt gleichgesetzt wird.

Zsuzsanna Török meint ebenfalls, dass Epple es sich mit Latour zu leicht macht und es nützlich ist, sich die Herkunft dieses Ansatzes vor Augen zu halten. Latour arbeitet zunächst im Feld

\footnotetext{
${ }^{27}$ Ebd., 475.

28 "Articulation of levels of analysis from a mesoscopic vantage point." ROSENTAL, Ebd., 480.

${ }^{29}$ Ebd., 459.

${ }^{30}$ EPPLE, Lokalität, 25.
} 
der Wissenschaftssoziologie und beobachtet das Arbeiten im Labor. Die Protokollierung der Netzwerke ist nicht der Verzicht auf Erklärung, sondern die Voraussetzung, um über das Geschehen im Labor sinnvoll etwas sagen zu können.

Latour halte Forscher*innen an zu basteln, in einem offenen Prozess Netzwerke als Kommunikationskanäle und Strukturen zu rekonstruieren. Manche dieser Netzwerke sind lokal verdichtet und/oder begrenzt, manche führen über weite Distanzen, ohne einen plötzlichen Sprung von lokal zu global zu machen.

\section{Absolute und relative Räume}

Gertrude Langer-Ostrawsky fragt, ob das Buchvorhaben zu „NÖ im 19. Jhdt.“ von einer gemeinsamen Übereinkunft ausgeht, was Niederösterreich ist, und ob man sich dann eine solche Übereinkunft wie eine Keksform vorstellen kann, mit deren Hilfe Forscher*innen aus ihrem Thema Niederösterreich ausstechen.

Elisabeth Loinig hebt hervor, dass es gerade ein Ziel der Bände sein müsse, der Frage nachzuspüren, wie Niederösterreich in verschiedenen Kontexten und von unterschiedlichen Akteuren bestimmt wurde. Es gehe also darum, diese Definitionen Niederösterreichs selbst zum Thema zu machen. Auffällig ist, dass sich seit dem 18. Jahrhundert viele Akteure bemühen, Grenzen zu setzen, Territorien zu bestimmen, sie zu vermessen (daher der Franziszeische Kataster) und durch neue Verwaltungseinrichtungen wie die Kreisämter beherrschbar zu machen. Die Vorstellungen und (Verwaltungs-)Praktiken von Zugehörigkeit verändern sich, auf Ebene des Landes ebenso wie auf lokaler Ebene. So sind die Menschen bis 1850 Untertanen von Herrschaften, oft von mehreren zugleich. Danach wird lokale Zugehörigkeit an die Gemeinde gebunden und damit in einer neuen Weise territorialisiert. Wenn man Räume als Netzwerke behandelt, die sich zu Knoten verdichten, ist außerdem eine für die Geschichte Niederösterreichs wesentliche Frage, inwiefern sich niederschlägt, dass in Niederösterreich die Metropole Wien liegt, in der sich so viele Netzwerke überkreuzen, und wie das „flache Land“ rundherum an diesen Netzwerken teilnimmt. Niederösterreich liegt am zentralen Knotenpunkt der Habsburgermonarchie. Das ist eine Besonderheit gegenüber allen übrigen Kronländern.

Rita Garstenauer erinnert an Latours Versuch eines „doppelten Denkens", das im Zuge von empirischer Forschung auch die eigene Fragestellung historisiert. So muss historische Forschung, die sich mit der Modernisierung von Gesellschaft im 19. Jahrhundert befassen will, eine Geschichte dessen beinhalten, was zeitgenössische Akteure über Modernisierung denken, und im Lichte dessen auch die Kategorien befragen, mit denen Forscher*innen diesen Untersuchungsgegenstand bearbeiten.

Stefan Eminger erinnert an die Unterscheidung, die schon für die Bände zu „NÖ im 20. Jahrhundert" diskutiert wurde: zwischen Forschen über Niederösterreich einerseits und Forschen in Niederösterreich andererseits; letzteres zu allen möglichen Themen, mit Material aus niederösterreichischen Quellen, ohne dass damit notwendigerweise das Ziel verbunden wäre, etwas spezifisch Niederösterreichisches zu finden oder primär über Niederösterreich etwas aussagen zu wollen. 
Für die Frage, wie sich das Zusammenspiel von Mikro/Makro denken lässt, ist Epples Betonung von Relationen zwar nicht falsch, aber auch nicht besonders hilfreich, weil Historiker doch ohnehin üblicherweise so vorgehen. Wenn es darum geht, einen Untersuchungsraum in vermeintlichen Besonderheiten zu verabsolutieren, so muss man eben vergleichende Literatur lesen.

Sabine Schmitner hält die Vorstellung vom Raum als Netzwerk für hilfreich, um nicht Niederösterreich als Raum von anderen Räumen zu isolieren und auch Biographien nicht an einen absolut gesetzten Raum zu binden, sondern wahrzunehmen, wie viel lokales Handeln in weiten Netzwerken eingebunden ist und sich auch nur erklären lässt, wenn man diese berücksichtigt.

Sie entnimmt den Texten damit auch die Anregung, nicht von einer Gleichsetzung zwischen global und dynamisch einerseits, lokal und stabil andererseits auszugehen. Lokale Gefüge sind nicht notwendigerweise die Orte von scheinbar ewiger Tradition und Unveränderlichkeit.

Zsuzsanna Török meint, dass es zwar zu kurz greift, in lokalen Konstellationen immer Stabilität zu suchen, aber man soll auch nicht in das umgekehrte Extrem verfallen - weder in Ansehung von lokalen Konstellationen noch bei Betrachtung von überlokalen Gefügen. Nicht alles ist mobil, nicht alles zirkuliert. Man muss jeweils durch genaue Beobachtung, wofür eben Latour Ansätze bietet, bestimmen, womit man es zu tun hat.

\section{Eine mittlere Beobachtungsebene?}

Gertude Langer-Ostrawsky: Eine mittlere Beobachtungsebene zu wählen, um Mikro- und Makroebenen zusammenzuführen, scheint zwar im Text von Margareth Lanzinger zu Illyrien überzeugend, aber die Strukturierung von Verwaltung, die eben lokale, mittlere und zentrale Ebenen aufweist, macht es auch leicht, Forschung auf einer Mesoebene anzusiedeln. Die mittlere Ebene zu suchen, ist also wohl nicht als verallgemeinerbare Empfehlung einer Forschungsstrategie zu verstehen.

Jessica Richter betont, dass es vor allem um die Rekonstruktion der Wechselwirkungen zwischen verschiedenen Skalenniveaus gehe, nicht darum, eines als Königsweg zur Erkenntnis herauszugreifen.

Stefan Eminger findet die Vorstellung attraktiv, eine mittlere Beobachtungsebene als Hebel zu verwenden. Ihn treibt die Frage um, wie sich das für seinen Beitrag umsetzen ließe, der die Formierung der Christlichsozialen als Massenpartei untersucht.

Georg Mitterlehner meint, dass jeweils zu klären ist, inwiefern ein kleiner Teil repräsentativ für größere Verhältnisse sein kann. Man müsse also nachzeichnen, wie viele kleine Strukturen eine größere, konkret z. B. eine Partei, ergeben. 


\section{Einladung zur dritten Lektürerunde am 3.4.2018 - ein langes 19. Jahrhundert?}

(Auszug aus dem Rundmail an die Autor*innen)

Liebe Kolleginnen und Kollegen,

Anbei finden Sie Notizen zur Diskussion über Mikro/Makroperspektiven, die wir am 12. März in St. Pölten geführt haben. Im Vorfeld unseres Autor*innenworkshops werden wir noch einmal eine Lektürerunde abhalten, konkret nächste Woche Dienstag, 3. April, 14:00-15:30. Wir werden uns diesmal der Frage zuwenden, wie sich das 19. Jahrhundert als Epoche fassen lässt.

Wir werden für die Diskussion vor allem von drei Texten ausgehen:

1. einem Aufsatz von Paul Nolte "Abschied vom 19. Jahrhundert“ (2006),

2. Abschnitten aus Jürgen Osterhammels „Verwandlung der Welt“ (2011), die fragen: „Wann war das 19. Jahrhundert?" und

3. einem Auszug aus Pieter Judsons 2017 erschienener Geschichte des Habsburgerreichs, und zwar einem Teil des Kapitels „Unser tägliches Reich“. Judson hält seine Periodisierung zwar erklärtermaßen konventionell, aber das Ziel eines liberalen Imperiums, auf das sich seine Geschichte zubewegt, ist zugleich eine Epochensignatur. Die Erzählung kreist um die Rolle der Mittelklasse, des Bürgertums.

Daher finden Sie in der Dropbox außerdem einen Aufsatz von Simon Gunn (2012), der die britische Mittelklasse, ein am Kontinent viel bewundertes Vorbild liberaler Bürgerlichkeit, als oszillierend zwischen Modernität und Rückständigkeit beschreibt. Der Text ist als Beitrag zu einer Globalgeschichte der Mittelklassen angelegt. Weit ausgreifende Vernetzungen und Vergleiche hat auch der Aufsatz von Claus Moller Jorgensen (2016) im Auge, der die Perspektiven einer transnationalen Geschichte von Stadt/urbanem Raum im 19. Jahrhundert untersucht.

Die selbst ernannte Mitte und die Städte sind freilich nicht alles. Die Arbeiterschaft oder die Bauern (die natürlich auch bei Judson vorkommen, wenngleich nicht besonders zentral) sind zwei weitere Großgruppen, rund um die oft die Auseinandersetzung mit dem 19. Jahrhundert aufgebaut wird. In der Dropbox finden Sie zwei Aufsätze, die jeweils von kanonischen Autoren bzw. Werken der 1960er-1970er Jahre ausgehen, um nach deren heutiger Relevanz zu fragen: von E.P. Thompson und Eric Hobsbawm zur Arbeiterklasse (2014), von Eugen Webers „Peasants into Frenchmen“ hinsichtlich der Landbevölkerung (2017). Letzteres Werk wird auch von Judson zitiert. Die schwer vermeidbare Frage nach Modernisierung (und der Modernisierungstheorie) im 19. Jahrhundert ist damit am Tapet.

Für das Projektteam

Oliver Kühschelm, Projektmanagement

Elisabeth Loinig, Projektleitung

Stefan Eminger

Willibald Rosner

Niederösterreich im 19. Jahrhundert

Ein Publikationsprojekt des NÖ Landesarchivs - NÖ Instituts für Landeskunde 


\section{Einladung zur Diskussionsrunde am 10.7.2018 - Regionalgeschichte sozialer Macht in Quellenbeispielen}

(Auszug aus den Mails an die Autor*innen)

Liebe Kolleginnen und Kollegen,

Archivrecherche: Auf die Möglichkeit am Dienstag, 10. Juli, 9:30-10:30, im NÖLA einen Überblick zu Archivbeständen (mit anschließender Beratung zum Recherchethema) zu erhalten, haben wir bereits hingewiesen.

Diskussionsrunde: Außerdem werden wir am 10. Juli von 11:00-12:30 im NÖLA nochmals den Faden unseres Lektürekreises aufnehmen, nicht als neuerliche Auseinandersetzung mit Sekundärliteratur, sondern indem wir von Themen der beiden Bände und je einem Quellenbeispiel (das vorab als PDF zur Verfügung stehen wird) ausgehen. Wir werden auf diesem Weg also versuchen, Fragen nach sozialer Macht, dem Zusammenspiel von Mikro-, Meso- und Makroebenen und nach dem 19. Jahrhundert als Epoche von Modernisierung auf den Boden unseres engeren Forschungsfelds zu holen.

Konkret werden wir für die Diskussion von Material der beiden folgenden Autor*innen ausgehen:

-) Georg Mitterlehner: Sparkassen als Instrument von Infrastrukturpolitik und Kapitalakkumulation

-) Sabine Schmitner: Innovation und Beharrungsvermögen. Zur gesellschaftspolitischen Rolle bürgerlicher Schichten in Niederösterreichs Kleinstädten

Alle Interessent*innen sind herzlich eingeladen. Für eine Nachricht bezüglich Teilnahme bis spätestens Montag, 9.7., sind wir auch in diesem Fall dankbar. Das ist für die Vorbereitung (ausreichend Sessel, Kaffee und Kekse) hilfreich.

Für das Projektteam

Oliver Kühschelm, Projektmanagement

Elisabeth Loinig, Projektleitung

Stefan Eminger

Willibald Rosner

Niederösterreich im 19. Jahrhundert

Ein Publikationsprojekt des NÖ Landesarchivs - NÖ Instituts für Landeskunde

Liebe Kolleginnen und Kollegen,

Für diejenigen, die am 10.7. an unserer Diskussionsrunde (11:00-12:30, im Anschluss an die Vorstellung von Ressourcen des NÖ Landesarchivs und Beratung zur Recherche, 9:30-10:30) teilnehmen wollen - und für alle, die es vielleicht unabhängig davon interessiert -, habe ich in der Dropbox zum NÖ-Projekt einen Ordner "Quellendiskussion“ eingerichtet. Er enthält Material, das Sabine Schmitner und Georg Mitterlehner zur Verfügung gestellt haben. Wir werden uns mithilfe dieses Materials in die zweite Hälfte des 19. Jahrhunderts bewegen, um einen Zusammenhang von (Klein-)Stadt und Bürgertum zu umkreisen. Das Material lässt sich gut im Sinn einer Regionalgeschichte sozialer Macht diskutieren. Es rückt zudem zentrale zeitgenössische Vokabel - und mögliche Begriffe für die Analyse - wie „Vertrauen“ 
und "Mittelstand" in den Blick. Wir werden Beispiele aus Zwettl, Baden und Wiener Neustadt, also verschiedene Stadttypen betreffend und zumindest aus zwei Vierteln Niederösterreichs, an der Hand haben.

\section{Konkret zu den Unterlagen:}

Georg Mitterlehner hat im Zuge seiner Recherchen aus den - online verfügbaren - Protokollen der Gemeindevertretung von Zwettl umfangreich zum Thema der 1856 von der Stadt gegründeten Sparkasse exzerpiert. Daraus hat er einen am 10. September 1863 verhandelten Fall ausgewählt, als sich eine Kluft zwischen Erwartungen und „Resultatergebnißen“ auftat und das Institut - so der Bürgermeister - nicht mehr „jenes unbegrenzte Vertrauen genießt, dessen sie sich bisher durch soviele Jahre ohne Unterbrechung erfreuen und rühmen konnte." Der Tagesordnungspunkt ist im PDF gelb markiert, von diesem werden wir ausgehen.

Georg Mitterlehner hat außerdem ein Wordfile zur Verfügung gestellt, das weitere Auszüge aus den Protokollen von 1850-1875 enthält und einen größeren, sparkassenbezogenen Kontext sichtbar macht.

Hingewiesen sei auch auf den Punkt 18 des Protokolls vom 10.9.1863 - ganz ohne Zusammenhang mit der Sparkasse. Hier ist zu entnehmen, dass sich die Gemeinde um die Einrichtung einer Zwangsarbeitsanstalt bemühte, weil „durch das Dasein einer solchen Anstalt nicht nur zur Unterbringung der arbeitsscheuen Glieder aus unserer und den sonstigen Gemeinden die Möglichkeit geschaffen, sondern überhaupt daß durch das Dasein von 300 Zwänglingen und dem dazu gehörigen Aufsichtspersonale der Verkehr gehoben und dadurch auf den Wohlstand unserer Stadt vortheilhaft eingewirkt werde." Das hat nun nichts mit der Sparkasse zu tun, aber doch mit Infrastrukturpolitik als Teil einer Regionalgeschichte von Macht - und ist einfach ein zu schönes Quellenbeispiel ...

Sabine Schmitner hat in Regionalzeitungen, vorwiegend aus Wiener Neustadt, acht Artikel ausgewählt, verstreut über einen Zeitraum von den 1860er Jahren bis kurz vor dem Ersten Weltkrieg. In der Dropbox finden Sie ein Wordfile, in dem die Forscherin knappe Informationen zu den Quellen gibt und ihre Zusammenstellung folgendermaßen begründet: „Die verschiedenen Beiträge zeigen - wenig überraschend -, dass sowohl ideologische (bzw. kulturelle, politische) als auch ökonomische Aspekte eine Rolle hinsichtlich der Positionierung bürgerlicher Individuen bzw. Schichten spielten. Interessant für die Diskussion erscheinen mir die verschiedenen ausmachbaren Bewältigungs- und Erklärungsangebote, die auf die freiere Gestaltbarkeit individuellen Lebens und sozialer Zusammenhörigkeit reagieren. Eine Frage, die mich sehr beschäftigt: Inwieweit lassen sich diese mit der Machttypologie Michael Manns in Verbindung setzen?“

Für das Projektteam

Oliver Kühschelm, Projektmanagement

Elisabeth Loinig, Projektleitung

Stefan Eminger

Willibald Rosner

Niederösterreich im 19. Jahrhundert

Ein Publikationsprojekt des NÖ Landesarchivs - NÖ Instituts für Landeskunde 


\section{Einladung zur Quellendiskussion am 11.9.2018}

(Auszug aus dem Mail an die Autor*innen)

Liebe Kolleginnen und Kollegen,

Wie angekündigt, möchten wir nochmals Quellenbeispiele aus dem Kontext unseres Buchvorhabens in einer Runde am NÖLA diskutieren, und zwar nächste Woche Dienstag, 11. September, 11:00-12:30 (aufgrund von Terminschwierigkeiten eine Verlegung vom ursprünglich geplanten Termin am 10.9.).

Das Material haben Thomas Stockinger und Waltraud Schütz zur Verfügung gestellt, es werden somit neuerlich beide geplanten Bände in der Diskussion vertreten sein. Die PDFs mit den Quellen finden Sie in der Dropbox.

Waltraud Schütz beschäftigt sich mit Frauenvereinen. Sie hat zwei gedruckte Rundschreiben von Marianna von Dietrichstein ausgewählt, ihres Zeichens Vorsteherin der Gesellschaft adeliger Frauen zur Beförderung des Guten und Nützlichen. Adressatin der zwei Schreiben von 1817 und 1819 war Catharina Luegmayer, Oberleiterin in Rohrau, einer der zahlreichen Filialgesellschaften in Niederösterreich. Ergänzt werden diese Scans aus dem ÖStA durch zwei Quellen aus ALEX: ein Hofkanzleidekret vom 26. September 1816 über Grundsätze bei der Bildung der Frauenvereine, an die sich die „Verfassung der Gesellschaft adeliger Frauen ..." anschließt, sowie eine „Erläuterung einiger Puncte“ aus dem folgenden Jahr. Die Statuten von 1816 halten in $\S 27$ fest: „Wenn dieses Institut in Wien organisiert ist, wird man es auch auf dem flachen Lande mittelst der Kreisämter zu verbreiten suchen."

Thomas Stockinger forscht zu gerade dieser Ebene der Verwaltung, den Kreisen und Bezirken, die eine Brücke zwischen Land und lokaler Selbstverwaltung schlugen. Das Archivmaterial, das er für die Diskussion bereitstellt, ist aus dem NÖLA und führt uns in die Mitte des langen 19. Jahrhunderts, in die Zeit des Umbaus von Justiz und Verwaltung zwischen Revolution und Neoabsolutismus, konkret in die Jahre 1852/53. Mit der Etablierung „gemischter Bezirksämter" wurde gerade ein Stück Gewaltentrennung zurückgenommen, hingegen setzte sich die Expansion des Staats in seine Fläche fort; und trotz der neoabsolutistischen Machtansprüche gab es nicht nur für die Obrigkeit, sondern auch für lokale Eliten etwas zu gewinnen. Unter dieser Erwartung agierten die Behörden ebenso wie Honoratioren von Gemeinden, die sich Hoffnung auf zentralörtliche Funktionen machten. Das zeigen die Quellen: je ein Gesuch der Gemeinden Guntersdorf (Weinviertel) und Pottenstein (Industrieviertel) sowie eine Verordnung der Kommission, die mit der Organisation der Bezirksverwaltung in Niederösterreich betraut war, an den Bezirkshauptmann von Zwettl. Thomas Stockinger hat für uns die Archivalien gescannt und außerdem eine Transkription der Dokumente angefertigt.

Für das Projektteam

Oliver Kühschelm, Projektmanagement

Elisabeth Loinig, Projektleitung

Stefan Eminger

Willibald Rosner 
V. Themenüberblick (Fassung vom September 2018) 
Niederösterreich im 19. Jahrhundert

Ein Publikationsprojekt des NÖ Landesarchivs - NÖ Instituts für Landeskunde in Kooperation mit \# Netzwerk Geschichte NÖ \#

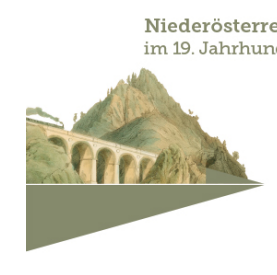

Herausgeber*innen: Elisabeth Loinig, Oliver Kühschelm, Stefan Eminger, Willibald Rosner

Projektleitung: Elisabeth Loinig, Projektmanagement: Oliver Kühschelm

\section{Aufbau der Bände und Themenüberblick}

Der erste Band wird sich mit der politischen Ökonomie Niederösterreichs befassen. Er wird den Formen von Herrschaft und Wirtschaft im Rahmen einer Geschichte von regionaler Staatsbildung nachgehen. Der zweite Band wird demgegenüber sozialgeschichtliche und historisch-anthropologische Perspektiven ins Zentrum stellen. Der erste Band wird sich der administrativen, ideologischen, politischen und wirtschaftlichen Erzeugung Niederösterreichs als Herrschaftszusammenhang widmen, der zweite wird den Schwerpunkt auf soziale Großformationen und Lebenswelten in Niederösterreich und seinen Regionen legen. Der erste Band wird tendenziell an einer Geschichte Niederösterreichs arbeiten, der zweite eine Geschichte von sozialen Gruppen, Alltagspraktiken und -räumen in Niederösterreich bieten.

Jeder der beiden Bände wird einen Fokus ausbilden, sie werden einander aber auch überlappen. So reichten z. B. die wirtschaftlichen Netze, die sich rund um Marktintegration ausbildeten, an vielen Punkten weit über das Kronland Niederösterreich hinaus, relativierten also diesen Zusammenhang möglicherweise mehr als sie ihn stützten. Umgekehrt lassen sich familiale Beziehungen nicht abseits von Fragen nach Herrschaft und Wirtschaft rekonstruieren.

Zudem fügen Leitfragen die beiden Bände zusammen und verschränken sie ineinander. Es sind dies Fragen nach:

- Formen sozialer Macht, ob in - und mithilfe von - Behörden, Unternehmen, Vereinen, Familien: Informelle und organisierte Machtnetzwerke strukturierten soziale Beziehungen. Der Staat suchte diese einzufangen, zu verdichten und zu steigern; andere Institutionen und Akteur*innen kooperierten, hielten dagegen oder hielten sich abseits.

- Untersuchungsebenen und -räumen: Diese sind nicht bloß lokal und regional niederösterreichisch zu bestimmen; ihre gesamtstaatlichen, internationalen und globalen Bezüge und Verflechtungen müssen aufgewiesen werden. Wie verband sich Lokales mit übergreifenden Entwicklungen und Konstellationen auf einer mittleren und Makroebene? Das Verhältnis von Wien und dem sogenannten flachen Land wurde schon von Zeitgenoss*innen thematisiert; doch war das flache Land erstens keineswegs nur flach, sondern in sich unterschiedlicher, als der Ausdruck suggerierte. Zweitens standen auch dessen Regionen untereinander und nicht nur über Wien vermittelt in Beziehung.

- (Modernen?) Zeiten: Wie lässt sich das lange 19. Jahrhundert als Untersuchungseinheit fassen? Wenn sich damals die Welt verwandelte, wann tat sie das genau, in welchen Rhythmen und in welchen Lebensbereichen? Inwiefern trat die regionale Gesellschaft in die Moderne ein? 


\section{Bd. 1 Politische Ökonomie / Herrschaft und Wirtschaft}

\section{Staatsbildung}

Wie formierte sich regionale Staatlichkeit in Landesverwaltung und Landesverfassung? Wie fügte sich das Kronland Niederösterreich in das Habsburgerreich ein, in Kooperation und Konkurrenz mit anderen Ländern? Im 19. Jahrhundert verdichtete sich der Staat. Neue Verwaltungseinheiten wurden geschaffen, in denen die Vertreter von Behörden, über- und untergeordneten Körperschaften um Finanzierung rangen und die Zuteilung von Kompetenzen aushandelten. Landesbeschreibungen und Statistiken machten den Staat, das Land und seine Gemeinden vorstellbar und zählbar.

\section{Lokale/regionale Verwaltung}

Die Beiträge untersuchen Verwaltungseinheiten und -praktiken, mit denen der Territorialstaat näher an die Menschen heranrückte. Bis in die Mitte des Jahrhunderts fungierten die Grundherrschaften als unterste Verwaltungseinheit, doch bildeten sie keine territorial geschlossenen Körperschaften, sondern beruhten auf komplizierten Untertänigkeitsverhältnissen. Das änderte sich erst mit der 1850 geschaffenen "freien Gemeinde“. Die Kommunalverwaltung war ein Ort der Bürgerlichkeit und des Bürgertums - sowie der Bauern. Im letzten Drittel des 19. Jahrhunderts trugen die Gemeinden in hohem Maß den Ausbau der Infrastruktur, von Straßen über Wasserleitungen bis hin zur Elektrizitätsversorgung. Das in der Forschung und von der Öffentlichkeit oft wenig beachtete Zwischenglied oberhalb der Gemeinden und unterhalb des Landes bildeten bis 1850 die Kreisämter und später die Bezirksbehörden.

\section{Der bewaffnete Staat}

Der moderne Staat formierte sich durch und mit der Anforderung, Kriege zu führen. Doch das 19. Jahrhundert kennzeichneten in Niederösterreich lange Friedensperioden. Aber Teile des Landes waren auch Schlachtfeld, so 1809 in den Kriegen mit dem napoleonischen Frankreich, und wurden von fremden Truppen besetzt, so wiederum in den „Franzosenkriegen“ und 1866 im Krieg gegen Preußen. Die allgemeine Wehrpflicht war ein Ergebnis des Übergangs zur konstitutionellen Monarchie. Sie machte den Armeedienst zu einem der Instrumente von „Durchstaatlichung“ - und zeigt deren Ambivalenz: Sie sollte die wehrfähige männliche Bevölkerung disziplinieren, ging aber auch mit einem neuen Bewusstsein für Rechte einher. Die bewaffnete Macht richtete sich freilich nicht nur gegen äußere Feinde der Habsburgermonarchie. Sie wandte sich auf deren eigenem Territorium gegen soziale und politische Proteste, nicht nur in den Revolutionen von 1848. Der Armee zur Seite trat die - bezeichnenderweise 1849 gegründete - Gendarmerie. Sie sollte am flachen Land den Staat repräsentieren, Ordnung durchsetzen.

\section{Ideologische Macht - Kirchen und Bildung}

Die katholische Kirche fungierte in der Allianz von Thron und Altar als Stütze der habsburgischen Herrschaft. Mit der Verdichtung des Pfarrnetzes seit dem späten 18. Jahrhundert bewegte sich die Kirche auf die Menschen zu - und mit ihr der Staat, der sie für seine Aufgaben einsetzte. Sie ging allerdings nicht allein darin auf, als Machtinstrument für Herrscherhaus und hohen Klerus 
zu dienen. Kirchliches Leben, auch der anderen christlichen Konfessionen, hatte mehrere Geschwindigkeiten und viele Akteur*innen.

Die Schule war eines der wichtigsten Instrumente, um Untertan*innen in Staatsbürger*innen zu verwandeln. Um die Kontrolle und Ausweitung des Schulwesens wurde daher heftig gestritten: zwischen kirchlichen und staatlichen Eliten, Konservativen und Liberalen. 1869 gelang es den Liberalen, mit dem Reichsvolksschulgesetz den Einfluss der katholischen Kirche zurückzudrängen - ein Grund anhaltender Empörung für den Klerus und viele Katholik*innen.

Kirche und Schule waren staatstragende Institutionen. Religion und Bildung waren aber auch Mittel der Selbstverständigung und der Ausprägung von Identitäten, die nicht zwangsläufig staatstragend ausfielen.

\section{Wohlfahrt}

Seit dem Spätmittelalter waren Gemeinden angehalten, sich in Kranken-, Alters- und Armenversorgung zu engagieren. Das Heimatrecht regelte den Zugang zu Unterstützung und sollte Gemeinden vor finanzieller Belastung durch die Ansprüche von Zugewanderten, ,Unzuständigen' schützen. Dies war Teil der steten obrigkeitlichen Sorge, zwischen jenen zu unterscheiden, die Unterstützung verdienten, und jenen, die von ihr ausgeschlossen bleiben sollten. 1840 listete ein Überblick zu „Humanitätsanstalten“ in Niederösterreich 42 Bürgerspitäler, 36 Spitäler, drei Armenspitäler, ein Dienstbotenspital, vier Siechenhäuser, 15 Armenhäuser, neun Versorgungshäuser, zwei Lazarette und ein Pilgrimhaus auf. Als Folge der Medikalisierung wurden Armen- und Krankenversorgung allmählich getrennt. Die Zahl der von Gemeinden und Land finanzierten Krankenanstalten nahm zu. Im letzten Drittel des 19. Jahrhunderts begann der langsame Übergang zum Wohlfahrtsstaat. Versicherungssysteme sollten existenzielle Risiken abfangen - zunächst Krankheit und Unfälle, im 20. Jahrhundert dann auch Alter und Arbeitslosigkeit.

\section{Politische Beteiligung}

Das Jahr 1848 war in Wien ein Moment spektakulären politischen und sozialen Aufruhrs - und am flachen Land, den Dörfern und Kleinstädten? Wie gingen traditionelle Formen des Protests in die Revolution ein? Inwiefern bereitete diese auch in der Provinz eine moderne politische Kultur vor?

Die freie Gemeinde, eines der wichtigsten Ergebnisse der Revolution, wurde zu einem Forum der politischen Selbstverständigung. Zunächst dominierte vielfach ein vager Deutschliberalismus, der immer deutschnationalistischere Züge annahm. Die Christlich-sozialen eroberten seit den 1890er Jahren nicht nur die Metropole und den Landtag, sondern beherrschten zunehmend die Gemeindevertretungen am flachen Land. Die Sozialdemokratie organisierte sich rund um Arbeiterbildungsvereine, Konsumgenossenschaften, Gewerkschaften und Unterstützungskassen. Ein dichtes Geflecht von Vereinen ermöglichte entlang von potentiellen Konfliktlagen wie Klasse, Religion und Nation die politische Mobilisierung. Diese wurde von ideologisch gebundenen Zeitungen und Zeitschriften angetrieben und formuliert.

\section{Wirtschaft}

Niederösterreich war wirtschaftlich ein Kernraum der Habsburgermonarchie. In der Hauptstadt und deren Umfeld entfalteten sich moderne Industrien und Dienstleistungen für eine Großstadt 
und ein großes Reich. Andere Gebiete des flachen Landes dienten als verlängerte Werkbank und große Teile Niederösterreichs blieben agrarisch geprägt. Davon traten einige in engen Austausch mit Wien, andere integrierten sich nur wenig in überregionale Märkte. Insgesamt eröffnete sich jedoch die Perspektive einer wachsenden Wirtschaft. Wie stark sie wuchs und mit welchen regionalen Unterschieden, diskutiert die Forschung kontrovers; ebenso fragt sie, wie sich dies in Einkommens- und Vermögensungleichheiten niederschlug. Ein Mittel des Vermögensaufbaus waren die Sparkassen. Sie dienten auch Menschen abseits des wohlhabenden Bürgertums dazu, „ein kleines Capital zurück zu legen“. Zugleich spielten sie eine wichtige Rolle für die Finanzierung kommunaler Infrastrukturen.

Die meisten Menschen waren weiterhin in der Landwirtschaft tätig. Die Produktionsbedingungen und der rechtliche Rahmen veränderten sich jedoch stark. Das Jahr 1848 brachte die Grundentlastung, ihr folgten die Liberalisierung des Grundverkehrs und die Abschaffung der Unteilbarkeit von Bauerngütern. Viel Aufmerksamkeit hat in der wirtschaftsgeschichtlichen Auseinandersetzung mit dem 19. Jahrhundert die Industrialisierung erhalten. Die Forschung hält eine Unzahl von Modellen bereit, mit denen sie die einschlägigen Prozesse und ihre Folgen erklären will. Die Relevanz dieser Modelle für die Entwicklungen in Niederösterreich gilt es zu untersuchen. Der steigende Ressourcenverbrauch, der Übergang in die energetische Moderne, warf neue Fragen auf. Schon im 18. Jahrhundert stand z. B. „Holznoth“ als Drohung im Raum, auf die neue Formen der Bewirtschaftung reagierten.

Verkehrs- und Kommunikationsrevolutionen, Eisenbahn und Telegraph, überzogen das Land mit einem Infrastrukturnetz. Die Mobilität von Personen, Waren und Ideen tat einen qualitativen und quantitativen Sprung. Teil dieser Veränderung war die Popularisierung des touristischen Reisens. Sommerfrischevillen, Hotels, Bäder, Reiseführer, Sommertheater und Kurkapellen gehörten zu einem sich differenzierenden Angebot. Handelsbeziehungen erstreckten sich weit über Niederösterreich hinaus und es war keineswegs nur Wien, das als Fenster in die Welt fungierte. Beispielsweise belegen Triestiner Notariatsakten für das frühe 19. Jahrhundert Direktkontakte zwischen dem Seehafen und Kaufleuten in Marktflecken wie Waidhofen an der Thaya. 


\section{Bd. 2 Soziale Formationen und Alltagsräume / Menschen und Lebenswelten}

\section{Soziale Großformationen}

Ein Beitrag umreißt die demographische Entwicklung, mehrere weitere konturieren große soziale Gruppen, ihre Lebensbedingungen und ihre Alltagskultur: den Adel, die alte Elite zwischen Behauptung ihres Vorrangs und Statusverlusten; das Bürgertum, eine heterogene Formation aus Besitz und Bildung, die im kommunalen Rahmen oft zwischen städtischer Traditionsbildung und Modernisierung navigierte; die Bauern und Bäuerinnen, die sich als Gruppe in Gemeinschaften von "Haus und Hof" bis zu Dorf und Pfarre entfalteten; den unterbäuerlichen Schichten, jener landwirtschaftlich tätigen Bevölkerung, von Dienstboten bis zu Kleinhäusler*innen, die über kaum oder wenig Besitz verfügten und nicht den dörflichen Eliten angehörten; als Produkt der Industrialisierung eine wachsende gewerbliche und industrielle Arbeiterschaft. Auch hier sind regionale Unterschiede und Ungleichzeitigkeiten auffällig.

\section{Lebenswelten und Praktiken}

Quer zur Analyse entlang von sozialen Großgruppen (Ständen, Klassen, Schichten) befasst sich ein Bündel von Beiträgen gruppenübergreifend mit Lebenswelten. Die Forschung beschreibt die Veränderung familialer Lebenswelten als Intimisierung und Emotionalisierung. Die horizontalen Beziehungen zu Geschwistern gewannen an Bedeutung; wie veränderte dies die vertikalen, also zwischen Eltern und Kindern? In Heirat und Ehe traten Vorstellungen von romantischer Liebe neben wirtschaftliche Rücksichten, die allerdings keineswegs verschwanden. Wie wirkten sich rechtliche und insbesondere besitzrechtliche Rahmenbedingungen aus? So z. B. die Gütergemeinschaft des bäuerlichen Ehegüterrechts oder das 1812 in Kraft getretene Allgemeine Bürgerliche Gesetzbuch, das die Ehe im Sinn eines bürgerlichen Familienbilds regelte? Es gilt hierbei stets, regionale und soziale Unter-schiede im Blick zu halten. Die Erwartungen, die Frauen und Männer an Ehe- und Familienleben richteten, werden an den Bruchstellen von Beziehungen deutlich. Scheidungsverfahren sind daher besonders aufschlussreich.

Eine moderne Form, soziales Leben abseits familialer und verwandtschaftlicher Netze zu organisieren, bot das Vereinswesen, das sich in einer unübersehbaren Vielfalt entwickelte. Vom politischen Verein zum Sparverein, vom Gesangs- zum Betverein, vom Lese- zum Konsumverein reicht ein Spektrum, das sowohl politische und wirtschaftliche Interessen bündelte als auch Geselligkeit ermöglichte. Das bürgerliche Modell der Geschlechterrollen wies Frauen zwar die Familie als Aktionsraum zu; Vereine eröffneten ihnen aber eine sozial akzeptierte Möglichkeit, in der öffentlichen Sphäre aufzutreten, insbesondere im Feld wohltätigen und religiösen Engagements.

Religiosität war eine weitere übergreifende Dimension von Lebensbewältigung. Die Räume und Praktiken der Religiosität hatten im privaten und familiären Bereich ihren Ort, ebenso in Kirchen und Vereinen. Religiosität zeigte viele Schattierungen zwischen einer herrschaftlichen Formung und den Ansprüchen der Menschen. Sie fand in sakraler Architektur, vom Kirchenbau bis zum Bildstock, einen greifbaren Ausdruck. Niederösterreich war für jede und jeden sichtbar katholisch dominiert; und doch war die katholische nicht die einzige Konfession und Religion im Land. In der zweiten Hälfte des 19. Jahrhunderts verdichtete sich die Präsenz jüdischen 
religiösen Lebens, nachdem die Niederlassungsfreiheit nach 1848 den Zuzug von Jüdinnen und Juden vielfach erst ermöglicht hatte. Die rechtliche Gleichstellung 1867 wurde von Antisemitismus unterlaufen, der als Instrument politischer Mobilisierung und in seinen alltäglichen Ausdrucksformen Diskriminierung fortführte und - neuerlich - vertiefte.

\section{Kultur/Betrieb}

Die Alphabetisierung der Bevölkerung, die schon der Reformabsolutismus vorangetrieben hatte, war ein Ergebnis und Motor von staatlicher Infrastrukturmacht. Pragmatische Berufsbildung und romantische Vorstellungen von Bildung rieben sich aneinander. Niederösterreich war ein Schauplatz dieser Auseinandersetzungen in ihren bürokratischen und hochkulturellen Verzweigungen. Hieran knüpft sich die Frage, was Lese- und Schreibfähigkeit für Einzelne in ihrem Alltag bedeutete.

Die kulturelle Selbstdarstellung von Eliten gehört wesentlich in den Zusammenhang einer Regionalgeschichte von Macht. Aristokratie und katholische Kirche hatten schon im Barock das Land baulich besetzt, das Bürgertum zog im 19. Jahrhundert nach. Gemeinden errichteten Infrastrukturen, die vom Schulbau bis zu den urbanistischen Projekten der (Klein- und Groß)Stadterweiterung reichten.

Auf vielfache Weise zeichnen sich Beziehungen zwischen Wien und dem flachen Land ab, als Abhängigkeiten, Gegensätze und Austausch. Der Kunstbetrieb war auf die Metropole Wien fokussiert, aber Theatergründungen demonstrierten selbst in den mittleren Städten des Landes bürgerliche Ansprüche an Kulturkonsum. (Hoch)kulturelle Formen strahlten auf die ,Provinz' aus, vom Theater bis zur Architektur. Die (alltags)kulturelle Besetzung des Ländlichen als Gegenpol zur Stadt trieb Tourismus und die Kultivierung von Volksmusik an. Kur und Sommerfrische verlegten während der Saison bürgerlichen Kulturkonsum aufs Land. Das traf ebenso auf die Kunst- und Kulturproduktion zu. Wandertheater und später Wanderkinos brachten neue Medien und Inszenierungen. Umgekehrt waren Naturaufnahmen ein beliebter Gegenstand des frühen kinematographischen Konsums in den Städten. Die Medien, Formen und Inhalte der Kulturproduktion bestimmten sich aber nicht nur im Wechselspiel von Land und Metropole. Film, Theater, Musik, Bildende Kunst und Architektur in Niederösterreich hatten an transnationalen Entwicklungen teil, weit über die Habsburgermonarchie hinaus.

\section{Räume}

Räume werden wirtschaftlich, kulturell und politisch konstruiert. Der Staat erfasst sie, Eliten beherrschen sie, Menschen mit viel oder wenig Ressourcen gestalten sie und eignen sie sich an. In dramatischer Weise schuf der Staat neue Raumvorstellungen und -politiken, als er im Ersten Weltkrieg sein Territorium abseits der Schlachtfelder als „Heimatfront" definierte. Wenngleich Niederösterreich von den Kriegshandlungen nicht unmittelbar betroffen war, so ordneten Ziele und Anforderungen des Krieges dennoch das Land neu.

Die militärisch-politische Großanstrengung entfaltete also raumstrukturierende Kraft, langfristige sozioökonomische Prozesse taten das noch nachhaltiger. Über das Kronland erstreckte sich ein Netz von Siedlungen unterschiedlichen Typs: unzählige Dörfer, einige Städte und eine Metropole. Verkehrswege verbanden die Siedlungen, die in sich dörfliche oder städtische Räume aufbauten. 
Wiederum griff die Metropole auf das Land aus und bestimmte z. B. einen großen Naturraum als „Wienerwald“. Sie inszenierte ihn journalistisch, lud ihn politisch auf und machte ihn für die Landpartie touristisch nutzbar. Der Konsumbedarf der Großstadt, ob Kultur oder Ernährung, strukturierte ganze Landschaften. Diese Beziehungen machten jedoch nicht an den Grenzen des Kronlandes halt. Dienstboten und - zumeist - Dienstbotinnen kamen aus der Umgebung Wiens, aber ebenso aus anderen Kronländern. Wien konnte auch nicht aus der regionalen niederösterreichischen Agrarproduktion versorgt werden. Am Beispiel des Getreideverbrauchs lässt sich eine komplexe Geographie von Produktion, Handel und Konsum aufweisen. Zu ihr gehörten Weizenfelder im Banat, eine Logistik des Transports, Mühlen im Industrieviertel, Verteilung und Konsum in Wien.

Auch aus Sicht des flachen Landes würde es zu kurz greifen, dieses nur als ein nach Wien orientiertes Umland zu begreifen. Migration erschöpfte sich nicht darin, dass Landbewohner*innen in die übermächtige Metropole zogen. Zum ersten reichte die Attraktion Wiens weit über Niederösterreich hinaus, zum zweiten war die Hauptstadt selbst Relais in kontinentalen und transkontinentalen Bewegungen und zum dritten vollzogen sich Migrationen oft innerhalb ländlicher Regionen und als saisonale zirkuläre Wanderungen. 
VI. Dokumentation des Symposions 2019 


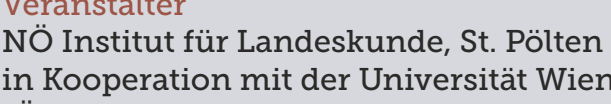

Tagungssletitung
Elisabeth Loinig, Leiterin des Nö Instituts fuir Landessunde

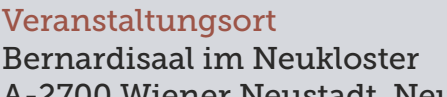

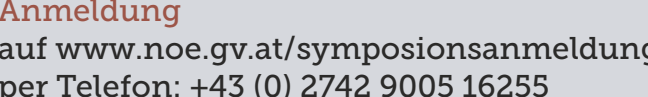

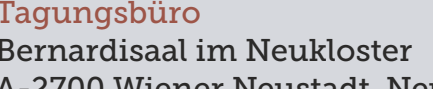

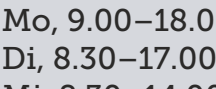

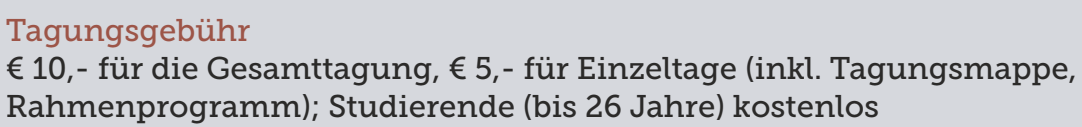

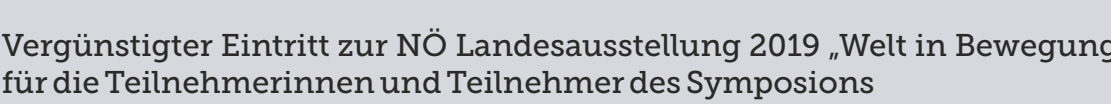

Kontakt
NO Institut fiur Landessunde

A-3109 St. Pötten, Kulturbe
$+43(0)$
+4742900516255

post.k2institutenoel.gv.at

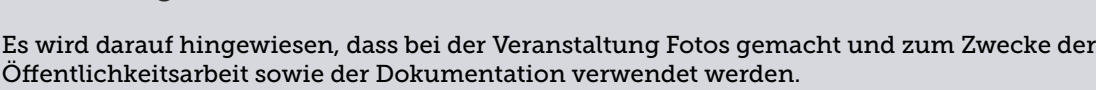

\section{Keynotes}

Pieter M. Judson, Florenz

. nhtag, 1.Juli, 18.15-19.15

Die Habsburgermonarchie des 19. Jahrhunderts war das Produkt des Staatsautbaus und der Zentralisierungsbemuhungen vieler Herrscher. Im

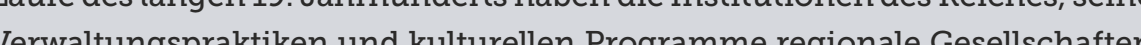
stark verändert. Auch waren unzzählige lokale und regionale Akteure daran beteiligt, diesen Modernisierungsstaat in alle Ecken des Reiches zu bringen. Gleichzeitig gelang es Burgem und Burgennnen aller sozilaten Klassen of Zwecke zu nutzen und sie so zu gestalten, dass sie ihren Interessen entsprachen. Um den besonderen Charakter und die Dauerhaftigkeit der Habsburgermonarchie richtig zu verstehen, mussen wir begreifen, wie dieser Staat aus zwei verschiedenen Richtungen geschaffen wurde - von oben und

Dirk van Laak, Leipzig
Infrastrukturgeschichte: N

Infrastruktur ist kein schönes Wort - und dennoch momentan in aller Munde. Auch politisch scheinen sich alle einig zu sein: es soltte immer mehr davon Versorgung und Entsorgung, der Kommunikation und des Verkehrs nun auch zunehmend historisch erforscht. Der Vortrag rekapituliert diese Konjonders aber mode materiellen und sozialen Vernetzung so aufschlussreich sind.

\section{Beharrung und Wandel}

39. Symposion des NÖ Instituts für Landeskunde

„FFrtschrittl Überall Fortschrittl,", denkt schockiert die Figur des Erzählers in erschien der rasante Wandel aller Lebensberesiche ein markantes Merkmal ihres Jahrhunderts zu sein. Doch dieser Wandel wurde nicht nur in der Metropole Wien sichtbar. Das "flache Land" veränderte sich ebenso: durch Agrarrevolution und Industrialisierung, durch neue Massenparteien und unzzählige Vereinsgrundungen, durch den Ausbau von Verwaltung und Veränderungen einverstanden - neben dem Wandel und gegen inn gerichtet also auch Beharrung.

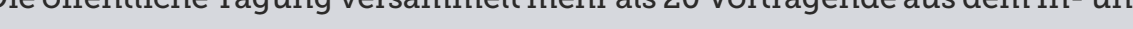
Ausland. Sie beleuchten Niederösterreich im 19. Jahrhundert und stellen international vergleichender Perspektive zu eröfren Das S Smlhussionen in vor dem Hintergrund eines umfangreichen, am NÖ Institut für Landeskunde laufenden Buchprojektes statt, das die Geschichte Niederösterreichs in langen 19. Jahrhundert von 1 180 bis zum Ende des Ersten Welthreges in meh

Für den Abendvortrag am 1. Juli konnte mit Pieter M. Judson (Europäisches seinem Buch, Habsburg. Geschichte eines Imperiums.1740-1918" (2017) ister einem breiten Publikum bekannt geworden. Am 2. Juli wird die Keynote von Dirk van Laak (Universitat Leiptig) - somalebeachtetes Buch, „Alles in Eine Führung durch die NÖ Landesausstellung. Welt in Bewegung" am $3 \mathrm{JuL}$ rundet das Programm des Symposions ab.

Wissenschaftliches Konzept und Organisation

Oliver Kühschelm, Do

der Universität Wien

Elisabeth Loinig, Leiterin des NÖ Instituts für Landeskunde
Beharrung und Wande

Niederösterreich

im 19. Jahrhundert

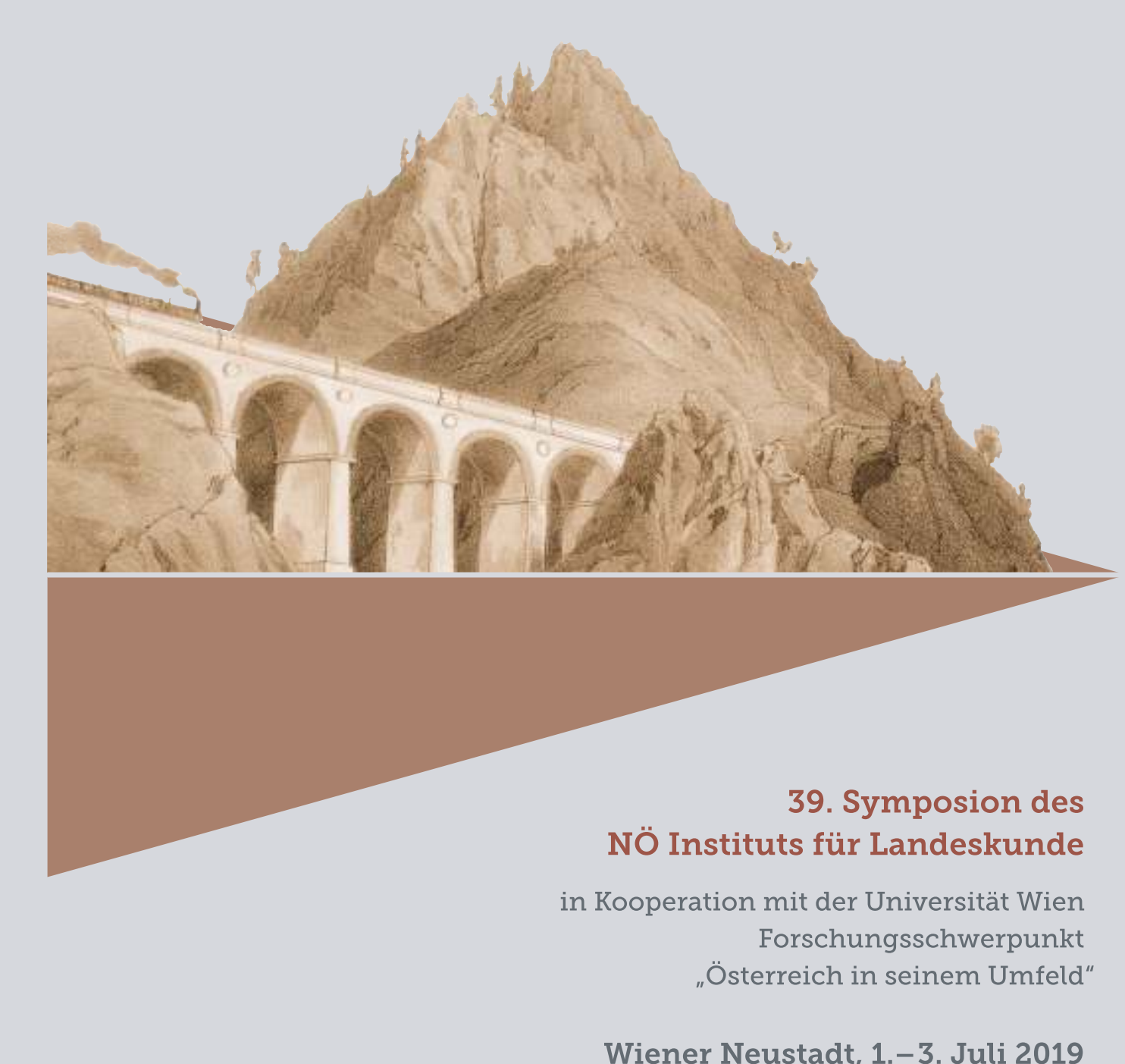

Wiener Neustadt 1-3. Juli 2019 


\section{Programm}

Montag, 1. Juli

Moderne Zeiten?

10.00-11.00 Begrüßung und Einführung
Elisabeth Loinig und Oliver Kühschel

1100-1130 Kalffeepause

$\begin{array}{ll}11.00-11.30 & \text { Kaffeepause } \\ 11.30-13.00 & \text { Panel I: Wirtschaften }\end{array}$

Martin Bauer, St. Pölten
Arrarrevolution in Raten. Die Agrarwirtschaft in
Niederossterreich 1790-1914

Andreas Resch, Wien
Induastrie und cewerbe in Niederösterreich -
charakteristische Entwicklungen und Beziehunge

Bernd Kreuzer, München
Korridore der Moderne und der Macht: Verkehrs-

Rita Garstenauer: Moderation

14.30-16.00 Panel II: (Gegen)Mach Thomas Hellmuth, Wien
Zwischen Freiheit Und Herr
burrgerlichen Gesellschaft

Sabine Schmitner, Wiener Neustadt
Bürgertum - die (OhnlMacht der Mitte?

John Evers, Wien
Gegennacht? Arbeiter- und Arbeiterinnenbewegungen
in Niederösterreich 1867-1914

Stefan Eminger: Moderation

16.00-16.30 Kaffeepause
16.30-17.30 Panel III: Räume

Annemarie Steidl, Wien
Viele Wege räumlicher Mobilität. Lokale und überregionale
Migrationen in Niederösterreich

Peter Eigner und Maximilian Martsch, Wien
Im Schatten der Metropole? Niederösterreichs Kleinstädte

Willibald Rosner: Moderation

$\begin{array}{ll}17.30-18.00 & \text { Kaffeepause } \\ 18.00-18.20 & \text { Grußworte }\end{array}$

Roman Zehetmayer, Leiter der Abteilung NÖ Landesarchiv

Vertretung der Stadtgemeinde Wiener Neustadt

18.20-19.20 Keynote

Piiter M. Judson, Florenz
Imperiale Herschatt und lokales Interesse: Staatsaurbau von
oben und von unten in der Habsburgermonarchie

19.20-20.00 Podium zu Staat und Moderne
Elisabeth Loinig: Moderation

Ausklang bei Brot und Wein

Dienstag, 2. Juli

Regionalgeschichte der Macht

9.00-9.30 Einführung

9.30-11.10 Panel I: Imperiale Herrschaft und das Land

Jana Osterkamp, München
Gleicher als andere. Nieder
Stephan Sander-Faes, Zürich
Staatsbildung als "ub ersetzung" (1800-1850). Das ländliche
Niederósterreich und der ôsterreichische Zentralststaat

Zsuzsanna Török, Wien
Stande end d thatsiski. Erreugung und Verwendung vol
Staatswissen in Niederostereich, ca. 1790-1848

11.10-11.40 Kaffeepause

Peter Becker: Kommentar
Kaffeepause

11.40-12.50 Panel II: Regionale Macht über/von Kirchen

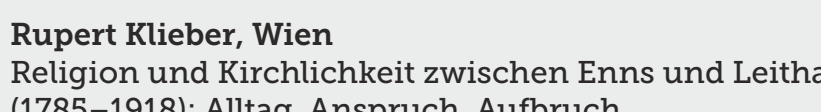

(1755-1918): Altag. Anss

Donatus Disterhaus, Fribourg
Zwischen Region und Nation- Die protestantische
Kirchenorganisation im Elsass 1802-1871

Willibald Rosner: Kommentar

12.50-14.20

14.20-15.30 Panel III: Adel und Staat

Tatajana Tönsmeyer, Wuppertal
Sttat, Adel und landliche eesellschaft. Zum Vorrucken des
Staates in die lache am Beispiel von Böhmen und England

Josef Löffler, Wien
Das Verhaltnis zwischen Grundherrschaft und Staat in der
Habbsburgermonarchie am Beispiel Niederösterreichs

Thomas Winkelbauer: Kommentar

Kaffeepause

16.00-17.00 Keynote

Dirk van Laak, Leipzig
Infrastrutrutrgeschichte: Neue Perspektiven auf
Raum und Zeit?

$\begin{array}{ll}17.00-17.40 & \text { Poumum zu Zn Infrastruktur } \\ & \text { Oliver Küsschelm: Moderation }\end{array}$

Empfang fur Vortragende mit freundlicher
von Landeshauptrau Johanna Mikl-Leitner
Mittwoch, 3. Juli

9.00-9.10 Einstieg

9.10-10.20 Panel IV: Drang zum Staat?

Clemens Tangerding, Berlin
Der Drang zum Staat - Würzburg um 1800



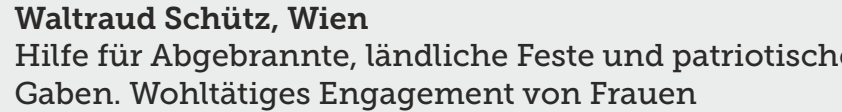
Therese Garstenauer: Kommentar

10.20-10.50 Kaffeepause

1050-12.00 Panel V: Kommunale Handlungsspielräume

Norbert Franz, Trier

Die Macht des sletzten Rädchens" - Landgemeinden

Thankeich und Luxemburg

Thomas Buchner, Amstetten
Kommunuale Finanzen und Staatsbildung.
Niederöstereich,

Margareth Lanzinger: Kommentar

12.00-12.30 Kaffeepause

12.30-13.40 Panel VI: Zivile Netzwerke

Patrick Kury, Basel
Aufrbuch und Stillstand einer bürgerlichen Gesellschaft.

Peter Hinterndorfer, Wien
Wohttatitigkeit, Selsbshthile und organisierte Geselligkeit -

Stefan Eminger: Kommentar

13.40-14.00 Schlussrunde

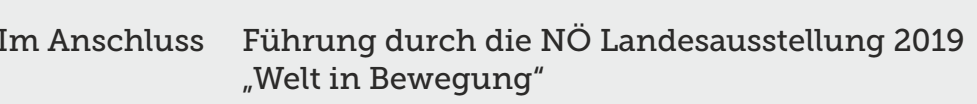




\section{Beharrung und Wandel. Niederösterreich im 19. Jahrhundert. 39. Symposion des NÖ Instituts für Landeskunde}

Veranstalter: Elisabeth Loinig, NÖ Institut für Landeskunde, St. Pölten; Oliver Kühschelm, Institut für Wirtschafts- und Sozialgeschichte, Universität Wien; Peter Becker, Institut für Österreichische Geschichtsforschung, Universität Wien

Datum, Ort: 01.07.2019-03.07.2019, Wiener Neustadt

Bericht von: Tobias Hämmerle, Institut für Geschichte, Universität Wien

Unter dem Titel „Beharrung und Wandel“ fand in Kooperation mit der Universität Wien das 39. Symposion des niederösterreichischen Instituts für Landeskunde statt. Ausgangspunkt war ein Buchprojekt des Instituts, das eine Gesellschaftsgeschichte Niederösterreichs, des zentralen Kronlands der Habsburgermonarchie, im langen 19. Jahrhundert, zum Gegenstand hat. ${ }^{1}$ Auf der Tagung wurden Fragen nach der Modernisierung und der Durchstaatlichung des Sozialen, insbesondere auf dem "flachen Land" diskutiert. Am zweiten und dritten Tag wurde der auf Niederösterreich fokussierte Horizont durch Beispiele aus anderen Regionen erweitert, wodurch sich transregional vergleichende Perspektiven eröffneten.

In ihrer Einleitung betonte ELISABETH LOINIG (St. Pölten), dass viele für die Gegenwart relevante Strukturen, z.B. in Verwaltung und Politik oder die Vereine als Instrument zivilgesellschaftlicher Mobilisierung, auf das 19. Jahrhundert zurückgehen, sich dieses somit tatsächlich als ein langes im Sinn von: lang wirkendes - erwiesen hat. OLIVER KÜHSCHELM (Wien) entwarf die Perspektive einer Regionalgeschichte sozialer Macht als Auseinandersetzung mit Prozessen der Vergesellschaftlichung und Durchstaatlichung in lokalen und regionalen Konstellationen.

Den Auftakt der Konferenz machte MARTIN BAUER (St. Pölten), der die agrarwirtschaftliche Situation Niederösterreichs von 1790 bis 1914 untersuchte und die Unterschiedlichkeit der Entwicklungspfade im Rahmen des stark differenzierten Kronlands veranschaulichte. Wien und das Alpenvorland wiesen größere Erträge in der Agrarproduktion auf als die Ackerbaugebiete im Osten Niederösterreichs. Im zweiten Vortrag analysierte ANDREAS RESCH (Wien) den Wandel von Industrie und Gewerbe in Niederösterreich. Er fasste das 19. Jahrhundert nicht als Zeitalter der Verdrängung von Kleingewerbe durch großbetriebliche Industrie, sondern als eine Periode von Symbiose und Koexistenz dieser Formen auf. „Industrial enlightenment" im Sinne von Joel Mokyr sei nicht auf Großbetriebe beschränkt geblieben. BERND KREUZER (München) widmete sich im letzten Beitrag des ersten Panels Verkehrs-, Mobilitäts- und Kommunikationsrevolutionen. Die gängige Auffassung, dass von Wien (Zentrum) ausgehend das Umland (Peripherie) durch Verkehrs- und Kommunikationsnetze rasch „erobert" werden konnte, treffe nicht zu. Vielmehr sei die Wirkung der Infrastruktur abseits der „Korridore der Moderne und der Macht" bald verpufft. In der regionalen Entwicklung ergab sich eine Kluft zwischen Ortschaften, die ans Transport-, Elektrizitäts-, Informations- und Kommunikationsnetz angeschlossen wurden, und solchen, die abseits der Korridore lagen.

Im zweiten Panel lag der Fokus auf den Machtverhältnissen in den unterschiedlichen sozialen Schichten. THOMAS HELLMUTH (Wien) diskutierte den Bildungsbereich als Seismograph gesellschaftlichen Wandels in der Spannung zwischen staatlicher Indoktrination und emanzipatorischen Perspektiven. Schulgesetze waren auch zentraler Schauplatz der Auseinandersetzung zwischen bürgerlichem Liberalismus und politischem Katholizismus, der in Niederösterreich seit den 1890er-Jahren die Landespolitik dominierte. SABINE SCHMITNER (Wiener Neustadt) befasste sich, fokussiert auf die (kleinen) Städte des flachen Lands und insbesondere Wiener Neustadt, mit dem Anspruch des Bürgertums, die gesellschaftliche Mitte zu verkörpern. Mit dem Kampfbegriff des „Mittelstands" artikulierte sich ein relativ privilegierter Teil der Bevölkerung, gerichtet gegen eine über die Kleinstadt hinausreichende soziale Elite ebenso wie gegen die Arbeiterklasse, der es - so JOHN EVERS (Wien) - in Niederöster-

\footnotetext{
${ }^{1}$ Vgl. http:/ / www.noe.gv.at/projekt19jh (19.11.2019)
} 
reich relativ früh gelang, Gegenmacht in drei Dimensionen aufzubauen: strukturell durch Arbeitskämpfe und organisatorisch durch deren Koordination im Rahmen einer überregionalen Gewerkschaftsbewegung. Auch begann der Versuch, institutionell an den Staat anzuknüpfen; der erfolgreiche Wahlrechtskampf stärkte eine "integrative Strategie“.

Das letzte Panel des ersten Tages stand unter dem Titel "Räume“. ANNEMARIE STEIDL (Wien) thematisierte lokale und überregionale Migrationen. Sie unterstrich, dass die "spektakulären" Wanderungen nach Übersee und in die Großstädte, damit auch das Bild rapider Urbanisierung, nach wie vor gängige Vorstellungen über Migrationsbewegungen im 19. Jahrhundert prägen. Hingegen seien bei der Untersuchung von räumlichen Mobilitäten kleinräumige und temporäre Wanderungen, etwa im Zug von Saisonarbeit oder als Vazieren, vernachlässigt worden. Es gilt die Topoi einer unidirektionalen Wanderung der Landbevölkerung in die städtischen Ballungszentren aufzubrechen. PETER EIGNER (Wien) widmete sich gemeinsam mit MAXIMILIAN MARTSCH (Wien) Niederösterreichs Kleinstädten. Das Spezifikum der Städteentwicklung im Kronland Niederösterreich war die Wechselwirkung mit der dominierenden Hauptstadt Wien, um 1900 eine der größten Städte der Welt. Neben der Ausstrahlung der Metropole aufs flache Land verdienen umgekehrt die dörflichen Strukturen Wiens Beachtung, die in Vororten und "Grätzln" bis heute erhalten sind. Der Befund vom Dorf in der Stadt relativiert wiederum das überkommene Bild einer einseitigen Wirkungsrichtung, hier als Überwuchern des Landes durch die Stadt.

PIETER M. JUDSON (Florenz) befasste sich in seiner Keynote mit der Spannung zwischen Zentrum und Provinz in der Habsburgermonarchie. Er schlug vor, das Narrativ eines von oben die Gesellschaft durchdringenden Imperiums kritisch mit dem Instrument regionalgeschichtlicher Studien zu befragen, die näher an Akteure „von unten“ heranrücken. Er verwies auf das Bürgertum und die Vereine als Akteure, die den Staat, dessen Infrastrukturen und Institutionen, insbesondere im Bereich der Wohlfahrt und der Bildung, trugen. Staatsaufbau vollzog sich somit nicht nur von "oben“, in Form des Zentralstaates, sondern auch von „unten“. In seinem Kommentar warf PETER BECKER (Wien) die Frage auf, ob sich der Imperiumsbegriff auf die Monarchie anwenden lässt. Asymmetrien seien auch in anderen Formen von Staatlichkeit möglich.

Im Zeichen des Bemühens, den Habsburgerstaat begrifflich $\mathrm{zu}$ fassen und die Stellung Niederösterreichs in diesem Gebilde $\mathrm{zu}$ analysieren, stand auch das erste $\mathrm{Pa}$ nel des zweiten Tages. JANA OSTERKAMP (München) diskutierte, ausgehend von einer Allegorie des "Staatsschiffes", die Sonderstellung Niederösterreichs als Kronland im föderativen habsburgischen „Empire“. STEPHAN SANDER-FAES (Zürich) wandte sich ebenfalls gegen das Bild einer top-downEntwicklung von staatlicher Herrschaft zum Anstaltsstaat. Man müsse das Nebeneinander von modernen und vormodernen Ordnungssystemen und die in beide Richtungen verlaufenden Übersetzungsprozesse zwischen lokalen Akteuren und zentralisierenden Instanzen analysieren. ZSUZSANNA TÖRÖK (Wien) untersuchte Statistik bzw. Staatenkunde als räumlich orientiertes, modular aufgebautes, pluridisziplinär organisiertes und öffentlich zugängliches Verwaltungswissen. Auch sie rückte neben den zentralstaatlichen die regionalen Akteure ins Blickfeld. Bei der von den niederösterreichischen Ständen 1793 initiierten topographischen Sammlung handelte es sich um das bemerkenswerte Projekt eines modernen Wissensspeichers.

Das zweite Panel untersuchte die Rolle der Kirche im Rahmen von Zentralisierungsprozessen. RUPERT KLIEBER (Wien) befasste sich mit (katholischer) Kirchlichkeit in Niederösterreich und der Prägung ländlicher Lebenswelten bis zum Anfang des 20. Jahrhunderts durch Religion und Kirche. DONATUS DÜSTERHAUS (Fribourg) stellte dem das Beispiel der protestantischen Kirchenorganisation des Elsass gegenüber. Die Sonderstellung der protestantischen Kirche in einer durch Multikonfessionalität geprägten Region führte er auf die 1802 unter Napoleon eingeführten "Organischen Artikel“ zurück. Sie garantierten einerseits die Rechte der protestantischen Bevölkerung und ermöglichten es andererseits, die protestantische Bevölke- 
rungsgruppe an den französischen Staat zu binden.

Das letzte Panel des zweiten Tages legte den Fokus auf das Verhältnis zwischen Adel und dem in die Fläche vorrückenden Staat. JOSEF LÖFFLER (Wien) diskutierte das Verhältnis von Grundherrschaft und Zentralstaat in der ersten Hälfte des 19. Jahrhunderts. Der Staat bemühte sich zwar um Einfluss, z.B. durch Einrichtung der Kreisämter als Kontrollinstanz, in der Verwaltungspraxis blieben aber bis 1848 die (adeligen) Grundherren weiterhin die maßgebenden Akteure. TATJANA TÖNSMEYER (Wuppertal) wandte sich gegen das Bild eines Niedergangs des Adels als Folge der Ablösung der Patrimonialherrschaft und wies auf neue Handlungsspielräume hin. Adelige Eliten nützten z.B. Gerichte erfolgreich als Plattform, um sich Wald- und Wassernutzungsrechte als Eigentumsrechte bestätigen zu lassen. Sie trugen damit zur Etablierung und Präsenz eines "performing state" in lokalen und regionalen Konstellationen bei.

In der zweiten Keynote des Symposions entwickelte DIRK VAN LAAK (Leipzig) Potentiale einer Infrastrukturgeschichte. Infrastruktur sei "das Stabile, das notwendig ist, um das Fließende zu fixieren." Bei Infrastrukturen handle es sich um materiell geronnene Aushandlungsprozesse, an die sich Nutzung schließen muss.

Die Nutzungs- und Nutzerperspektive betonte am dritten Tag auch der Vortrag von CLEMENS TANGERDING (Berlin). Er thematisierte anhand von Würzburg an der Wende zum 19. Jahrhundert den "Drang zum Staat", die Anrufung staatlicher Institutionen zur Stabilisierung der eigenen Lebenswelt. WALTRAUD SCHÜTZ (Wien) untersuchte wohltätiges Engagement anhand der "Gesellschaft der adeligen Frauen zur Beförderung des Guten und Nützlichen", die sich 1810 bei ihrer Gründung explizit als Stütze eines durch die napoleonischen Kriege geschwächten Staates antrug.

Mit den Handlungsspielräumen und Verhaltensmustern der Kommunen befasste sich ein weiteres Panel. NORBERT FRANZ (Trier) lenkte die Aufmerksamkeit auf die Macht des "letzten Rädchens" im Prozess der Durchstaatlichung. Anhand französischer und luxemburgischer Kommunen zeigte er, wie
Landgemeinden Mitgestalter, aber auch Verweigerer moderner Staatsverwaltung sein konnten. THOMAS BUCHNER (Amstetten) analysierte die kommunalen Finanzen als Dreh- und Angelpunkt im Prozess von Durchstaatlichung, die nur in Kooperation mit den Gemeinden gelingen konnte. Allerdings delegierte der cisleithanische Zentralstaat zwar Aufgaben an die Gemeinden, stattete sie aber nicht mit einer entsprechenden Finanzierung aus. Das 19. Jahrhundert beginne somit, wenn man Durchstaatlichung als ein Signum ansetzt, in Luxemburg und Frankreich früher als in Niederösterreich. Hier vollzog sich Durchstaatlichung nach 1848 in gedrängterer Zeit und führte in eine endemische Verschuldung der Kommunen. Allerdings war die Klage über (finanzielle) Überforderung wohl auch Teil der Rechtfertigungsstrategien von Gemeindevorständen.

Das letzte Panel der Tagung rückte neuerlich die Macht von "Intermediären", von Mittlern zwischen der Zivilgesellschaft und dem Anstaltsstaat in den Mittelpunkt. PATRICK KURY (Basel) wandte sich Vereinen und Stiftungen im (groß)städtischen Rahmen Basels zu und analysierte sie als Sublimierung bürgerlicher Macht in sozialen, kulturellen und wissenschaftlichen Organisationen. PETER HINTERNDORFER (Wien) zeigte hingegen, wie das Vereinswesen am flachen Land in Niederösterreich in der zweiten Hälfte des 19. Jahrhunderts einen rasanten Aufschwung nahm und sich über bürgerliche Gruppen hinaus entwickelte.

Die internationale Zusammensetzung des Symposions ermöglichte es, regionalgeschichtliche Fragestellungen mit der Analyse von übergreifenden Entwicklungstendenzen $\mathrm{zu}$ verbinden und als Prozesse der Moderne $\mathrm{zu}$ diskutieren. Als Ertrag des Symposions ist insbesondere hervorzuheben, dass viele Beiträge die Vorstellung vom 19. Jahrhundert als Zeitalter einer radikalen Umwälzung der Gesellschaft relativierten, die sich von "oben" nach „unten" und vom Zentrum an die Peripherie bewegte. Der Zeitgeist des 19. Jahrhundert war zudem in wirtschaftlicher, konfessioneller und kultureller Sicht nicht nur durch Aufbrüche geprägt, sondern ebenso durch beharrende Kräfte. 


\section{Konferenzübersicht:}

Elisabeth Loinig (St. Pölten) / Oliver Kühschelm (Wien): Begrüßung und Präsentation des Buchprojekts

\section{Panel I: Wirtschaften}

Martin Bauer (St. Pölten): Agrarrevolution in Raten. Die Agrarwirtschaft in Niederösterreich $1790-1914$

Andreas Resch (Wien): Industrie und Gewerbe - charakteristische Entwicklungen und Beziehungen

Bernd Kreuzer (München): Korridore der Moderne und der Macht: Verkehrs-, Mobilitätsund Kommunikationsrevolutionen

Panel II: (Gegen)Macht

Thomas Hellmuth (Wien): Zwischen Freiheit und Herrschaft. Bildung in der bürgerlichen Gesellschaft

Sabine Schmitner (Wiener Neustadt): Bürgertum - die (Ohn)Macht der Mitte?

John Evers (Wien): Gegenmacht!? Arbeiterund Arbeiterinnenbewegungen in Niederösterreich 1867-1914

\section{Panel III: Räume}

Annemarie Steidl (Wien): Viele Wege räumlicher Mobilität. Lokale und überregionale Migrationen in Niederösterreich

Peter Eigner (Wien) / Maximilian Martsch (Wien): Im Schatten der Metropole? Niederösterreichs Kleinstädte

\section{Keynote}

Pieter Judson (Florenz): Zur Spannung Zentrum-Provinz in der Habsburgermonarchie

\section{Panel I: Imperiale Herrschaft und das Land}

Jana Osterkamp (München): Gleicher als andere. Niederösterreich als Kronland im habsburgischen Imperium

Stephan Sander-Faes (Zürich): Staatsbildung als ,Übersetzung' (1800-50). Das ländliche Niederösterreich und der österreichische Zentralstaat

Zsuzsanna Török (Wien): Stände und Statistik. Erzeugung und Verwendung von Staatswissen in Niederösterreich, ca. 1790-1848

Panel II: Regionale Macht über/von Kirchen

Rupert Klieber (Wien): Religion und Kirch- lichkeit zwischen Enns und Leitha (17851918): Alltag. Anspruch. Aufbruch

Donatus Düsterhaus (Fribourg): Zentralstaatliche Regulierung und regionale Selbstverwaltung im Frankreich des 19. Jahrhunderts. Zur Wahrnehmung und Wirklichkeit der protestantischen Kirchenorganisation im Elsass

Panel III: Adel und Staat

Tatjana Tönsmeyer (Wuppertal): Staat, Adel und ländliche Gesellschaft. Zum Vorrücken des Staates in die Fläche am Beispiel von Böhmen und England

Josef Löffler (Wien): Das Verhältnis zwischen Grundherrschaft und Staat in der Habsburgermonarchie am Beispiel Niederösterreichs

\section{Keynote}

Dirk van Laak (Leipzig): Infrastrukturgeschichte: Neue Perspektiven auf Raum und Zeit?

Panel IV: Drang zum Staat?

Clemens Tangerding (Berlin): Der Drang zum Staat - Würzburg um 1800

Waltraud Schütz (Wien): Hilfe für Abgebrannte, ländliche Feste und patriotische Gaben. Wohltätiges Engagement von Frauen

Panel V: Kommunale Handlungsspielräume

Norbert Franz (Trier): Die Macht des „letzten Rädchens" - Landgemeinden als Mitgestalter moderner Staatsverwaltungen im 19. Jahrhundert (Frankreich und Luxemburg)

Thomas Buchner (Amstetten): Kommunale Finanzen und Staatsbildung. Niederösterreich, ca. 1850-1914

\section{Panel VI: Zivile Netzwerke}

Patrick Kury (Basel): Aufbruch und Stillstand einer bürgerlichen Gesellschaft. Basel und die Ambivalenzen der Moderne

Peter Hinterndorfer (Wien): Wohltätigkeit, Selbsthilfe und organisierte Geselligkeit - Vereinswesen in Niederösterreich

Tagungsbericht Beharrung und Wandel. Niederösterreich im 19. Jahrhundert. 39. Symposion des NÖ Instituts für Landeskunde. 01.07.2019-03.07.2019, Wiener Neustadt, in: H-Soz-Kult 25.11.2019. 
VII. Erläuterung des Farbkonzeptes der Bände 


\section{Farbkonzept}

Die erste Frage, die man stellen könnte: Wozu braucht eine umfangreiche wissenschaftliche Publikation ein Farbkonzept? Die praktische Antwort: zur deutlicheren Trennung der inhaltlichen Themenbereiche. Die atmosphärische Antwort: um Entwicklungen und Transformationen, von denen diese Publikation erzählt, visuell zu unterstreichen, zu untermalen und zu begleiten. Umschlagmotiv beider Bände ist ein Semmeringbahn-Viadukt - aus der landschaftlichen Umgebung herausgehoben, erscheint dieser Bildausschnitt vertraut und zugleich leise verfremdet. Viadukt steht für „Überführung" von einem Ort zum anderen - und entspricht damit der inhaltlichen Konzeption dieser niederösterreichischen Regionalgeschichte, sich gesellschaftlichen und politischen Übergängen im 19. Jahrhundert zu widmen.

"Übergang" ist auch das visuelle Leitmotiv des Farbkonzepts, das wie ein "Colorduct" durch die Themenwelt führt. Die Umschläge der Bände sind in ruhigen, gedämpft-erdigen Tönen gehalten. Ausgehend vom Olivgrün des Titelbilds schlägt die Farbwelt des ersten Bands eine Brücke von Grün- zu Blautönen. Der zweite Band knüpft daran an: Rottöne mit bläulichem Einschlag führen hin zu Brauntönen, die wiederum Farbanklänge an das bräunliche Titelbild von Band 2 schaffen.

Auf der Palette ist der Weg von Grün zu Blau (Band 1) und von Rot zu Braun (Band 2) nicht weit, aber insgesamt bilden die gewählten Farbbereiche - so wie die InhaltsBandbreite der Publikation - doch einen beträchtlichen Teil des gesamten Spektrums ab. 